\title{
Development of a Probabilistic Tornado Wind Hazard Model for the Continental United States Volume I: Main Report
}

A. Boissonnade, Q. Hossain, J. Kimball, R. Mensing, J. Savy

July 20, 2000

U.S. Department of Energy

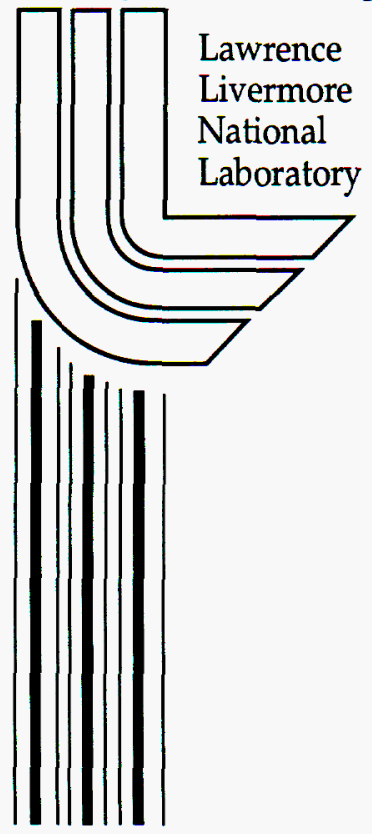




\section{DISCLAIMER}

This document was prepared as an account of work sponsored by an agency of the United States Government. Neither the United States Government nor the University of California nor any of their employees, makes any warranty, express or implied, or assumes any legal liability or responsibility for the accuracy, completeness, or usefulness of any information, apparatus, product, or process disclosed, or represents that its use would not infringe privately owned rights. Reference herein to any specific commercial product, process, or service by trade name, trademark, manufacturer, or otherwise, does not necessarily constitute or imply its endorsement, recommendation, or favoring by the United States Government or the University of California. The views and opinions of authors expressed herein do not necessarily state or reflect those of the United States Government or the University of California, and shall not be used for advertising or product endorsement purposes.

This work was performed under the auspices of the U. S. Department of Energy by the University of California, Lawrence Livermore National Laboratory under Contract No. W-7405-Eng-48.

This report has been reproduced directly from the best available copy.

Available electronically at http://www.doe.gov/bridge

Available for a processing fee to U.S. Department of Energy and its contractors in paper from

U.S. Department of Energy

Office of Scientific and Technical Information P.O. Box 62

Oak Ridge, TN 37831-0062

Telephone: (865) 576-8401

Facsimile: (865) 576-5728

E-mail: reports@adonis.osti.gov

Available for the sale to the public from

U.S. Department of Commerce

National Technical Information Service

5285 Port Royal Road

Springfield, VA 22161

Telephone: (800) 553-6847

Facsimile: (703) 605-6900

E-mail: orders@ ntis.fedworld.gov

Online ordering: http://www.ntis.gov/ordering.htm

OR

Lawrence Livermore National Laboratory Technical Information Department's Digital Library http://www.llnl.gov/tid/Library.html 


\title{
ACKNOWLEDGEMENT
}

The authors wish to acknowledge the active support and participation of the following members of the Expert Panel who provided data, opinions and judgement on the characterization of parameters considered in this report for developing the tornado hazard model.

\author{
Robert Abbey, Consultant \\ Joseph Golden, NOAA \\ Robert A. Kornasiewicz, U.S. NRC \\ Jim McDonald, Texas Tech University \\ Joseph Schaefer, NOAA \\ Emil Simiu, NIST
}

The invaluable technical contributions and guidance provided by Jeff Kimball, the DOE/DP Project Manager for this project, are also acknowledged. The authors are also indebted to the following experts who participated in the three Tornado Hazard Workshops organized by the LLNL/DOE Team and provided their opinions and judgements for consideration by the Expert Panel and the Project Team.

\author{
Harish Chander, DOE \\ Asadour Hadjian, DNFSB \\ Claire Drury, FEMA \\ Brent Gutierrez, DOE Savannah River Site \\ Robert Murray, LLNL \\ Stuart Nishanko, FEMA \\ Subir Sen, DOE \\ Irwin Spickler, DOE \\ John Stevenson, J.D. Stevenson and Associates \\ Jilene Weber, Westinghouse Savannah River Company.
}

Programming expertise and help provided by Chris Goryan and Don Vecellio of Logicon RDA are also acknowledged.

This work was performed under the auspices of the U.S. Department of Energy by the University of California, Lawrence Livermore National Laboratory under Contract No. W-7405-Eng-48. 


\title{
DEVELOPMENT OF A PROBABILISTIC TORNADO WIND HAZARD MODEL FOR THE CONTINENTAL UNITED STATES \\ VOLUME I: MAIN REPORT
}

\author{
A REPORT PREPARED \\ FOR \\ THE DEFENSE PROGRAMS \\ OF \\ THE UNITED STATES DEPARTMENT OF ENERGY
}

HAZARDS MITIGATION CENTER

LAWRENCE LIVERMORE NATIONAL LABORATORY

LIVERMORE, CALIFORNIA

July 20, 2000 


\section{TABLE OF CONTENTS}

\section{VOLUME I: MAIN REPORT}

\subsection{Introduction}

$1.1 \quad$ Background

1.2 Project Scope

1.3 Sequence of Project Activities and Report Organization

1.4 Definitions and Explanation of Terms

1.4.1 Wind Speed Measure

1.4.2 Tornado Heading or Path Direction

1.4.3 F-scale Intensity Classification

1.4.4 Length and Width of the Tornado Damage Area

1.4.5 Storm Prediction Center (SPC) Tornado Database

1.4.6 F-Scale to Wind Speed Relation

2.0 First DOE/LLNL Tornado Wind Hazard Workshop 12

3.0 Second DOE/LLNL Tornado Wind Hazard Workshop 14

4.0 Overview of the Model Development Process 15

$\begin{array}{lll}\text { 5.0 Tornado Wind Hazard Model } & 16\end{array}$

6.0 Model Parameter Estimation and Uncertainty 22

6.1 Expected Frequency of Tornadoes in the CONUS

6.2 Touchdown Location Distribution

6.3 F-Scale Intensity Distribution

6.4 F-Scale to Wind Speed Relations

6.5 Tornado Classification Error

6.6 Tornado Path Heading Distribution

6.7 Damage Area Length and Width Distribution

6.8 Wind Speed Distribution within the Damage Area

7.0 Uncertainty Analysis

8.0 Initial Elicitation of Experts' Judgements 34

9.0 Tornado Wind Hazard Program, TORNADO 36

10.0 Sensitivity Analyses $\quad 42$ 
10.1 Size and Orientation of the Site

10.2 Model Parameters

10.3 Location Distribution Kernel Estimator Smoothing Parameter

10.4 Additional Sensitivity Analyses

11.0 Test Application of TORNADO to DOE Sites

11.1 Test Cases

11.2 Results

11.3 Comparisons with Previous Model Results

12.0 Third DOE/LLNL Tornado Wind Hazard Workshop

12.1 Purpose of Workshop

12.2 Summary of Workshop Proceedings

12.2.1 Resolution of Experts' Comments

12.2.2 Review of Sensitivity Analyses

12.2.3 Discussion of the Experts' Initial Judgements About the Model Parameters

12.3 Second Elicitation of the Experts' Judgements About the Model Parameters

12.4 Summary and Application of Elicited Inputs

13.0 Estimated Tornado Wind Hazard at Selected DOE Sites 110 and US Cities

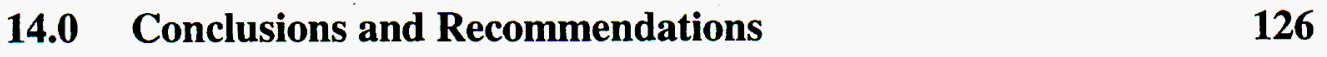

$\begin{array}{llr}15.0 & \text { References } & 129\end{array}$

\section{VOLUME II: APPENDICES}

Appendix I: $\quad$ Expert Judgement Elicitation Questionnaire

Appendix II: $\quad$ Summary of Elicitation Results

Appendix III: $\quad$ Users Manual for TORNADO

Appendix IV: $\quad$ Coded Inputs for TORNADO

Appendix V: $\quad$ Second Tornado Hazard Workshop Presentation

Appendix VI: $\quad$ Second Tornado Hazard Workshop Summary

Appendix VII: $\quad$ First Tornado Workshop Presentation 
Appendix VIII: $\quad$ First Tornado Workshop Summary

Appendix IX: $\quad$ Third Tornado Wind Hazard Workshop Summary

Appendix X: $\quad$ Revised Coded Inputs for TORNADO 


\subsection{INTRODUCTION}

\subsection{Background}

Since the mid-1980's, assessment of the wind and tornado risks at the Department of Energy (DOE) high and moderate hazard facilities has been based on the straight wind/tornado hazard curves given in UCRL-53526 (Coats, 1985). These curves were developed using a methodology that utilized a model, developed by McDonald, for severe winds at sub-tornado wind speeds and a separate model, developed by Fujita, for tornado wind speeds. For DOE sites not covered in UCRL-53526, wind and tornado hazard assessments are based on the criteria outlined in DOE-STD-1023-95 (DOE, 1996), utilizing the methodology in UCRL-53526: Subsequent to the publication of UCRL-53526, in a study sponsored by the Nuclear Regulatory Commission (NRC), the Pacific Northwest Laboratory developed tornado wind hazard curves for the contiguous United States, NUREG/CR-4461 (Ramsdell, 1986).

Because of the different modeling assumptions and underlying data used to develop the tornado wind information, the wind speeds at specified exceedance levels, at a given location, based on the methodology in UCRL-53526, are different than those based on the methodology in NUREG/CR-4461. In 1997, Lawrence Livermore National Laboratory (LLNL) was funded by the DOE to review the current methodologies for characterizing tornado wind hazards and to develop a state-of-the-art wind/tornado characterization methodology based on probabilistic hazard assessment techniques and current historical wind data. This report describes the process of developing the methodology and the database of relevant tornado information needed to implement the methodology. It also presents the tornado wind hazard curves obtained from the application of the method to DOE sites throughout the contiguous United States.

\subsection{Project Scope}

The project scope consists of the following major tasks:

1. Review of the current methodologies for characterizing tornado wind hazards.

2. Development of an updated wind/tornado characterization methodology based on probabilistic hazard assessment techniques.

3. Development of a computer program implementing the updated methodology.

4. Performing trial applications of the methodology to several DOE sites.

5. Formation of a Tornado Wind Hazard Expert Panel (hereafter called Expert Panel). This panel would assist in the review of current methods, identify tools and techniques to be incorporated in the updated hazard characterization methodology, be a resource for the development and interpretation of relevant historical tornado data and review the methodology developed. The panel consisted of the 
following members: Robert Abbey, Joseph Golden, Robert

Kornasiewicz, Jim McDonald, Joseph Schaefer, and Emil Simiu.

6. Organizing three tornado wind hazard workshops to discuss the technical issues associated with the development of a probabilistic tornado wind hazard model.

\subsection{Sequence of Project Activities and Report Organization}

The LLNL Project Team consisted of Auguste Boissonnade, Quazi Hossain, Richard Mensing and Jean Savy. The project was started by forming the Expert Panel (with the concurrence of DOE Project Manager, Jeffery Kimball) and by organizing a workshop (The First DOE/LLNL Tornado Wind Hazard Workshop) to discuss the technical issues associated with the development of a probabilistic tornado wind hazard model. The activities conducted during this first workshop are summarized in Section 2 of this report. To facilitate discussion of the issues in the workshop, the LLNL Project Team performed a review of the methodologies available in the literature and identified the major issues. The review is documented in a report (see Appendix VII) that was presented to the Expert Panel and other industry experts who attended the workshop. The first workshop minutes, summarizing the discussions and results of the workshop, were sent to the workshop participants following the workshop. They are presented in Appendix VIII.

Following the discussion of the major issues during the first workshop, the LLNL Project Team developed a preliminary model, described in Appendix V, and organized a second workshop (The Second DOE/LLNL Tornado Wind Hazard Workshop) to discuss this preliminary model. The activities conducted during this second workshop are summarized in Section 3 of this report. The second workshop minutes, summarizing the discussions and results of the workshop, were sent to the workshop participants following the workshop. They are presented in Appendix VI.

With the inputs received from the second workshop participants and the Expert Panel members, the LLNL Project Team developed the model described in Sections 4 through 7 of this report. The model recognizes that there are uncertainties associated with the values of the model parameters. It uses inputs elicited from the Expert Panel to characterize the uncertainties in the model parameters. The process of eliciting judgements from the Expert Panel members is described in Section 8. The elicitation questionnaire and the summary of the responses from the Expert Panel members are presented in Appendices I and II, respectively.

The inputs received from the Expert Panel members were used to define the model parameters and their uncertainty distributions, which were coded in a computer program, TORNADO. A listing of values of the model parameters and distributions, with their uncertainty weights, are presented in Appendix IV. This listing represents the file of default inputs included as part of the TORNADO program. The program is described in Section 9, and a Users Manual for the program is provided in Appendix III. 
Sensitivity of the computed hazard values to various model parameters is discussed in Section 10. Initial test application of the TORNADO program to seven DOE sites is described in Section 11. Hazard curves and tabulated values provided in these two sections (i.e., Sections 10 and 11) are based on the hazard model and TORNADO code version before these were modified on the basis of revised inputs from the Expert Panel members (see Sections 12 and 13 for details).

The results of the sensitivity analyses and the test application of the methodology to estimate the tornado wind hazard at several DOE sites were included in a Draft Final Report, which was submitted to the Expert Panel for their review. A third workshop, The Third DOE/LLNL Tornado Wind Hazard Workshop, was organized to discuss the sensitivity and application results, to review the Panel's comments on the draft report and to give the experts an opportunity to make adjustments to their original inputs on the values of the model parameters. The activities and results of the workshop are summarized in Section 12. The third workshop summary was sent to the workshop participants. They are presented in Appendix IX.

After the third workshop the default input files for TORNADO were revised. They are in Appendix X. Using the revised inputs, estimates of the tornado wind hazard at seven selected DOE sites and for seven cities in the continental United states were developed. These estimates are provided in Section 13. Some conclusions and recommendations relevant to the methodology developed in this project and probabilistic modeling of tornado wind hazards are summarized in Section 14.

\subsection{Definitions and Explanation of Terms}

\subsubsection{Wind Speed Measure}

When using TORNADO to estimate the tornado wind hazard at a site, the measure of wind speed (or velocity) is based on the measure of wind speed defined for the relations used to map the F-scale intensities to wind speed intervals. The wind speeds in the three relations (as well as in the Dames \& Moore relation currently not used), included in the default parameters and distributions in TORNADO, are consistent with the wind speed measure used by Fujita (Fujita, 1971) when he developed the F-scale classifications. Thus, wind speed is measured by the horizontal velocity and expressed in terms of the fastest quarter-mile speed. Based on this observation, all hazard results included in the report are in terms of fastest quarter-mile speeds.

\subsubsection{Tornado Heading or Path Direction}

The heading or path direction of a tornado, as used in this report and in TORNADO, is the angular orientation of a vector between the longitude, latitude of the beginning (touchdown) of the tornado and the longitude, latitude of the end (lift-off) of the tornado. A zero degree heading corresponds to a south to north orientation of the travel path of the tornado. Heading values increase as the orientation moves in the counter-clockwise direction. Thus, a west to east travel path corresponds to a $90^{\circ}$ heading. In using this 
definition, it is recognized that the heading is a macro-measure of direction, which does not reflect the many irregularities in direction that might occur along the tornado path.

\subsubsection{F-scale Intensity Classification}

The F-scale intensity classifications, F0 through F6, referred to in this report and used in TORNADO are consistent with the Fujita F-scale intensity classifications (Fujita, 1971). A summary of the classifications and the associated damage descriptions and wind speed ranges are included in Appendix I of this report (included as Appendix I of the Questionnaire submitted to the Expert Panel). It is recognized that the maximum conceivable damage corresponds to an F5 classification. Thus, tornadoes can only be classified as F0 to F5. However, level F6 is included in the model to accommodate potentially higher wind speeds (i.e., speeds higher than $319 \mathrm{mph}$, the maximum speed associated with classification F5) and the possibility of misclassification of the intensity of a tornado, either due to under estimating the intensity or due to the limitation of the F0 to F5 scale.

\subsubsection{Length and Width of the Tornado Damage Area}

The length and width of the tornado damage area, used in this report and in TORNADO, are based on the definitions of length and width in the SPC Tornado database. As described in the explanation of the fields in the database, the length is the length of the tornado track. Since it accounts for nonlinear tracks, it might not be the same as great circle distance from touchdown to lift-off points. The width is the mean width along the entire track of the tornado.

In the description of the tornado wind hazard model in Section 5 and other sections throughout the Report, the damage area length and width variables are described as "correlated" stochastic variables. The use of the term correlation in this context refers to the potential probabilistic relationship between the two stochastic variables. An analysis of the recorded lengths and widths of the historical tornadoes was not performed as part of this project. Considering the length and width as correlated is based on the reported analyses performed by other researchers, e.g., Thom (1963), and the observed change in the empirical conditional distributions of width, given the damage area length. This statement does not imply any level of correlation, only that the variables are not treated as probabilistically independent. Since the estimated joint distributions of length and width, as a function of F-scale intensity, used as inputs into TORNADO are based on empirical distributions derived from the historical record, any correlation inherent in the data exists in the derived distributions.

This use of the term correlation is in contrast to the more mathematical and engineering use of the term to describe mathematical relationships between deterministic variables. The two uses of the term overlap only in the case when (probabilistic) correlation implies (mathematical) correlation between the expected values and variances of the stochastic variables. 
Correlation, in this Report, is limited to probabilistic correlation.

\subsubsection{Storm Prediction Center (SPC) Tornado Database}

The source of information about the historical tornadoes and the basis for many of the estimates of the distributions of tornado variables, used in TORNADO and discussed in this report, is the SPC Tornado database. The original file of data covered events, which occurred between 1950 and 1995 . The original file, as received, contained 36,007 records. Not all records corresponded to a unique tornado. Segments were defined when a "tornado markedly changed direction, changed states, and when it entered or left a county in which there were deaths or injuries". Thus, some records were continuation records for the same tornado. Prior to using the database for analysis it was modified by eliminating the continuation records and only retaining one record per unique tornado. In doing this, selected variables, e.g., tornado length, were adjusted, if it was appropriate. After modification, the file contained 35,435 unique tornadoes.

Subsequent to the completion of the original draft of this Report, Joe Schaeffer, Director of the SPC, provided an updated version of the SPC Tornado database. The updated file contained information about historical tornadoes from 1950 through 1998. As the original file, the updated file contained multiple (continuation) records, representing various segments, for some tornadoes. After removal of the continuation records, thus leaving one record per unique tornado, and deleting tornadoes in Alaska, Hawaii, Puerto Rico and the Virgin Islands, the file contained 39,143 records or unique tornadoes. This database of historical tornadoes formed the basis for many of the distributions used as inputs into TORNADO.

The SPC database originated in the early 1970's and is a database of tornado records dating back to 1950. Identification and classification of tornadoes prior to the initiation of the database were based on reviewing Weather Bureau records, newspaper articles, photographs of damage and other relevant historical resources and information. Because of the reduced awareness of tornadoes, lower population densities and no established depository of information about tornadoes during this time, the early data is incomplete. There is a trend in increased reporting of tornadoes, particularly since the late 1970's. Several analyses of the reported trend indicate that the greatest percentage (77 per cent) of the average annual increase in the number of tornadoes is in the lowest intensity categories (F0, F1). On the other hand, the annual number of high intensity (F4, F5) tornadoes has remained unchanged. The analyses suggest that increased awareness, increases in population densities and improved communication are responsible for the increasing number of reported tornadoes over time rather than meteorological factors. Unreported tornadoes in the early years can result in non-conservative estimates of occurrence rates. On the other hand, since most unreported events are low intensity tornadoes, this can lead to conservative estimates of the distribution of intensities. In addition, reliance on newspaper accounts of the damage, hence on the estimated intensity, can also skew the intensity distribution. Because newspaper stories tend to accentuate the 
effects of catastrophic events, there is the possibility of over classifying the intensity. Nuclear Regulatory Commission (NRC) funded projects since the mid 1970's have resolved some, but not all, differences in the reported events and intensities between the SPC and other databases.

Other tornado variables, such as path heading, the damage area length and width and the wind field within the damage area are even more difficult to assess and quantify. Overall, when using the information in the SPC database it is important to recognize the magnitude of compiling such a volume of data and the potential for misrepresentation of some facts and the potential incompleteness of the data. In this project, the issue of errors in the classification of tornado intensities is recognized and handled directly in the model

through the use of the misclassification matrix. Incompleteness in the data and changes in the quality of the data over time are handled in the uncertainty analysis portion of the methodology by using the historical data over different time periods to develop the model parameter values and distributions. The judgements of a panel of experts were elicited to choose the appropriate time periods.

\subsubsection{F-scale to Wind Speed Relations}

The F-scale to wind speed relation, one of the parameters of the tornado model, associates a range of wind speeds to each F-scale intensity level. This is an important parameter because the tornado wind hazard is expressed in terms of wind speed while the severity of tornadoes is described in terms of F-scale intensities. Nearly all information about tornado characteristics is based on observed damage rather than on direct physical measurements such as pressure or wind velocity. Since wind speeds are not directly measured in a tornado, the winds are implied from the damage observed. To use observed or photographed damage to estimate wind speeds it is necessary to conceptually make some estimate of the wind pressure needed to cause the damage. The associated wind speed would then be estimated by use of some pressure coefficient. Ideally, any relationship between damage and wind speed is based on a rational procedure, which incorporates consideration of structural resistance, exposure, rate of loading, duration of load application and wind pressure distribution. Practically, it is impossible to incorporate all these variables simultaneously or with any level of certainty. Thus, any relation is inherently subject to considerable judgement.

The first intensity to wind speed relation was the Fujita relation, developed in the early 1970 's. The relation represents an empirical estimate of the speeds required to create the observed damage. Two other relations, the Twisdale uniform and Twisdale linear models, are derived from the Fujita relation by assuming the upper bounds of each wind speed interval is subject to uncertainty. Uncertainty distributions for the interval upper bounds are developed by applying either a uniform or a linear distribution to the ranges of wind speeds in the Dames \& Moore (Beebe, 1975) relation. Justification for using the Dames $\&$ Moore intervals in this way is based on the perception that the structural failure analyses used in the development of these intervals provides information about the maximum wind speeds associated with certain levels of damage. Assuming the wind speeds in each of the Fujita intervals is uniformly distributed, the updated distribution for 
each interval is uniform with revised upper bounds as given in the two Twisdale relations. Thus, all three relations are based on the original Fujita relation.

During the discussion of the intensity to wind speed relation at the third workshop, the panel identified two criteria for a reasonable relation. One, the maximum wind speeds must be reasonable. The Fujita relation was criticized based on this criterion. The general perception was that the wind speeds, particularly those associated with the high intensities, are unrealistically high. On the other hand, the two Twisdale relations were considered to associate unrealistically low wind speeds to the damage, particularly the damage associated with high intensities. The second criterion identified by the panel was that the range of the wind speed intervals should increase as the intensity increases. This partly comes from the perception that it is more difficult to assess the speeds that can cause the more extensive damage associated with the higher intensities. The Fujita relation satisfies this property in the sense that the ranges increase by $5 \mathrm{mph}$ for each succeeding intensity level. The two Twisdale relations do not display a consistent pattern in this regard.

Based on a lack of satisfaction with any of the three relations, the panel developed an alternative empirical relation. Although it is not based on new scientific data and analysis, it is based on critique and knowledgeable judgements about the previously derived relations as well as information about the damaging effects of winds gathered since the early 1970's when the Fujita relation was first developed. This new relation is one of the relations included in the re-elicitation of the model parameters. 


\subsection{First DOE/LLNL Tornado Wind Hazard Workshop}

The First DOE/LLNL Tornado Wind Hazard Workshop was held in Gaithersburg, MD on May 21 and 22, 1997. The broad objective of the workshop was to foster interaction among experts in the tornado hazard research field. The project specific objective was to review the existing hazard determination methodologies for the purpose of identifying the major issues that should be addressed in developing a state-of-the-art probabilistic model. In addition to the Expert Panel members and the LLNL Project Team, other government and industry experts in this field were also invited. The workshop announcement, agenda, list of participants, and a description of the role of the participants are provided in Appendix VII. To facilitate discussion of issues, the workshop participants were provided with a literature survey report prepared by the LLNL Project Team. This report is included in Appendix VII.

In the workshop, the LLNL Project Team presented an overall review of the existing hazard determination methodologies, compared their relative strengths and weaknesses, and identified the issues that the team considered significant. This was followed by a presentation by Jim McDonald, a developer of tornado hazard methodology, who also discussed the existing methodologies and major issues (the other developer, Larry Twisdale, who was invited, could not attend the workshop). Jim McDonald was a major contributor in developing hazard curves for DOE sites. Robert Abbey, who worked with Theodore Fujita on the determination of tornado wind hazards, discussed several topics, including the status of the available tornado databases, the DAPPLE method for assessing tornado hazards and the regionalization of tornado hazards. Thereafter, other members of the Expert Panel presented their evaluations of the existing methods.

The LLNL Project Team summarized the presentations by the speakers and prepared a list of significant issues identified by them. This was followed by a discussion of the issues by all the participants. Following an extensive discussion, the LLNL team proposed a very preliminary concept for the development of a state-of-the-art hazard model that would address the issues identified. The workshop summary and closures on issues discussed is presented in Appendix VIII.

Based on the discussions during this workshop the LLNL Project Team proposed a hazard model that would have the following attributes:

1. It would be an explicit probabilistic model that incorporates both aleatory (random) and epistemic (modeling) uncertainties associated with the parameters that affect tornado wind hazards.

2. It would be a site specific areal probability model having the capability of taking into consideration the size of the facility, the length and width of the tornado damage area (idealized as a rectangle), wind speed variation within the damage area and the tornado path direction. 
3. It would account for misclassification errors (i.e., errors in assigning a Fujita intensity scale based on a damage survey); such errors are considered aleatory uncertainties. It would include the epistemic uncertainties associated with modeling classification errors in the uncertainty analysis.

4. It would model the temporal occurrence of tornadoes throughout the contiguous United States as a Poisson process. A spatial distribution of tornado touchdown location would be determined empirically based on observed historical events within the contiguous U.S. and, instead of assuming a uniform distribution over a sitespecific tornado effect area (SSTEA), the relevant conditional distribution applicable to the SSTEA would be used.

5. It would be capable of accounting for the uncertainty associated with the conversion from Fujita intensity scale to horizontal wind speed (by allowing for more than one conversion scale). 


\subsection{Second DOE/LLNL Tornado Wind Hazard Workshop}

The Second DOE/LLNL Tornado Wind Hazard Workshop was held in Washington D.C. on August 27 and 28, 1998. The primary goal of this workshop was for the LLNL Project Team to present to the Expert Panel the details of the proposed hazard model that was developed based on inputs received during the first workshop. A second goal was for the Expert Panel to review the proposed model and interrogate the Project Team on the model details. Another important workshop objective was for the Project Team to elicit from the Expert Panel members their judgement on the values of the model parameters, including parameters as well as probability disributions of modeled stochastic variables. The workshop announcement, agenda, list of participants, and a description of the proposed model, presented at the workshop, are included in Appendix V.

In the Workshop, the LLNL Project Team presented the proposed method along with the results of some sensitivity analyses. During the discussion of the proposed model, the Expert Panel members recommended revision of the model to include development of a site-specific intensity distribution rather than a distribution based on the entire contiguous U.S. This recommendation has been included in the final model. In addition, the process for eliciting the Expert Panel members' input on the model parameters and distributions was developed at the workshop. The elicitation, done after the workshop, was based on members responding to a written questionnaire.

The workshop summary and closures on issues discussed is presented in Appendix VI. 


\subsection{An Overview of the Model Development Process}

The tornado wind hazard at a facility is generally characterized in terms of a probabilistic hazard curve. It is defined to be the expected frequency, per year, that tornado wind speeds at a site exceed a specified velocity. The tornado wind hazard curve quantifies the hazard as a function of velocity. To develop such a curve, it is necessary to model tornado temporal occurrences, touchdown locations, and characteristics, e.g., intensities, path directions, damage areas and distribution of wind intensities within the damage area. These are stochastic variables, and must be recognized accordingly while calculating the hazard.

The tornado wind hazard estimation methodology developed and described here is based on probabilistic risk assessment techniques. In addition to using some new methods and models, the methodology also utilizes some previously developed techniques. The major features of the methodology include:

1. Estimation of the parameters and probability distributions included in the calculation model based on information derived from historical tornadoes.

2. Modeling the site as an area, thus taking into consideration the dimensions and orientation of the site. Such a model is referred to as an areal model.

3. Defining the hazard to exist if some part of the facility experiences a tornado with winds of at least a specified velocity, referred to as the union definition of a tornado strike. This is in contrast to the intersection definition, which considers the hazard to exist only if the entire facility experiences winds of at least a specified velocity.

4. Development of an estimate of a site-specific intensity distribution

5. Development of a site-specific occurrence rate of tornadoes in the area surrounding the site.

6. Making no assumption about the distribution of the tornado touchdown locations in the vicinity of the site of interest. Instead, an empirical distribution of locations is developed based on the recorded touchdown locations of the historical tornadoes throughout the contiguous U.S.

The hazard model derivation and formulation is described in Section 5. Estimation of the model parameters and characterization of parameter epistemic uncertainties is presented in Section 6. Section 7 discusses the analysis for quantifying the epistemic uncertainty associated with the estimation methodology and the use of model parameter values subject to uncertainties. A default set of alternative values of the model parameters and distributions, with uncertainties, (summarized in Appendix IV) was developed based on eliciting the judgements of the Expert Panel members. This process is described in Section 8. A computer program, TORNADO, has been written to develop the sitespecific intensity distribution models and the hazard curves including epistemic uncertainty. The program features and capabilities are described in Section 9. A series of TORNADO runs were made to assess the sensitivity of the computed hazard values to changes in the input parameters and to evaluate the significance of the model parameters. These sensitivity analyses are described in Section 10. 


\subsection{Tornado Wind Hazard Model}

The basic assumption underlying the model for estimating the tornado wind hazard at any site in the contiguous U.S. is that the temporal occurrence of a tornado in any area can be modeled as a stationary Poisson process. Associated with a site is an area surrounding the site, referred to as the 'the site specific tornado effect area' (SSTEA). The SSTEA is the area surrounding the site which, if a tornado touchdown occurs within the area, the site could experience wind speeds of at least intensity F0. The tornado occurrence rate, i.e., the expected frequency, per year, of tornado touchdowns occurring within the SSTEA is considered to be site specific. Let $\lambda_{s}$ denote the site-specific expected frequency. Given that a tornado occurs within the SSTEA, the event 'the wind speed (WS) at the site exceeds a specified velocity, $\mathrm{v}$ mph' is modeled as a Bernoulli event with parameter

$$
\mathrm{P}=\mathrm{P}(\mathrm{WS}>\mathrm{v} \mid \mathrm{a} \text { tornado occurs in the SSTEA })
$$

Given these basic assumptions, the occurrence of a tornado in the SSTEA such that the wind speed at the site exceeds $\mathrm{v}$ mph is modeled as a Poisson process with expected frequency, per year, equal to $\lambda_{s} \mathrm{P}=\lambda_{\mathrm{s}} \mathrm{P}(\mathrm{WS}>\mathrm{v} \mid \mathrm{a}$ tornado occurs in the SSTEA $)$. The expected frequency, as a function of $\mathrm{v}$, is the tornado wind hazard curve.

Given that a tornado touches down in the SSTEA, the conditional probability that the wind speed at the site exceeds $\mathrm{v}$ mph is a function of a number of tornado related characteristics, including:

1. The intensity of the tornado

2. The heading, or path direction, of the tornado

3. The touchdown location within the SSTEA

4. The 'size' of the tornado damage area (TDA), i.e., the area in which the wind speeds are at least of intensity F0

5. The variation of wind speeds (i.e., wind field) within the TDA

These characteristics are stochastic variables thus it is necessary to average the tornado wind hazard with respect to the probability distributions of the variables.

As described in Section 1.4, the model is based on using the F-scale intensity classifications, $\mathrm{F} 0$ through $\mathrm{F} 6$. Given the intensity distribution, $\mathrm{P}_{\mathrm{T}}(\mathrm{Fi}), \mathrm{i}=0,1, \ldots, 6$, the tornado wind hazard at the site, $\mathrm{EF}(\mathrm{v})$, is

$$
\mathrm{EF}(\mathrm{v})=\lambda_{\mathrm{s}} \Sigma_{\mathrm{i}} \mathrm{P}(\mathrm{WS}>\mathrm{v} \mid \text { an Fi tornado occurs in SSTEA }) \mathrm{P}_{\mathrm{T}}(\mathrm{Fi})
$$

Although not obvious in the equation, inherent to the calculation is the existence of a relation between the intensity F-scale values and wind speed levels. The intensity to wind speed relation, which associates an interval of wind speeds with each intensity, is an important model parameter. Several relations have been developed (Twisdale, 1978). The methodology allows for the uncertainty in relating wind speeds to tornado damage by 
using several relations with associated weights. The methodology develops a distribution for wind speeds, which is used to distribute the wind speeds within an interval.

Estimation of the tornado wind hazard depends on estimating the intensity distribution. The methodology uses a site-specific intensity distribution in addition to the site-specific tornado occurrence rate. The process for developing estimates of the site-specific intensity distribution is discussed in Section 6.3. Since the methodology uses the historical data to estimate the intensity distribution, the model accounts for the potential errors in the recorded historical intensities. The primary sources of classification errors are due to the random encounter of the tornado with structures and to human errors in classification. The intensity classification is intended to reflect the maximum wind speed within the tornado and is dependent on observations of the damage produced by the tornado. The tornado is capable of producing a given amount of damage (e.g., F3 intensity damage) provided the opportunities exist to produce that level of damage. The existence of opportunities is a function of the tornado touchdown location and path as well as the number, locations and type of structures, trees, vehicles, etc. within the tornado damage area. Given the tornado damage, human judgement is required to translate the observed damage to an intensity level. This is another source of classification error. Since the random encounter error is considered to be the dominant source of error, the model treats the classification errors as a stochastic source of variation. The variation in intensity classification due to classification errors is quantified in terms of a 'misclassification matrix', i.e., a matrix of conditional probabilities, $\mathrm{p}_{\mathrm{ij}}$, defined as:

$$
\mathrm{p}_{\mathrm{ij}}=\mathrm{P}(\text { true intensity is } \mathrm{Fi} \mid \text { recorded intensity is } \mathrm{Fj})
$$

Given an estimate of the intensity distribution based on the recorded data, i.e.,

$$
\mathrm{P}_{\mathrm{R}}(\mathrm{Fj}), \quad \mathrm{j}=0,1, \ldots 5,
$$

the estimate of the 'true' intensity distribution is:

$$
\mathrm{P}_{\mathrm{T}} *(\mathrm{Fi})=\Sigma_{\mathrm{j}} \mathrm{p}_{\mathrm{ij}} \mathrm{P}_{\mathrm{R}}(\mathrm{Fj}), \quad \mathrm{i}=0,1, \ldots, 6
$$

Many models for estimating tornado wind hazard are based on assuming (1) that the site is a point and (2) the distribution of touchdown locations within the SSTEA is a uniform distribution. Under these assumptions, the probability that the wind speed exceeds a specified velocity at any point within the SSTEA is equal to the ratio of the average size of a sub-area within the tornado damage area in which the wind speeds exceed the velocity and the size of the SSTEA. The updated methodology extends these assumptions by treating the site as an area rather then a point and allows for a non-uniform distribution of touchdown locations within the SSTEA. Given that the site is modeled as an area, it is appropriate to define a 'tornado origin area' (Twisdale, 1978). The wind speed at the site is considered to be greater then a specified velocity if the wind speed at some point within the site area is greater then the specified velocity. This is the union definition of a tornado strike at a site (Twisdale, 1978). Using this definition, the 'tornado origin area' is 
the set of touchdown locations such that a tornado strike occurs at the site, i.e., the wind speed at some point within the site area is greater then the specified velocity. In addition to the dimensions of the site, the 'tornado origin area' depends on the 'damage area' of the tornado. Given a touchdown location and the direction of the tornado path, the 'damage area' is the area of the tornado path in which the wind speeds are at least of intensity F0. The 'damage area' is modeled as a rectangular area (Twisdale, 1978). The length, L, and width, W, of the 'damage area' are stochastic variables. Based on a review of other modeling efforts (e.g., Thom, 1963), the dimensions of the 'damage area' are assumed to be correlated. Also, as indicated by the distributions derived from the historical data (presented in Appendix IV), the joint distribution of L and $\mathrm{W}$ is a function of the F-scale intensity. Thus, the joint variability of $\mathrm{L}$ and $\mathrm{W}$ is represented by a separate joint distribution for each intensity classification level. The joint distributions are estimated by joint empirical discrete distributions based on the historical tornado lengths and widths as recorded in the SPC tornado database.

Within the damage area the winds are of varying intensities. This is included by modeling areas of increasing 'local intensity' as included rectangles, centered, lengthwise, at the center of the damage area. Wind speeds associated with tornadoes are based on the tangential velocities of the winds on the outer edge of the tornado funnel. Due to the combined effects of the radial and translational velocities of a tornado, the wind field profile across the width of the damage area is asymmetric about the center of the tornado path. This is modeled by offsetting the center, along the width of the included rectangles, (representing the areas of local intensities) to the right of the center of the tornado path, represented by the center of the width of the damage area. This is shown in Figure 5.1. Each of the included sub-areas of 'local intensity' within the damage area represents the set of touchdown locations such that the winds at the site are of the specified local intensity. The dimensions of the sub-areas of 'local intensity' are proportional to the dimensions of the 'damage area' of the tornado and are denoted by $(\delta \mathrm{L}, \delta \mathrm{W})$. Several sets of the proportional values, based on the work of several researchers in the tornado community, are considered for inclusion in the model. A damage area and the included sub-areas of local intensities for an F2 tornado are illustrated in Figure 5.1.

Treating the damage area in this way, the tornado origin area depends on the dimensions and orientation of the facility as well as the direction of the tornado path. This is illustrated, for a F2 tornado, in Figure 5.2, in which the facility is assumed oriented in the $\mathrm{N}-\mathrm{S}$ direction. The model assumes that a facility can be represented by a collection of convex polygons.

Since the wind speed at the site is a function of the F-scale intensity level, the probability that the wind speed at a site, given a Fi intensity tornado, is:

$\mathrm{P}(\mathrm{WS}>\mathrm{v} \mid \mathrm{a}$ Fi tornado in SSTEA $)=\sum_{\mathrm{j} \leq \mathrm{i}} \mathrm{P}(\mathrm{WS}>\mathrm{v} \mid \mathrm{Fj}, \mathrm{Fi}) \int_{\mathrm{A}(\mathrm{Sij})} \mathrm{dF}(\mathrm{x}, \mathrm{y} \mid \mathrm{SSTEA})$

The terms in the equation refer to: 
- $\quad P(W S>V \mid F j, F i)=$ probability that the wind speed at the site is greater then $v$ mph, given winds of intensity $\mathrm{Fj}$ within the damage area of an Fi intensity tornado

- $\mathrm{dF}(\mathrm{x}, \mathrm{y} \mid \mathrm{SSTEA})=$ density function of the distribution of touchdown locations given that the tornado touchdown is within the SSTEA

- $\mathrm{A}(\mathrm{Sij})$ denotes the $\mathrm{Fj}$ intensity sub-area within the Fi tornado damage area, i.e., the touchdown locations such that the wind intensity at the site is of level $\mathrm{Fj}$; this area is a function of the direction of the tornado path (heading), $\theta$, the length and width $(\mathrm{L}, \mathrm{W})_{\mathrm{i}}$ of the damage area of the Fi intensity tornado and the fractions $(\delta \mathrm{L}, \delta \mathrm{W})_{\mathrm{ij}}$ defining the $\mathrm{Fj}$ subarea.

$$
\text { - } \quad \operatorname{Sij}=\left\{\theta,(L, W)_{i},(\delta L, \delta W)_{i j}\right\}
$$

Since the tornado path heading and the damage area length and width are stochastic variables, the calculation is based on averaging the integral of the location distribution over $\mathrm{A}(\mathrm{Sij})$ with respect to the probability distributions of the variables defining $\mathrm{A}(\mathrm{Sij})$. Thus, Equation (5.4) becomes:

$$
\begin{aligned}
& \mathrm{P}(\mathrm{WS}>\mathrm{v} \mid \text { Fi in SSTEA })= \\
& \quad \Sigma_{\mathrm{j} \leq \mathrm{i}} \mathrm{P}(\mathrm{WS}>\mathrm{v} \mid \mathrm{Fj}, \mathrm{Fi}) \int_{\theta} \int_{(L, W) i} \int_{\mathrm{A}(\mathrm{Sij})} \mathrm{dF}(\mathrm{x}, \mathrm{y} \mid \mathrm{SSTEA}) \mathrm{dH}(\mathrm{L}, \mathrm{W}) \mathrm{dG}(\theta)
\end{aligned}
$$

Inserting Equation (5.5) into Equation (5.1), the calculation model for the tornado wind hazard is:

$$
\begin{aligned}
& \mathrm{EF}(\mathrm{v})= \\
& \lambda_{\mathrm{s}} \Sigma_{\mathrm{i}}\left\{\Sigma_{\mathrm{j} \leq \mathrm{i}} \mathrm{P}(\mathrm{WS}>\mathrm{v} \mid \mathrm{Fj}, \mathrm{Fi}) \int_{\theta} \int_{(\mathrm{L}, \mathrm{W}) \mathrm{i}} \int_{\mathrm{A}(\mathrm{Sij})} \mathrm{dF}(\mathrm{x}, \mathrm{y} \mid \operatorname{SSTEA}) \mathrm{dH}(\mathrm{L}, \mathrm{W}) \mathrm{dG}(\theta)\right\} \mathrm{P}_{\mathrm{T}}(\mathrm{Fi})
\end{aligned}
$$

Estimation of the tornado wind hazard using the model in Equation (5.6) depends on developing estimates of the expected frequency, the WS exceedance probability and the distributions in the model. The estimate of the intensity distribution is given in Equation (5.3). Estimates of the distributions of path heading and damage area length and width, $\mathrm{G}(\theta)$ and $\mathrm{H}(\mathrm{L}, \mathrm{W})$ respectively, are empirical distributions based on the recorded tornado information in the Storm Prediction Center (SPC) Tornado database. The probability $\mathrm{P}(\mathrm{WS}>\mathrm{V} \mid \mathrm{Fj}, \mathrm{Fi})$ is based on the $\mathrm{F}$-scale to wind speed relations and the distributions of wind speeds developed as part of the process for estimating the intensity distribution.

A feature of the methodology is the estimation of the site-specific tornado occurrence rate, i.e., the expected frequency of tornadoes in the SSTEA, and the conditional distribution of touchdown locations, give a tornado touches down in the SSTEA. This estimate is based on touchdown locations of the historical tornadoes in the SPC Tornado database. First, an estimate of the expected frequency, per year, of tornadoes occurring in the contiguous U.S. is developed. The estimation method is discussed in Section 6. Secondly, a 2-dimensional kernel is used to estimate the distribution of touchdown 
locations throughout the contiguous U.S. Given the locations of the historical tornadoes, the 2-dimensional normal kernel is:

$$
f\left(x_{1}, x_{2}\right)=\frac{1}{2 \pi h_{1} h_{2}} \sum_{i=1}^{n} \operatorname{Exp}\left\{-\frac{1}{2} \sum_{j=1}^{2}\left(\frac{x_{j}-x_{i j}}{h_{j}}\right)^{2}\right\}
$$

where $\left(x_{1}, x_{2}\right)$ and $\left(x_{i 1}, x_{i 2}\right), i=i, \ldots, n$, are the (latitude, longitude) of an arbitrary location in the contiguous U.S. and the touchdown locations of the historical tornadoes respectively. The smoothing parameters, $h_{1}, h_{2}$, model the expected variability of locations of future tornadoes relative to the locations of the historical locations. The values of these parameters are discussed in Section 6. Given the estimate of the expected frequency of tornadoes in the contiguous U.S., $\lambda$, and the kernel estimate, $\mathrm{dF}(\mathrm{x}, \mathrm{y})=$ $f\left(x_{1}, x_{2}\right)$, in Equation (5.7), the estimates of the site-specific expected frequency and conditional distribution of touchdown locations, given a tornado occurs within the SSTEA, are:

$$
\begin{gathered}
\lambda_{\mathrm{s}}^{*}=\lambda \mathrm{P}(\text { a tornado touchdown occurs in the SSTEA }) \\
=\lambda \int_{\text {SSTEA }} \mathrm{dF}(\mathrm{x}, \mathrm{y})
\end{gathered}
$$

Combining the two estimates results in the identity:

$$
\lambda_{\mathrm{s}}^{*} \mathrm{dF}(\mathrm{x}, \mathrm{y} \mid \operatorname{SSTEA}) *=\lambda \mathrm{dF}(\mathrm{x}, \mathrm{y})
$$

Inserting these estimators, as well as the estimator of the intensity distribution (Equation (5.2)), into Equation (5.6), the calculation model for estimating the tornado wind hazard at a site anywhere in the contiguous U.S. is:

$\mathrm{EF}(\mathrm{v})=\lambda \sum_{\mathrm{i}}\left\{\Sigma_{\mathrm{j} \leq \mathrm{i}} \mathrm{P}(\mathrm{WS}>\mathrm{v} \mid \mathrm{Fj}, \mathrm{Fi}) \int_{\theta} \int_{(\mathrm{L}, \mathrm{W}) \mathrm{i}} \int_{\mathrm{A}(\mathrm{Sij})} \mathrm{dF}(\mathrm{x}, \mathrm{y}) \mathrm{dH}(\mathrm{L}, \mathrm{W}) \mathrm{dG}(\theta)\right\}\left[\Sigma_{\mathrm{k}} \mathrm{p}_{\mathrm{ik}} \mathrm{P}_{\mathrm{R}}(\mathrm{Fk})\right]$

This is the basic model implemented in the TORNADO code to estimate the tornado wind hazard at any site within the contiguous U.S. 


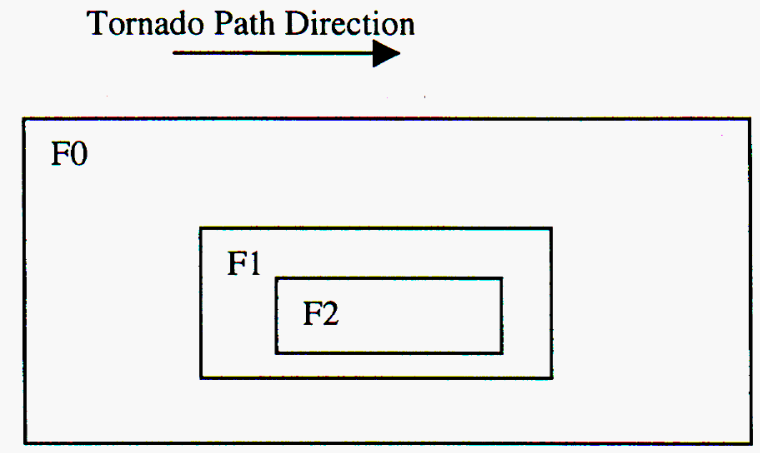

Figure 5.1: Damage Area and Include Sub-areas of Local Intensities for a F2 Tornado

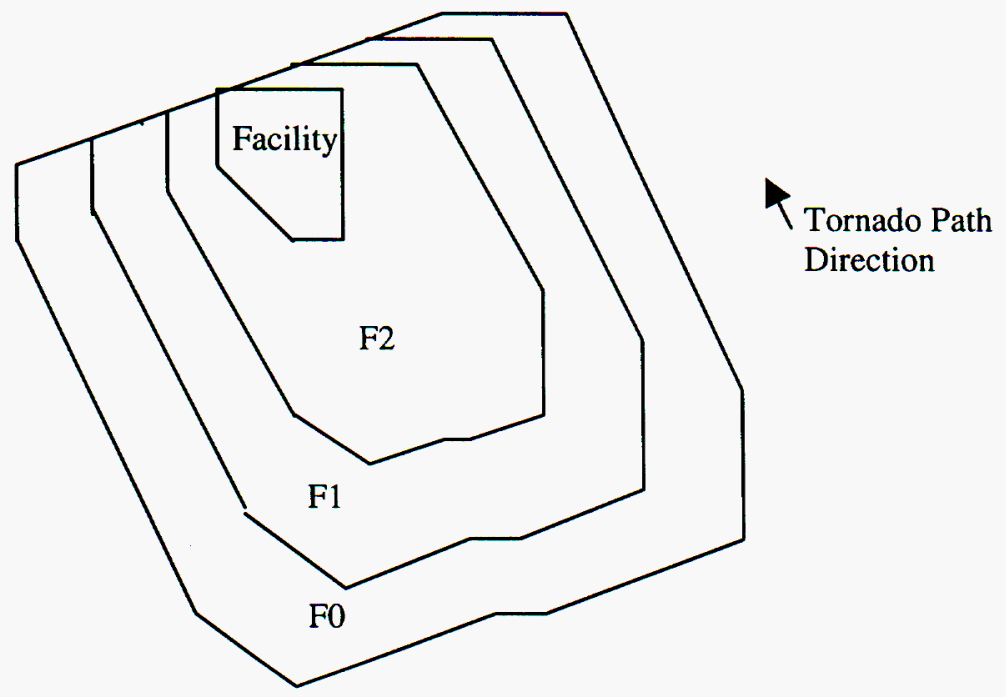

Figure 5.2: Origin Areas for Each of the Local Intensities for a F2 Tornado 


\subsection{Model Parameter Estimation and Uncertainty}

The estimates of the parameters in the calculation model in Equation (5.11) were derived from a variety of sources. One principle source was the SPC Tornado database of information relevant to the historical tornadoes. The historical data was used to estimate the touchdown location distribution, the tornado path heading distributions, the joint distributions of the damage area length and width, and is the source of data for the sitespecific intensity distributions. The second principle source of information was the tornado wind hazard literature. Four models of the relation between F-scale intensity and wind speeds were derived from the literature (Twisdale, 1978). Misclassification matrices and matrices of fractions for modeling the sub-areas of 'local intensity' within the damage area were developed based on models for these matrices found in the literature (See Sections 6.5 and 6.8). The tornado wind hazard community, as represented by the Expert Panel, served as the resource for estimating the expected frequency, per year, of tornadoes occurring within the contiguous U.S. The Expert Panel also served as the resource for quantifying the uncertainties associated with estimating the model parameters using the information from the primary sources of information. The uncertainty information was derived through an elicitation process. The elicitation is discussed in Section 8.

The estimated parameters and distributions, and the weights provided by the Expert Panel, are based on the data and knowledge available at the time of this study. It should be emphasized that these inputs into the model can easily be updated as knowledge of tornado physics and climatology increases and additional research and modeling of tornado parameters and characteristics are conducted.

\subsection{Expected Frequency of Tornadoes in the Contiguous U.S.}

The SPC Tornado database is a likely resource for estimating the expected frequency of tornadoes in the contiguous U.S. However, several questions were raised concerning deriving an estimate of the expected frequency directly from the database. One concern is the potential of significant underreporting of tornadoes in the early years of the SPC database. This is due to a number of things. For example, the population density in some areas has increased considerably over time, thus, improving the likelihood of tornadoes being reported. Also, the events in the early years are based on newspaper accounts and not directly observed. Perhaps the primary reason for the apparent increase in reports is improved communication (e.g., cell phones). Based on these observations, an estimate of the expected frequency was not derived directly from the historical data. Rather, the estimate of the expected frequency, per year, of tornadoes occurring in the contiguous U.S. was developed by asking the members of the Expert Panel to provide an estimate of the expected frequency. Each panelist, as a member of the tornado wind hazard community, was asked to provide an empirical distribution describing their uncertainty in estimating the value of the expected frequency. The average of these distributions, summarized in Table (6.1), is used to describe the uncertainty, within the tornado wind hazard community, in estimating the expected frequency, $\lambda$. 
Table 6.1: Uncertainty Distribution for Expected Frequency of Tornadoes, per year, Within the Contiguous U.S.

\begin{tabular}{|c|c|}
\hline Occurrence Rate, $\mathbf{r}$ & $\mathbf{P}(\lambda \leq \mathbf{r})$ \\
\hline 500 & 0 \\
\hline 600 & 0.108 \\
\hline 700 & 0.216 \\
\hline 800 & 0.314 \\
\hline 900 & 0.428 \\
\hline 1000 & 0.590 \\
\hline 1100 & 0.709 \\
\hline 1200 & 0.808 \\
\hline 1300 & 0.896 \\
\hline 1400 & 0.951 \\
\hline 1500 & 0.994 \\
\hline 1600 & 1.0 \\
\hline
\end{tabular}

\subsection{Touchdown Location Distribution}

As described in Section 5, the distribution of tornado touchdown locations throughout the contiguous U.S. was estimated using a normal kernel estimator [Equation (5.7)]. The parameters of the estimator are the smoothing parameters, $\mathrm{h}_{1}, \mathrm{~h}_{2}$, which reflect the variability of future tornado locations relative to the locations of the historical tornado locations. The values of $h_{1}, h_{2}$ determine the 'smoothness' of the distribution. If $h_{1}, h_{2}$ are too large, the estimated distribution will tend to distribute probability to locations, which, historically, have not experienced tornadoes. On the other hand, if $h_{1}, h_{2}$ are too small, the distribution would not allow any variation from the historical distribution. Experience in using such estimators suggests that the 'best' values of $h_{j}, j=1,2$, are a fraction of the nominal estimator, $\sigma_{\mathrm{j}} \mathrm{n}^{-1 / 6}$, where $\sigma_{1}, \sigma_{2}$ are the standard deviation of the latitude, longitude of the location, respectively, and $n$ is the number of historical locations. A series of studies were done using a number of different locations and area sizes to investigate the relationship of the values of the $h_{j} s$ and the ability of the estimator to predict the historical number of tornadoes that occurred in the areas. The results of these studies are summarized in Table 10.1. Based on these studies, it was determined that, for this application, the 'best' value for $h_{j}$ is $0.1 \sigma_{j} n^{-1 / 6}$. These are the values currently used in the TORNADO code. Uncertainties associated with estimating the location distribution 
are not included in the current model. It is recommended that this issue be considered for future study (see Section 14.0).

\subsection{F-scale Intensity Distribution}

One of the features of the methodology is the development of a site-specific intensity distribution using the intensity data, from the SPC Tornado database, for historical tornadoes which touchdown in an area surrounding the site. The area, labeled the site effect area (SEA), is centered at the location of the site and is a $2^{\circ} \times 2^{\circ}$, a $3^{\circ} \times 3^{\circ}$, or a $5^{\circ} \times 5^{\circ}$ square area. The three sizes of the SEA were considered because of the uncertainty in knowing the appropriate area size needed to estimate a site-specific intensity distribution. The (uncertainty) weights associated with the 3 area sizes, based on the inputs provided by the Expert Panel members in the elicitation, are summarized in Table 6.2.

Table 6.2: Weights for SEA Sizes

\begin{tabular}{|c|c|}
\hline Area Size (degr.) & Weight \\
\hline $2 \times 2$ & 0.2 \\
\hline $3 \times 3$ & 0.28 \\
\hline $5 \times 5$ & 0.52 \\
\hline
\end{tabular}

The process for estimating the site-specific intensity distribution is based on the following analysis:

A. Inputs:

1. Site location (latitude, longitude) and dimensions

2. The 3 SEA sizes with weights

3. The 5 misclassification matrices (Matrix) with weights

4. The 3 F-scale intensity to wind speed relations (Relation) with weights

5. A data file of the historical tornado touchdown locations and recorded intensities (Data File)

B. Analysis:

Develop a wind speed distribution and F-scale intensity distribution for each combination of a SEA and Relation:

1. Using the location and intensity data in the Data File, derive an estimated F-scale intensity distribution for each SEA

2. For each Relation, transform the F-scale intensity distribution to a histogram of the numbers of occurrences for each wind speed interval

3. For each of the 3 distribution models, uniform, beta, and Weibull, estimate the parameters of the distribution using Maximum Likelihood Estimation (MLE), i.e., assessing the values of the parameters which maximize the log likelihood function: 


$$
\operatorname{Ln} L=\sum_{\mathrm{i}} \operatorname{Ln}\left[\mathrm{F}\left(\mathrm{WS}_{\mathrm{Ui}}\right)-\mathrm{F}\left(\mathrm{WS}_{\mathrm{Li}}\right)\right]^{\mathrm{ni}}
$$

where $F($.$) is either the uniform, beta or Weibull distribution function;$ $\mathrm{WS}_{\mathrm{Ui}}, \mathrm{WS}_{\mathrm{Li}}$ are the upper and lower bounds of the $\mathrm{i}^{\text {th }}$ wind speed interval and $n_{i}$ is the number of occurrences of wind speeds in the $i^{\text {th }}$ interval.

4. Select the distribution which has the highest maximum likelihood (see Section 9.0)

5. Save the continuous wind speed distribution to be used to compute the probability that the wind speed exceeds a specified value given a local intensity

6. Based on the selected wind speed distribution, compute the probability for each wind speed interval and transform this to an estimated 'recorded' F-scale intensity distribution, $\mathrm{P}_{\mathrm{R}}(\mathrm{Fi}), \mathrm{i}=1, \ldots, 5$.

7. The weight associated with the estimated intensity distribution is the product of the weights associated with each pair of SEA and Relation (9 intensity distributions)

8. Multiply each of the 9 intensity distributions by each of the Matrix to estimate the 'true' intensity distribution $\mathrm{P}_{\mathrm{T}}(\mathrm{Fi}), \mathrm{i}=1, \ldots, 6$.

9. Calculate the weight for each 'true' intensity distribution based on the weights associated with the inputs used in the calculation.

\section{Output:}

Estimates of the 'true' F-scale intensity distribution for use in the tornado wind hazard calculations. Assuming the inputs described above, there would be 45 estimates of the F-scale intensity distribution, with weights, to use for the uncertainty analysis associated with estimating the tornado wind hazard at a site.

\subsection{F-scale to Wind Speed Relations}

Three F-scale intensity to wind speed relations were selected to represent the uncertainty in associating wind speeds to F-scale intensities. The three relations are the Fujita relation (Fujita, 1978), and two relations developed by Twisdale (Twisdale, 1978), referred to as the TWL (linear) and TWU (uniform) relations. They are summarized in Table 6.3. 
Table 6.3: F-scale intensity to Wind Speed Relations

\begin{tabular}{|c|c|c|c|}
\hline $\begin{array}{c}\text { F-scale } \\
\text { Intensity }\end{array}$ & $\begin{array}{c}\text { Fujita Wind } \\
\text { Speed Intervals }\end{array}$ & $\begin{array}{c}\text { TWU Wind } \\
\text { Speed Intervals }\end{array}$ & $\begin{array}{c}\text { TWL Wind } \\
\text { Speed Intervals }\end{array}$ \\
\hline F0 & $40-73$ & $40-65$ & $40-73$ \\
\hline F1 & $73-113$ & $65-96$ & $73-103$ \\
\hline F2 & $113-157$ & $96-114$ & $103-135$ \\
\hline F3 & $157-206$ & $114-139$ & $135-168$ \\
\hline F4 & $206-260$ & $139-181$ & $168-209$ \\
\hline F5 & $260-319$ & $181-236$ & $209-277$ \\
\hline F6 & $319-380$ & $236-289$ & $277-295$ \\
\hline
\end{tabular}

Two other relations were also considered but not used in the current version of TORNADO. One, a relation developed by Dames \& Moore was not used because of the complexity of overlapping wind speed intervals in developing the site-specific intensity distributions. The second relation, developed by Dr. G. Terence Meaden in 1972 for the UK and Europe, is based on the TORRO scale, which is a 10-point scale. Since the historical data have not been classified using the TORRO scale, it is not convenient to use this scale. To do so would have required reclassification of the historical data using the TORRO scale or developing a relation between the F-scale and the TORRO scale. In any case, the experts did not give any weight to this relation. The weights associated with the three relations used in TORNADO are summarized in Table 6.4.

Table 6.4: Weights Associated with F-scale Intensity to Wind Speed Relations

\begin{tabular}{|l|l|}
\hline Relation & Weight \\
\hline Fujita & 0.6 \\
\hline Twisdale-Uniform & 0.078 \\
\hline Twisdale-Linear & 0.322 \\
\hline
\end{tabular}




\subsection{Tornado Classification Error (Misclassification Matrices)}

Several models for developing misclassification matrices to quantify the potential errors due to random encounters of tornadoes and structures, etc. and due to direct (human) classification errors were found in the literature. Three models for random encounter errors were combined with two models for direct classification errors to create five misclassification matrices. The sources of the models selected were:

A. Random Encounter

1. A1: Twisdale Additive (Twisdale, 1978)

2. B1: Twisdale Multiplicative (Twisdale, 1981)

3. C1: Reinhold \& Ellingwood Multiplicative (Reinhold \& Ellingwood, 1982)

B. Direct Classification

1. A2: Twisdale (Twisdale, 1978)

2. B2: Twisdale Multiplicative (Twisdale, 1981)

The combinations of models used to develop the misclassification matrices and the weights associated with the matrices are summarized in Table 6.5. The misclassification matrices are included in the default input files in Appendix IV.

Table 6.5: Weights Associated with Misclassification Matrices

\begin{tabular}{|l|l|}
\hline Misclassification Matrix & Weight \\
\hline $\mathrm{A} 1, \mathrm{~A} 2: \alpha=0.9$ & 0.46 \\
\hline $\mathrm{B} 1, \mathrm{~A} 2$ & 0.08 \\
\hline $\mathrm{B} 1, \mathrm{~B} 2$ & 0.08 \\
\hline $\mathrm{C} 1, \mathrm{~A} 2$ & 0.24 \\
\hline $\mathrm{C} 1, \mathrm{~B} 2$ & 0.14 \\
\hline
\end{tabular}

\subsection{Tornado Path Heading Distribution}

During the Workshops with the Expert Panel, there was some disagreement on whether the distribution of tornado path headings could be considered to be the same for all locations in the contiguous U.S. or to be regionally dependent. To accommodate this uncertainty, heading distributions were developed for both assumptions. The historical tornado headings were used to estimate the distribution of the tornado heading. To reflect the uncertainty in using the historical data to estimate the distribution, three time periods of data were considered in the estimation. The periods considered were:

1. $1953-95$

2. $1973-95$

3. $1980-95$ 
One period was chosen to represent the 'entire' database, e.g., 1953-95, since the database was first developed in the early 1950's. In the early 1970's Fujita developed the F-scale for intensity classification. Thus, a second period, starting at 1973, was selected to represent the time between assigning F-scale values retrospectively from historical data versus prospectively at the time of the tornado occurrence. The period starting in 1980 was chosen to represent the more current period in which many technological advances have been applied to the collection of the data.

For each of the time periods, the headings recorded in the SPC Tornado database were used to assess the empirical distribution functions as estimates of the tornado path heading distributions.

Accounting for both sources of uncertainty resulted in three sets of distributions, corresponding to the three time periods listed above, being estimated. Three heading distributions are in each set:

1. Contiguous U.S. distribution, assuming the distribution is the same for all of the contiguous U.S.

2. East distribution, assuming the distribution is regionally dependent; applicable if the site is in the East, defined to be a line 150 miles east of and paralleling the Rocky Mountains.

3. West distribution, assuming the distribution is regionally dependent; applicable if the site is in the West

The uncertainty sampling involves two steps, choosing a time period, i.e., one of the 3 sets of distributions, and then choosing whether the distribution is regionally dependent or not. If not, the appropriate contiguous U.S. distribution is selected. If yes, the appropriate East or West distribution is selected, depending on the location of the site.

In the elicitation of the Expert Panel members, a question related to the regional dependence of the heading distribution and a question related to the appropriateness of the three time periods of data for estimating the distributions were asked. The responses received indicated a weight of 0.6 for a contiguous U.S. distribution and weight 0.4 for a regionally based distribution. For the heading distribution, the weights for the three time periods were 0.39 for $1953-95,0.445$ for $1973-95$ and 0.165 for $1980-95$. Combining these weights and following the sampling procedure outlined above is equivalent to associating the weights listed in Table 6.6 to the respective distributions. 
Table 6.6: Weights Associated with Heading Distributions

\begin{tabular}{|l|l|l|}
\hline Time Period & CONUS & $\begin{array}{l}\text { East- } \\
\text { West }\end{array}$ \\
\hline $1953-95$ & 0.234 & 0.156 \\
\hline $1973-95$ & 0.268 & 0.178 \\
\hline $1980-95$ & 0.098 & 0.066 \\
\hline
\end{tabular}

\subsection{Damage Area Length and Width Distribution}

The tornado damage area is modeled as a rectangular area (Twisdale, 1978). The dimensions of the rectangle are given by the length $(\mathrm{L})$ and width $(\mathrm{W})$ of the tornado as defined in the SPC tornado database. As discussed in Section 5, these dimensions are considered correlated stochastic variables and the joint distribution of $\mathrm{L}$ and $\mathrm{W}$ is a function of the tornado F-scale intensity classification level. The joint distributions of $\mathrm{L}$ and $\mathrm{W}$ are estimated by empirical distributions based on the recorded lengths and widths of the historical tornadoes in the SPC database. Lengths and widths are not recorded for all tornadoes in the SPC database. Since the number of historical F4 and F5 tornadoes is somewhat limited, the sample of lengths and widths was supplemented by using the recorded Pearson lengths and widths as surrogate values when there are no reported lengths and/or widths. The supplemented data represented less than $2 \%$ of the records used to estimate the distributions. The surrogate values were computed by sampling a value for the length (width) at random from the length (width) interval corresponding to the appropriate Pearson classification. Other modelers (Thom, 1963; Twisdale, 1978) have attempted to estimate the joint distributions by continuous distributions. However, for simplicity and concern that the available data would not support the estimation of parametric continuous joint distributions, particularly for F4 and F5 intensities, the joint distributions were modeled by discrete empirical distributions. Bins for the length and width values were based on the intervals associated with the Pearson length and width scales.

To accommodate the uncertainties associated with using the historical data, three time periods of the data were used to estimate alternative distributions. The time periods and the weights associated with them are given in Table 6.7. 


\section{Table 6.7: Weights Associated with Time Periods Used to Estimate Distributions of Damage Area Length and Width}

\begin{tabular}{|l|l|}
\hline Time Period & Weight \\
\hline $1960-95$ & 0.31 \\
\hline $1973-95$ & 0.37 \\
\hline $1980-95$ & 0.32 \\
\hline
\end{tabular}

\subsection{Wind Speed Distribution within the Damage Area}

The distribution of wind speeds in the damage area is modeled by included rectangles representing sub-areas of winds of increasing intensities. As illustrated in Figure 5.1, the distribution of wind speeds in the damage area of a F2 intensity tornado is represented by 2 sub-areas, i.e., areas of 'local intensity', of the damage area. The inner most sub-area corresponds to the area of F2 intensity winds. The larger sub-area corresponds to the area in which the wind speeds are at least intensity F1. Of course, the largest rectangle, the damage area itself, is the area in which the winds are at least intensity F0. The dimensions of the included areas of 'local intensity' are modeled as fractions of the dimensions of the damage area. The fractions are a function of the F-scale intensity of the tornado. Thus, the distribution of wind speeds within the tornado wind field is modeled by the sub-areas of 'local intensity'. The size of each sub-area is represented by a pair of matrices. One matrix contains the fractions for the length and the second matrix contains the fractions for the width. The rows of each matrix index the tornado F-scale intensity and the columns index the local F-scale intensity.

Several methods for estimating appropriate fractions for both the lengths and the widths were derived from the tornado wind hazard literature. The matrices developed, based on these methods, were combined to derive several alternative pairs of matrices to represent the uncertainties associated with modeling the distribution of wind speeds in the tornado damage area. The sources of the respective methods are:

A. Length

1. L1: (Fujita, 1978)

2. L2: (McDonald, 1980) + (Reinhold \& Ellingwood, 1982 ), for F6

3. L3: (Reinhold \& Ellingwood, 1982)

B. Width

1. W2: (Fujita \& Abbey, 1978)

2. W4: (McDonald, 1983)

3. W6: (Reinhold \& Ellingwood, 1982)

Several other methods were initially considered and included in the elicitation but ultimately were not included in the current version of TORNADO. These were 
considered to be very similar to one of the matrices included or received relatively low weights in the elicitation. In addition, the issue of the ability of the code to efficiently handle such a large number of alternatives needed to be considered.

A listing of the combinations of these matrices and the weights associated with each pair is given in Table 6.8. The values of the fractions are included in the listing of the default model parameters and distributions in Appendix IV. 
Table 6.8: Weights Associated with Pairs of Matrices Representing the Distribution of Wind Speeds in the Damage Area

\begin{tabular}{|l|l|}
\hline Distribution & Weight \\
\hline L1, W2 & 0.236 \\
\hline L1, W4 & 0.016 \\
\hline L1, W6 & 0.066 \\
\hline L2, W2 & 0.188 \\
\hline L2, W4 & 0.22 \\
\hline L2, W6 & 0.108 \\
\hline L3, W2 & 0.08 \\
\hline L3, W4 & 0.03 \\
\hline L3, W6 & 0.056 \\
\hline
\end{tabular}




\subsection{Uncertainty Analysis}

Another feature of the methodology presented here is the recognition of the epistemic uncertainties associated with estimating the tornado wind speed hazard at any site in the contiguous U.S. As has been described in the preceding Section, weights, representing the perceived potential credibility of estimated values and/or distributions based on the historical data, have been elicited. Similar weights have been associated with inputs derived from the tornado wind hazard literature. These weights represent the uncertainty in the current state of knowledge about the values of the model parameters and distributions. They are the basis for quantifying the uncertainty in estimating the tornado wind hazard.

To quantify the uncertainty in estimating the tornado wind hazard, the analysis in TORNADO involves a 2-loop process. The inner loop is the analysis associated with estimating the tornado wind hazard at selected velocities spanning the range of velocities of interest. Each run of the inner loop is based on a fixed set of model parameters (values, matrices or probability distributions) selected based on their respective weights. The output of a single run of the inner loop is a hazard value for each of the selected velocities in the range of interest. The outer loop involves resampling values of the model parameters and distributions based on the uncertainty weights. Replicating the inner loop hazard estimation for a sample of values of the model parameters and distributions results in a distribution of hazard values at the selected velocities. The variation in the sampled hazards at each velocity represents the uncertainty in estimating the hazard at the given velocity. The empirical distributions of the sampled hazards are used to evaluate selected uncertainty percentiles and the arithmetic mean of the hazard. The envelope uncertainty curve, for a fixed percentile (e.g., $95^{\text {th }}$ percentile), is the curve connecting the $95^{\text {th }}$ percentiles at the selected velocities. The outputs of the analysis, i.e., the estimated hazard curves for a site, are envelope curves of the mean and the selected percentiles. 


\subsection{Elicitation of Expert Judgement}

An important element of the probabilistic methodology developed for this project are estimates of the frequency of tornadoes occurring and the probabilistic descriptions of the tornado characterization, given that it occurs. The methodology is based on using information from the historical events to develop estimates of the frequency and probability distributions of the tornado characteristics. The primary source of this information is the SPC database, which includes data on storms from 1950. The data used to develop the tornado information for this study is based on storms through 1995 . When considering using the historical data as a basis for estimating future wind hazards, a question that must be considered is 'does the historical events represent a credible sample of future events'? In terms of meteorological time, one might accept that the 'immediate' future would not be any different from the past 35 years. Thus, meteorologically, the events of the past $35+$ years could represent a credible sample. Another question is "what is the credibility of the data accumulated over time'? This is an issue because things, which affect the data, have changed over time. For example, the increased density of the population, the apparent interest in catastrophic events and, perhaps most significant, improved communications have resulted in increased reporting of tornadoes. Events that went unreported years ago are now recorded. Also, the technology for deriving estimates of the wind velocities within a storm, as well as the dimensions of the damage area, all have improved over time. For example, data that depended on the judgements of knowledgeable individuals years ago are now recorded electronically. Given these issues, it is appropriate to consider the question of what historical data should be used to characterize future tornadoes.

The methodology is based on using the historical data to characterize tornadoes and to quantify the uncertainties associated with using the historical data. To do this, a credible way of dealing with the question of what historical data to use to characterize tornadoes is to rely on the judgements of the tornado scientific community. The variation in the judgements within the community would be the basis of the uncertainty associated with using the historical data. Assessment of the uncertainty within the technical community about the use of the historical data was based on an elicitation of the Expert Panel. The members of the Panel, as members of the technical community, were asked to provide their judgements about the use of the historical data. In addition, historical data does not exist for all tornado characteristics, e.g., variability of wind speeds within the tornado and the appropriate representation of the errors associated with classifying storms using the Fscale intensity classification. Thus, the panel members were tasked to assess these models as well. Their judgements were elicited to describe the uncertainties associated with these characteristics as well.

The panel members were provided with several alternatives for each of the tornado characteristics and asked to provide relative weights to each alternative. The weights were to reflect their assessment of the credibility of each alternative as a basis for developing the description of the stochastic variation of each tornado characteristic. For 
characteristics available in the historical database, the alternatives were presented to the panelists in terms of several time periods of historical data, e.g., 1953-95 versus 1973-95, etc. To judge alternative empirical models, several models were provided to the panelists for their assessment. This format for eliciting the judgements of the panelists was used for all characteristics except the parameter, the expected frequency, per year, of tornadoes occurring within the cotiguous U.S. The panelists were asked to provide their uncertainty regarding the value of the expected frequency in terms of an empirical uncertainty (probability) distribution.

Elicitation of the uncertainties associated with using historical data and empirical models to model the expected frequency of tornado occurrence and the stochastic variability in the tornado characteristics was done by way of a Questionnaire. A copy of the Questionnaire is included as Appendix I. The most ideal elicitation method for deriving uncertainty information of the type required for this project would involve individual interviews with each panelist as well as a feedback meeting involving all of the participants. Interviews provide an excellent forum to assure that the respondents clearly understand the questions being asked. Such a process was not feasible for this project. In recognition of the limitations associated with using questionnaires for deriving uncertainty information, an effort was made at the second Workshop to highlight the issues to be elicited and to describe the kind of information that the panelist would be requested to provide in the Questionnaire. In addition, after the experts submitted their judgements, individual respondents were queried by telephone to confirm and/or discuss specific responses. In this way, an attempt was made to confirm that the panelists fully understood the questions being asked. This was all part of the process to assure the credibility of the results.

The inputs from the Panel were compiled by the LLNL/DOE team and used to develop the final uncertainty models. The LLNL team considers the members of the Expert Panel to be a reasonable representative sample of the technical community. As such, integration of the judgements of the individual experts provides an estimate of the present state of knowledge about the model parameters within the technical community.

The responses received from the Questionnaire are summarized in Appendix II and have been described in Section 6. Application of the responses to develop an input file of tornado frequency and characteristic stochastic variations has also been discussed in Section 6. 


\subsection{Tornado Wind Hazard Program, TORNADO}

The tornado wind hazard program, TORNADO, is designed to estimate the tornado wind hazard at any site in the contiguous U.S. The hazard is described by a tornado wind hazard curve, which quantifies the expected frequency, per year, that the wind speed at the site exceeds a specified velocity, as a function of the velocity. Calculation of the hazard for a given velocity involves the product of the expected frequency of a tornado touching down and the probability, given a touchdown, that the wind speed at the site exceeds the given velocity. The occurrence and magnitude of wind speeds at a site are functions of a number of stochastic variables. These variables include the occurrence and locations of touchdowns in the area surrounding the site, the tornado intensity, the path direction, dimensions of the tornado damage area and the distribution of wind speeds in the tornado. Estimation of the hazard involves calculating an estimate of the expected value of the probability of the wind speed exceeding a specified velocity with respect to the distributions of the stochastic variables. This is a numerical integration calculation. The calculation is done by averaging the probability of exceeding a specific velocity, conditional on values of the tornado stochastic variables, over a Latin Hypercube sample of 125 sets of values of the stochastic variables. The conditional probability of exceedance itself is an integral of the conditional probability of exceedance, given a touchdown location, averaged, with respect to the conditional distribution of touchdown locations, over the effective damage area. This area is a function of the stochastic variables (heading, (L, W), local intensity factors, tornado intensity). The latter integration is a function of the integration grid size, which is a user input (Appendix III). Knowledge of the distributions of the stochastic variables is subject to uncertainty. This is recognized by performing an uncertainty analysis based on alternative estimates of the distributions of the stochastic variables. The output of the program is a set of envelope hazard curves, which reflect the uncertainties. The output of the program can be used to derive point or interval estimates of either the hazard at a specific velocity or the wind speed corresponding to a specific expected frequency or its reciprocal, return period.

The program requires the user to provide the location and description of the site of interest included in the 'site file'. In addition, the program requires two files, a parameter file and a file of touchdown locations and intensities. The parameter file contains alternative estimates of the model parameter values and/or distributions of the stochastic variables. A default parameter file exists. It contains the parameter values and distributions developed for this study. The default file will be used for the calculations unless the user provides an alternative file. It is also possible for the user to edit the default file for a specific set of runs. Similarly, the default touchdown location file consists of the touchdown locations and intensities of the historical tornadoes as recorded in the SPC Tornado database.

Given the description of the location, dimensions and orientation of the site in the site file, the parameter file and the tornado location file, the first step in the hazard estimation process is the development of the site-specific intensity distribution. Based on the tornado 
intensities of tornadoes touching down in the Site Effect Area (SEA) and the misclassification matrix and F-scale to wind speed relation used, a histogram of wind speeds is developed. This interval type data is used to determine Maximum Likelihood Estimates (MLE) of a wind speed distribution based on the uniform, beta and Weibull distributions. The distribution selected is the one with the largest maximum likelihood value. Maximum Likelihood Estimation (MLE) is a classical statistical estimation method (Lehmann, 1983). It involves determining the values of the parameters of a probability distribution, which maximize the likelihood function, which is the natural logarithm of the probability of the observed data. A uniform, beta or Weibull distribution is assumed to adequately model the distribution of wind speed. MLE is used to estimate the parameters of each of these distributions and the selection of which distribution is 'best' is based on which distribution has the highest value of the maximum likelihood function. The F-scale to wind speed relation is used in reverse to estimate the true intensity distribution. Using all combinations of SEA, misclassification matrix and Fscale to wind speed relation, a collection of intensity distributions, with uncertainty weights, is transferred to the main part of the program for the hazard calculation.

The first step in the hazard calculation is initializing the uncertainty analysis process. This involves selecting values of the model parameters and distributions. Given a set of model parameters and distributions, the program steps through a series of calculations before getting to the final calculation of hazard as given in Equation 5.11. The major parts of this process involve:

1. Development of the damage area and the included sub-areas of local intensities as a function of heading direction, damage area length and width, sub-area size and facility size and orientation.

2. Development of the kernel estimate of the touchdown location distribution within the site-specific tornado affect area

3. Integration of the touchdown location distribution to estimate the probability of the appropriate tornado 'origin areas'. Integration is based on a Monte Carlo sampling procedure.

Replication of the hazard calculation process for a set of wind speeds provides hazard values for one set of the model parameters and distributions. Resampling the uncertain model parameters and distributions produces a distribution of hazard values at each wind speed. The means, medians and appropriate fractiles at each wind speed form the basis for developing the envelope hazard curves, which are the primary outputs of the program.

A flow chart of the TORNADO program is given in Figure 9.1.

Discussion of the installation of the program, running the program and information on the required inputs are in the User Guide included in Appendix III. 


\section{Figure 9.1: TORNADO Flow Chart}

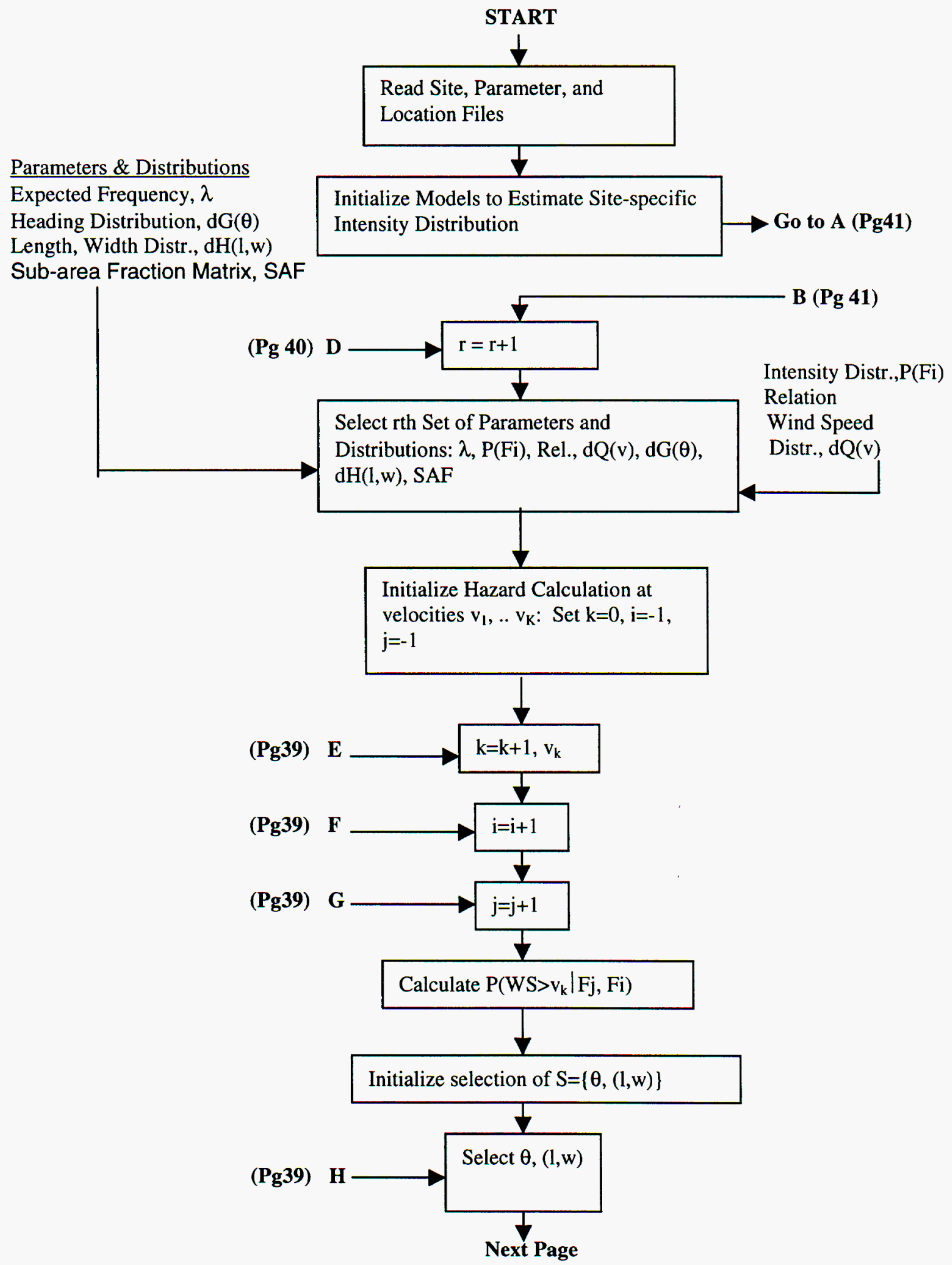




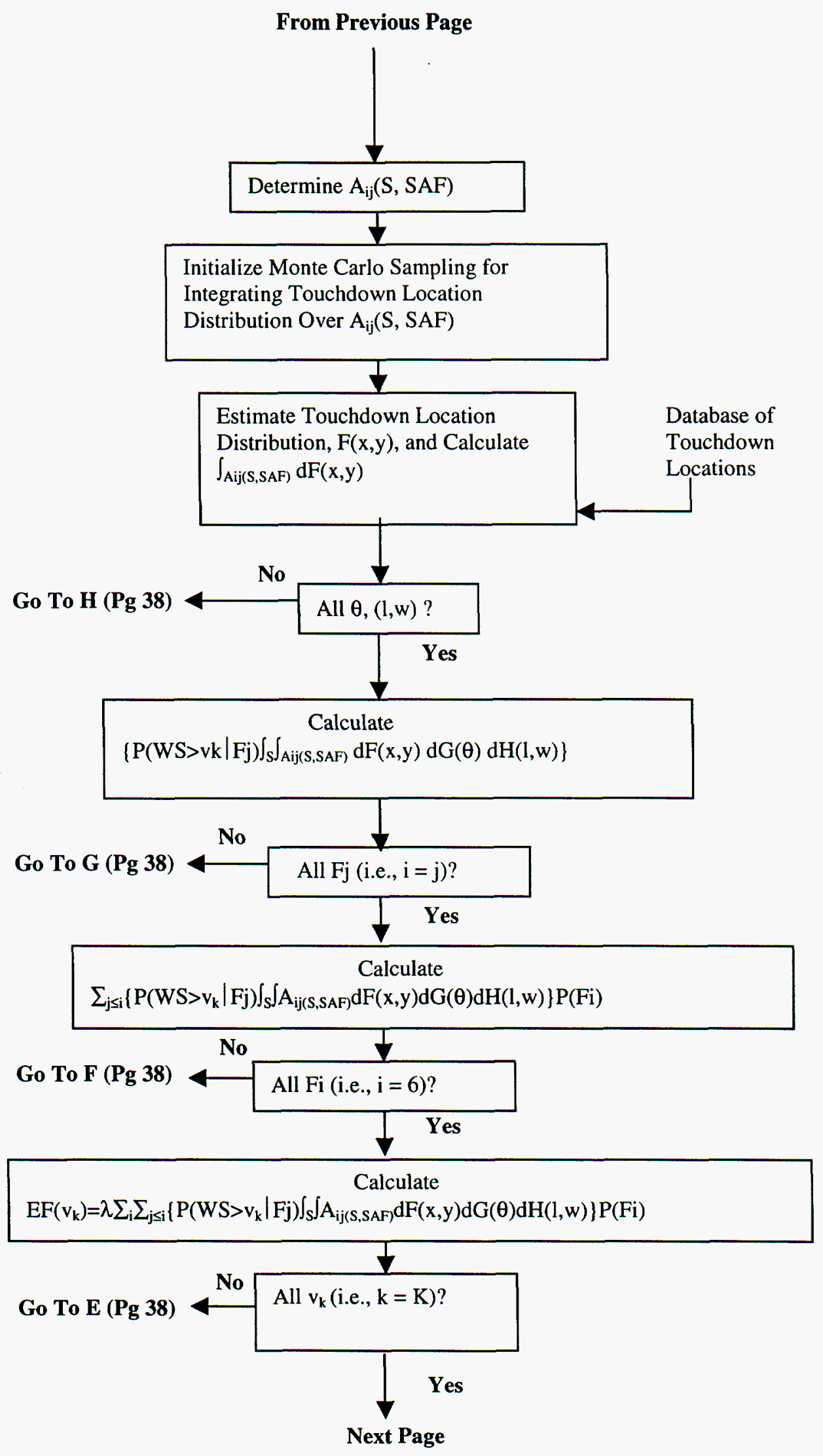




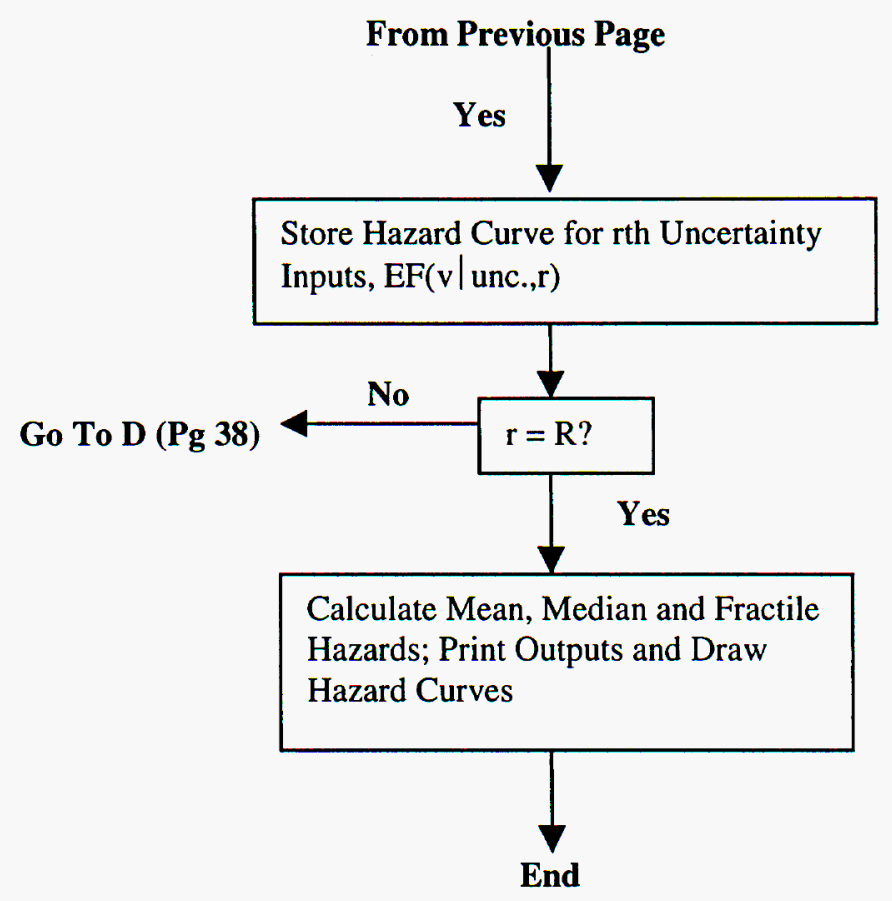









\subsection{Sensitivity Analyses}

An important part of the model and program code development process is the identification and analysis of significant modeling parameters. The following modeling parameters were initially identified and analyzed:

1. Size and orientation of the site

2. Model parameters, e.g., expected frequencies, distributions of tornado stochastic variables

3. Smoothing parameters, $\mathrm{h}_{1}, \mathrm{~h}_{2}$, of the kernel estimator of the tornado touchdown location distribution

The following sections are descriptions of sensitivity analyses performed and discussion of the analysis results.

\subsection{Size and Orientation of the Site}

As part of the application of the methodology and program code, several DOE sites were analyzed. The results of these analyses are summarized in Section 11. At the Savannah River Site (SRS), separate runs were done for two facilities, one a $300 \mathrm{ft}$ x $300 \mathrm{ft}$ structure and the second a $200 \mathrm{ft} \times 800 \mathrm{ft}$ structure. The results for these two facilities are shown in Figures 10-1 and 10-2. They are almost identical. Based on this and other similar prior analyses, it is concluded that, within the range of realistic values of facility dimensions and the model parameters, the results are insensitive to structure size and orientation. This result makes sense when one considers the size of the facility relative to the size of the SSTEA. The SSTEA is a circular area around the site with a 'radius' equal to the longest length of the tornado damage area, about 320 miles. The average damage area within the SSTEA is a rectangle with dimensions in miles. The size of a structure is very small relative to the tornado area. Thus, the probability the tornado intersects with the structure will be essentially the same for either of the 'small' structures.

There are, however, special situations where the orientation of the facility could be significant. For example, suppose a facility is a long, narrow structure such that one of the long sides faces the locations of most of the tornado touchdowns (perhaps due to the presence of a large water body or mountain range) and the dominant tornado path direction is toward the structure. In this case, the hazard is likely to be significantly higher then if the structure was oriented such that the narrow side faced the touchdown location area.

\subsection{Model Parameters}

The model parameters included one single-valued parameter, the expected frequency of tornadoes within the contiguous U.S., probability distributions of several tornado stochastic variables, the F-scale to wind speed relation and two deterministic matrix 
parameters. Several analyses, using an early version of TORNADO, were performed to study the sensitivity of the tornado wind hazard to these parameters. When discussing the results of these studies, it must be recognized that in the case of the tornado stochastic variables the results do not reflect the sensitivity of the hazard to the variable itself but to the distribution of the variable. For these cases, the spaces of the parameters are different probability distributions describing the stochastic variation of the respective variables. Since probability distributions are functions, there is a problem of 'ordering' the distributions and selecting 'extremes' to measure the sensitivity of the hazard to the range of distributions.

The sensitivity analysis was based on a series of runs in which each of the individual parameters was fixed at their 'extreme' values. All other parameters were considered uncertain with their respective weights. The Savannah River Site was used as the site of interest. The results of the analyses are shown in terms of three median hazard curves. One corresponds to the nominal case, in which all parameters were assigned a set of nominal weights to reflect uncertainty. The other two hazard curves correspond to assigning weight 1.0 to each of the 'extreme' values of the parameter being analyzed.

The sensitivity of the tornado wind hazard to the value of the expected frequency of tornadoes in the contiguous U.S. was based on using 'extreme' occurrence rates of 936.8 (based on the data in years 1973-95) and 1176 (based on the data in years 1990-95). In hindsight, judging from the elicitation, this range is too small. The uncertainty range from the elicitation is 500 to 1600 per year. Since the hazard is the product of the expected frequency and the probability that the wind speed exceeds a given velocity, given a tornado, it is a linear function the expected frequency. Since the ratio of the 'highest' and 'lowest' frequency is at most 3 , the hazard will change, at most, by a factor of 3 . The plot of the hazard curves for the original sensitivity runs are given in Figure 10-3. Given the small range of the expected frequency in those runs, there is little change in the hazard within the range.

The hazard curves based on the 'extremes' of the F-scale intensity distributions are shown in Figure 10-4. Since the study was done prior to including site-specific intensity distributions, the results are based on distributions derived from the historical data from the entire contiguous U.S. The distribution estimated from the recorded data was 'corrected' by applying a misclassification matrix, one of the fixed matrix parameters, to estimate the true intensity distribution. The misclassification matrix was based on selecting from a range of matrices. Again, the 'range' of distributions is insufficient to produce a significant change in the hazard. Leading up to using a site-specific intensity distribution in the model, a study of possibly using regionally based intensity distributions was done. The significance of regionalization is reflected in the hazard curves in Figures 10-5 and 10-6. These are hazard curves for the Idaho National Engineering and Environmental Laboratory (INEL). Figure 10-5 is based on using a contiguous U.S. based intensity distribution. Figure 10-6 is based on using an estimated intensity distribution (Twisdale, 1978) applicable to the NRC Region III, which includes INEL. The significant difference in the two sets of hazard curves reflects the significant differences in the two intensity distributions. In particular, the regional distribution has 
zero probability of an F5 tornado and a lower probability of an F4 tornado. The difference in the hazard is also reflected in the wind speed corresponding to a $10^{-7}$ per year hazard. The estimate based on the intensity distribution for the contiguous U.S. is $285 \mathrm{mph}$ and the regional based estimate is approximately $205 \mathrm{mph}$.

Figures 10-7 and 10-8 are the hazard curves resulting from varying the heading distribution and the damage area length-by-width distribution respectively. In both cases the differences in the hazard curves are not significant. Again, it should be recognized that these results do not imply that the hazard is not sensitive to a change in the variable, e.g., heading, itself. Certainly, depending on the size and orientation of the site, the heading of the tornado path could result in a significant change in the hazard. However, given that the path heading varies over a range of angles, changing the relative frequency of the different headings, at least in the range of realistic probability distributions, produces an insignificant change in the hazard.

The sensitivity of hazard to changes in the distribution of wind speeds in the tornado, i.e., the sub-areas of increasing 'local intensities' within the damage area, are shown in Figures 10-9 and 10-10. The change in hazard due to variations in the length of the subarea, in Figure 10-9, is insignificant. In Figure 10-10 there is some change in the hazard curves, especially at the high wind speeds. This sensitivity reflects the greater variability in the range of distributions of variation in the width of local intensity areas.

The hazard curves in Figure 10-11 reflect the changes in hazard due to using different Fscale to wind speed relations. The high hazard curve corresponds to using the Fujita relation and the low hazard curve is associated with the Twisdale 'uniform' relation. Considering the differences in the wind speed ranges associated with the high intensity levels, the differences in the hazard should be expected.

\subsection{Location Distribution Kernel Estimator Smoothing Parameters}

Estimation of the probability that a tornado touchdown occurs in a specified area is a significant element in the estimation of the tornado wind hazard. Such probabilities are based on an estimate of the probability distribution of touchdown locations throughout the contiguous U.S. The estimator of the touchdown location distribution is the normal kernel estimator given in Equation (5.7). The parameters of the estimator are the two smoothing parameters, $h_{1}$ and $h_{2}$. The estimator is based on locating a 2-dimensional normal density function at the location (latitude, longitude) of each historical touchdown. The density function spreads a unit of probability over the area around the historical location representing the probability, given the historical touchdown, that a future tornado will touchdown at each of the locations in the area. The estimate of the probability that a future touchdown occurs at a specified location is the normalized sum of the probabilities contributed by the historical tornadoes. The smoothing parameters determine how peaked the normal densities are at each historical location. Thus, the values of $h_{1}, h_{2}$ determine the modeled probability that future tornado touchdowns will be in the vicinity of historical touchdowns. In terms of the overall location distribution, the values of $h_{1}, h_{2}$ determine how flat and smooth or peaked and uneven the distribution is. 
Nominal values of $h_{1}, h_{2}$ are $\sigma_{x} n^{-1 / 6}$ and $\sigma_{y} n^{-1 / 6}$ ( $n$ is the number of historical tornado locations used to develop the estimate) respectively. Kernel density estimators are frequently used to estimate the distribution of some phenomenon (e.g., location of tornado touchdown) over a spatial area. The object of the estimator is to best describe the "true" distribution of the phenomenon. Experience in applying the kernel density estimator has indicated that using the nominal values of $h_{1}, h_{2}$ often results in a distribution, which is unrealistically uniform over space, i.e., the parameters tend to 'over smooth' the estimator.

To determine the 'best' values for $h_{1}, h_{2}$, a study of the sensitivity of the kernel estimator, as an estimator of the probability that a touchdown occurs in a specified area, to the values of $h_{1}, h_{2}$ was done. Several areas at various locations throughout the contiguous U.S., representing low, moderate and high frequency locations were analyzed. Also, the size of the area was varied between $1^{\circ} \times 1^{\circ}$ areas to $5^{\circ} \times 5^{\circ}$ areas. The results of the analyses are summarized in Table 10.1. In each area, the values of $h_{1}, h_{2}$ were a fraction or multiple of the nominal values. For each case, the estimate of the expected number of touchdowns, per year, in the area was the product of an estimate of the expected number of touchdowns in the CONUS and the probability the location is in the area based on the kernel estimator. This was compared to the average number of historical touchdowns, per year, in the area. Based on the study results, the 'best' values of $h_{1}, h_{2}$ are approximately $10 \%$ of the nominal values. These are the values incorporated in the TORNADO code. As used in the selection of the values of $h_{1}, h_{2}$, 'best' refers to the values of these parameters which minimize the difference between the estimated value (based on the kernel estimator) and the recorded value (based on the historical data) of the expected/average number of touchdowns, per year, within the area. Although the minimum difference did not occur at the same values, relative to the nominal values, for all locations and size of area, the 'best' values were always close to $10 \%$.

To further illustrate the dependence of the location distribution on the smoothing parameters, Figures 10-13,10-14, and 10-15 are contour plots of the location distribution throughout the contiguous U.S. using the smoothing parameter values shown. Figure 1012 shows the actual touchdown locations. From these plots one is able to see how the distribution becomes more localized as the values of the smoothing parameters are decreased. In these plots, the smoothing parameters $h_{1}, h_{2}$ are labeled $h_{x}, h_{y}$.

\subsection{Additional Sensitivity Analyses}

In response to review comments received subsequent to performing the parametric sensitivity studies described above, three additional sets of analysis runs were made using the latest version of the TORNADO code. In these runs, the sensitivity of the TORNADO results to the following parameters was evaluated:

1. Geographical Location of the Site

2. Site Effect Area (SEA) or the Grid Size for estimating the Site-Specific Intensity Distribution 


\section{F-Scale Intensity to Wind Speed Relation}

All analyses are based on runs using 100 simulations. The results of the analyses are summarized in the following subsections. All results are presented in terms of the mean hazard curves. Hazard curves and tabulated values provided in this section are based on the hazard model and TORNADO code version before these were modified on the basis of revised inputs from the Expert Panel members (see Sections 12 and 13 for details).

\subsubsection{Sensitivity to Geographical Location of the Site}

To evaluate the reasonableness of the TORNADO results and show how the tornado wind hazard varies throughout the U.S., tornado wind hazard curves were developed for seven sites in various regions of the contiguous United States. The locations of the sites are as follows:

- Boston, MA

- Washington, D.C.

- Detroit, MI

- Oklahoma City, OK

- Pierre, SD

- New Orleans, LA

- Salt Lake City, UT
@ $42.5 \mathrm{~N} 71 \mathrm{~W}$

@ 39N 77W

@ $42.5 \mathrm{~N} 83 \mathrm{~W}$

@ 35N 97.5W

@ 44N 100.5W

@ 30N 90W

@ 41N 112W

The size of the facility at each site was the same, 300 ' long and 300 ' wide. Tornado wind hazard curves for all of the sites were developed using the default input values and distributions of the TORNADO code (hereafter, runs using the default input values and distributions are designated as "nominal" runs). The resulting hazard curves are presented in Figure 10-16. The corresponding numerical values are given in Table 10.2. As anticipated, Oklahoma City has the highest hazard. New Orleans is also a location of high hazard. Although the level of hazard varies between locations, the general 'shapes' of the hazard curves are consistent with the results previously developed for some of the DOE sites and presented in Section 11. For example, the hazard at Pantex, Figure 11-1, is similar to that at Oklahoma City. Although it is higher, the trend of the hazard curve at Savannah River, Figure 11-2, is similar to that at Washington DC. Similarly, the Oak Ridge curve, Figure 11-4, is similar in shape to that at Detroit.

For the four locations in the central part of the US, Oklahoma City, New Orleans, Detroit and Pierre, the $10^{-7}$ wind speeds are almost identical, between 361 and $364 \mathrm{mph}$, a range of less than $1 \%$. At the higher frequencies, e.g., $10^{-3}$ per year, the wind speeds vary over a 
greater range, between 65 and $116 \mathrm{mph}$. This may reflect the overall higher frequency of tornadoes, hence, higher frequency of low intensity tornadoes, in the Oklahoma area.

Figure 10-17 presents the hazard curves for the seven generic sites and the six DOE sites. Hazard curves for the three DOE sites east of the Rockies are compared in Figure 10-18. Hazard curves for three DOE sites and two generic sites west of the Rockies are compared in Figure 10-19. Finally, in Figures 10-20 through 10-22, hazard curves for three DOE sites east of the Rockies are compared separately with those of three generic sites east of the Rockies. From these comparisons it can be concluded that the dependence of the tornado wind hazard on the geographical location of the site is appropriately and reasonably represented in the present hazard model.

Figure 10-23 shows the hazard curves for Oklahoma City, Detroit, and New Orleans at higher frequency ranges $\left(10^{-4}\right.$ to $\left.10^{-2}\right)$. Tornado wind speeds from this figure can be compared to the wind speeds in ASCE-7 for general facility design to determine if tornado hazard should also be considered for designing such facilities in the tornado alley.

\subsubsection{Sensitivity to F-Scale Intensity to Wind Speed Relation}

To test the sensitivity of the estimated wind hazard curve to the F-Scale Intensity to Wind Speed Relation, hazard curves for three of the relations presented in the expert panel elicitation were compared to the hazard curve based on the nominal inputs. All other inputs were set to the default values of the TORNADO code. Runs were made for four DOE sites: Pantex, Oakridge, SRS, and NTS. The four F-Scale Intensity to Wind Speed Relation inputs used were:

- Fujita with $100 \%$ weight

- Twisdale-Uniform with $100 \%$ weight

- Twisdale-Linear with $100 \%$ weight

- the default or the nominal value (i.e., $60 \%$ weight on Fujita, $7.8 \%$ on TwisdaleUniform, and $32.2 \%$ on Twisdale-Linear)

Hazard curves for these runs are presented in Figures 10-24 through 10-27. As was observed in Figure 10-11, the hazard curves in Figures 10-24 through 10-27 also show that the Fujita relation produces the highest wind speeds for a fixed expected frequency or return period. The differences in the relations occur in the higher wind speeds, as it should, since the upper bound wind speed for the Fujita relation is $380 \mathrm{mph}$ compared to 295 and 289 for the Twisdale Linear and Uniform relations respectively.

\subsubsection{Sensitivity to Site Effect Area Grid Size}

To test the sensitivity of the estimated tornado wind hazard to the size of the area (i.e., SEA grid size) used to estimate the site-specific intensity distribution, hazard curves for the three grid sizes presented in the expert panel elicitation were compared to the hazard curve based on the nominal inputs. All other inputs were set to the default values of the 
TORNADO code. Runs were made for four DOE sites: Pantex, Oak Ridge, SRS, and NTS. The four SEA grid size inputs used were:

- $2 \times 2$ with $100 \%$ weight

- $3 \times 3$ with $100 \%$ weight

- $5 \times 5$ with $100 \%$ weight

- the default or the nominal value (i.e., $20 \%$ weight on $2 \times 2,28 \%$ on $3 \times 3$, and $52 \%$ on $5 \times 5)$

The hazard curves for these runs, presented in Figures 10-28 through 10-31, show that, for the ranges of grid size tested, the difference in the estimated curves is insignificant (less than $2 \%$ for all four sites). Even if it is small, the greatest variability occurred at NTS. This is as it should be, since NTS is in the west, where there are only a limited number of historical events. Interestingly, NTS was the only site at which the $5 \times 5$ grid size resulted in the highest estimated hazard. At the 3 eastern sites, the $5 \times 5$ grid corresponded to the lowest estimate of hazard. In general, it might be concluded that any grid size in the $2 \times 2$ to $5 \times 5$ range is adequate for estimating the intensity distribution, at least for sites in the central and eastern US. In the west, where there are fewer historical events, the larger grid sizes may be preferred. The important conclusion is that the SEA area must be large enough to assure that there are enough historical events to adequately estimate the intensity distribution. 
Table 10.1

Sensitivity Analysis Results for Kernel Estimator Smoothing Parameter

\begin{tabular}{|r|c|c|c|c|}
\hline \multicolumn{5}{|c|}{ Tornado Frequency 1950-1995 } \\
1x1 Degree Bin, Latitude 40 Longitude -80 \\
\hline & \multicolumn{3}{|c|}{ Expected Number of Tornadoes per Year } \\
\cline { 2 - 5 } h1, h2 & $\begin{array}{c}\text { Relative } \\
\text { Frequency }\end{array}$ & $\begin{array}{c}\text { Density } \\
\text { Estimation }\end{array}$ & $\begin{array}{c}\text { Historical } \\
\text { Average }\end{array}$ & $\begin{array}{c}\text { Percent } \\
\text { Difference }\end{array}$ \\
\hline $1 \%$ & $1.418 \mathrm{E}-03$ & 1.09 & 1.02 & $6.5 \%$ \\
\hline $5 \%$ & $1.212 \mathrm{E}-03$ & 0.93 & 1.02 & $-9.3 \%$ \\
\hline $10 \%$ & $1.146 \mathrm{E}-03$ & 0.88 & 1.02 & $-15.7 \%$ \\
\hline $25 \%$ & $1.034 \mathrm{E}-03$ & 0.80 & 1.02 & $-28.2 \%$ \\
\hline $50 \%$ & $9.188 \mathrm{E}-04$ & 0.71 & 1.02 & $-44.3 \%$ \\
\hline $75 \%$ & $8.844 \mathrm{E}-04$ & 0.68 & 1.02 & $-49.9 \%$ \\
\hline Baseline & $8.991 \mathrm{E}-04$ & 0.69 & 1.02 & $-47.4 \%$ \\
\hline $150 \%$ & $9.464 \mathrm{E}-04$ & 0.73 & 1.02 & $-40.1 \%$ \\
\hline $175 \%$ & $9.615 \mathrm{E}-04$ & 0.74 & 1.02 & $-37.9 \%$ \\
\hline $200 \%$ & $9.692 \mathrm{E}-04$ & 0.75 & 1.02 & $-36.8 \%$ \\
\hline
\end{tabular}

Historical Number of Tornadoes 1950-1995:

Bin Total $=47$ Average per Year: CONUS $=769.5$

\begin{tabular}{|r|c|c|c|c|}
\hline \multicolumn{5}{|c|}{ Tornado Frequency 1950-1995 } \\
$5 \times 5$ Degree Bin, Latitude 34 Longitude -85 \\
\cline { 2 - 5 } & \multicolumn{3}{|c|}{ Expected Number of Tornadoes per Year } \\
\cline { 2 - 5 } h1, h2 & $\begin{array}{c}\text { Relative } \\
\text { Frequency }\end{array}$ & $\begin{array}{c}\text { Density } \\
\text { Estimation }\end{array}$ & $\begin{array}{c}\text { Historical } \\
\text { Average }\end{array}$ & $\begin{array}{c}\text { Percent } \\
\text { Difference }\end{array}$ \\
\hline $1 \%$ & $3.391 \mathrm{E}-02$ & 26.10 & 32.46 & $-24.4 \%$ \\
\hline $5 \%$ & $4.176 \mathrm{E}-02$ & 32.13 & 32.46 & $-1.0 \%$ \\
\hline $10 \%$ & $4.185 \mathrm{E}-02$ & 32.20 & 32.46 & $-0.8 \%$ \\
\hline $25 \%$ & $4.183 \mathrm{E}-02$ & 32.18 & 32.46 & $-0.9 \%$ \\
\hline $50 \%$ & $4.155 \mathrm{E}-02$ & 31.97 & 32.46 & $-1.5 \%$ \\
\hline $75 \%$ & $4.158 \mathrm{E}-02$ & 32.00 & 32.46 & $-1.4 \%$ \\
\hline Baseline & $4.162 \mathrm{E}-02$ & 32.03 & 32.46 & $-1.4 \%$ \\
\hline $150 \%$ & $4.107 \mathrm{E}-02$ & 31.60 & 32.46 & $-2.7 \%$ \\
\hline $175 \%$ & $4.058 \mathrm{E}-02$ & 31.22 & 32.46 & $-4.0 \%$ \\
\hline $200 \%$ & $4.003 \mathrm{E}-02$ & 30.81 & 32.46 & $-5.4 \%$ \\
\hline
\end{tabular}

Historical Number of Tornadoes 1950-1995:

Bin Total $=1493$ Average per Year: CONUS $=769.5$ 
Table 10.1 (Cont'd)

\begin{tabular}{|r|c|c|c|c|}
\hline \multicolumn{5}{|c|}{ Tornado Frequency 1950-1995 } \\
1x1 Degree Bin, Latitude 34 Longitude -100 \\
\hline & \multicolumn{2}{|c|}{ Expected Number of Tornadoes per Year } \\
\cline { 2 - 5 } h1, h2 & $\begin{array}{c}\text { Relative } \\
\text { Frequency }\end{array}$ & $\begin{array}{c}\text { Density } \\
\text { Estimation }\end{array}$ & $\begin{array}{c}\text { Historical } \\
\text { Average }\end{array}$ & $\begin{array}{c}\text { Percent } \\
\text { Difference }\end{array}$ \\
\hline $1 \%$ & $9.349 \mathrm{E}-04$ & 0.72 & 1.89 & $-162.7 \%$ \\
\hline $5 \%$ & $2.291 \mathrm{E}-03$ & 1.76 & 1.89 & $-7.2 \%$ \\
\hline $10 \%$ & $2.322 \mathrm{E}-03$ & 1.79 & 1.89 & $-5.8 \%$ \\
\hline $25 \%$ & $2.645 \mathrm{E}-03$ & 2.04 & 1.89 & $7.1 \%$ \\
\hline $50 \%$ & $3.220 \mathrm{E}-03$ & 2.48 & 1.89 & $23.7 \%$ \\
\hline $75 \%$ & $3.582 \mathrm{E}-03$ & 2.76 & 1.89 & $31.4 \%$ \\
\hline Baseline & $3.683 \mathrm{E}-03$ & 2.83 & 1.89 & $33.3 \%$ \\
\hline $150 \%$ & $3.412 \mathrm{E}-03$ & 2.63 & 1.89 & $28.0 \%$ \\
\hline $175 \%$ & $3.197 \mathrm{E}-03$ & 2.46 & 1.89 & $23.2 \%$ \\
\hline $200 \%$ & $2.987 \mathrm{E}-03$ & 2.30 & 1.89 & $17.8 \%$ \\
\hline
\end{tabular}

Historical Number of Tornadoes 1950-1995:

Bin Total $=87$ Average per Year: CONUS $=769.5$

\begin{tabular}{|r|c|c|c|c|}
\hline \multicolumn{5}{|c|}{ Tornado Frequency 1950-1995 } \\
1x1 Degree Bin, Latitude 43 Longitude -115 \\
\hline & \multicolumn{3}{|c|}{ Expected Number of Tornadoes per Year } \\
\cline { 2 - 5 } h1, h2 & $\begin{array}{c}\text { Relative } \\
\text { Frequency }\end{array}$ & $\begin{array}{c}\text { Density } \\
\text { Estimation }\end{array}$ & $\begin{array}{c}\text { Historical } \\
\text { Average }\end{array}$ & $\begin{array}{c}\text { Percent } \\
\text { Difference }\end{array}$ \\
\hline $1 \%$ & $4.209 \mathrm{E}-04$ & 0.32 & 0.33 & $-1.9 \%$ \\
\hline $5 \%$ & $4.263 \mathrm{E}-04$ & 0.33 & 0.33 & $-0.6 \%$ \\
\hline $10 \%$ & $4.160 \mathrm{E}-04$ & 0.32 & 0.33 & $-3.1 \%$ \\
\hline $25 \%$ & $3.381 \mathrm{E}-04$ & 0.26 & 0.33 & $-26.8 \%$ \\
\hline $50 \%$ & $2.402 \mathrm{E}-04$ & 0.18 & 0.33 & $-78.5 \%$ \\
\hline $75 \%$ & $1.885 \mathrm{E}-04$ & 0.15 & 0.33 & $-127.5 \%$ \\
\hline Baseline & $1.610 \mathrm{E}-04$ & 0.12 & 0.33 & $-166.4 \%$ \\
\hline $150 \%$ & $1.289 \mathrm{E}-04$ & 0.10 & 0.33 & $-232.7 \%$ \\
\hline $175 \%$ & $1.185 \mathrm{E}-04$ & 0.09 & 0.33 & $-261.8 \%$ \\
\hline $200 \%$ & $1.117 \mathrm{E}-04$ & 0.09 & 0.33 & $-283.8 \%$ \\
\hline
\end{tabular}

Historical Number of Tornadoes 1950-1995:

Bin Total $=15$ Average per Year: CONUS $=769.5$ 
Table 10.1 (Cont'd)

\begin{tabular}{|r|c|c|c|c|}
\hline \multicolumn{5}{|c|}{ Tornado Frequency 1950-1995 } \\
1x1 Degree Bin, Latitude 34 Longitude -85 \\
\hline & \multicolumn{2}{|c|}{ Expected Number of Tornadoes per Year } \\
\cline { 2 - 5 } h1, h2 & $\begin{array}{c}\text { Relative } \\
\text { Frequency }\end{array}$ & $\begin{array}{c}\text { Density } \\
\text { Estimation }\end{array}$ & $\begin{array}{c}\text { Historical } \\
\text { Average }\end{array}$ & $\begin{array}{c}\text { Percent } \\
\text { Difference }\end{array}$ \\
\hline $1 \%$ & $3.099 \mathrm{E}-03$ & 2.38 & 2.35 & $1.4 \%$ \\
\hline $5 \%$ & $2.857 \mathrm{E}-03$ & 2.20 & 2.35 & $-6.9 \%$ \\
\hline $10 \%$ & $2.801 \mathrm{E}-03$ & 2.16 & 2.35 & $-9.0 \%$ \\
\hline $25 \%$ & $2.549 \mathrm{E}-03$ & 1.96 & 2.35 & $-19.8 \%$ \\
\hline $50 \%$ & $2.290 \mathrm{E}-03$ & 1.76 & 2.35 & $-33.4 \%$ \\
\hline $75 \%$ & $2.099 \mathrm{E}-03$ & 1.62 & 2.35 & $-45.5 \%$ \\
\hline Baseline & $1.942 \mathrm{E}-03$ & 1.49 & 2.35 & $-57.3 \%$ \\
\hline $150 \%$ & $1.759 \mathrm{E}-03$ & 1.35 & 2.35 & $-73.6 \%$ \\
\hline $175 \%$ & $1.708 \mathrm{E}-03$ & 1.31 & 2.35 & $-78.8 \%$ \\
\hline $200 \%$ & $1.667 \mathrm{E}-03$ & 1.28 & 2.35 & $-83.2 \%$ \\
\hline
\end{tabular}

Historical Number of Tornadoes 1950-1995:

Bin Total $=108$ Average per Year: CONUS $=769.5$

\begin{tabular}{|r|c|c|c|c|}
\hline \multicolumn{5}{|c|}{ Tornado Frequency 1950-1995 } \\
2x2 Degree Bin, Latitude 34 Longitude -85 \\
\hline & \multicolumn{2}{|c|}{ Expected Number of Tornadoes per Year } \\
\cline { 2 - 5 } h1, h2 & $\begin{array}{c}\text { Relative } \\
\text { Frequency }\end{array}$ & $\begin{array}{c}\text { Density } \\
\text { Estimation }\end{array}$ & $\begin{array}{c}\text { Historical } \\
\text { Average }\end{array}$ & $\begin{array}{c}\text { Percent } \\
\text { Difference }\end{array}$ \\
\hline $1 \%$ & $7.382 \mathrm{E}-03$ & 5.68 & 6.35 & $-11.8 \%$ \\
\hline $5 \%$ & $8.161 \mathrm{E}-03$ & 6.28 & 6.35 & $-1.1 \%$ \\
\hline $10 \%$ & $8.232 \mathrm{E}-03$ & 6.33 & 6.35 & $-0.2 \%$ \\
\hline $25 \%$ & $8.361 \mathrm{E}-03$ & 6.43 & 6.35 & $1.3 \%$ \\
\hline $50 \%$ & $8.302 \mathrm{E}-03$ & 6.39 & 6.35 & $0.6 \%$ \\
\hline $75 \%$ & $7.916 \mathrm{E}-03$ & 6.09 & 6.35 & $-4.2 \%$ \\
\hline Baseline & $7.503 \mathrm{E}-03$ & 5.77 & 6.35 & $-10.0 \%$ \\
\hline $150 \%$ & $6.954 \mathrm{E}-03$ & 5.35 & 6.35 & $-18.7 \%$ \\
\hline $175 \%$ & $6.778 \mathrm{E}-03$ & 5.22 & 6.35 & $-21.8 \%$ \\
\hline $200 \%$ & $6.628 \mathrm{E}-03$ & 5.10 & 6.35 & $-24.5 \%$ \\
\hline
\end{tabular}

Historical Number of Tornadoes 1950-1995:

Bin Total $=292$ Average per Year: CONUS $=769.5$

\begin{tabular}{|r|c|c|c|c|}
\hline \multicolumn{5}{|c|}{ Tornado Frequency $1950-1995$} \\
$5 \times 5$ Degree Bin, Latitude 34 Longitude -85 \\
\hline & \multicolumn{3}{|c|}{ Expected Number of Tornadoes per Year } \\
\cline { 2 - 5 } h1, h2 & $\begin{array}{c}\text { Relative } \\
\text { Frequency }\end{array}$ & $\begin{array}{c}\text { Density } \\
\text { Estimation }\end{array}$ & $\begin{array}{c}\text { Historical } \\
\text { Average }\end{array}$ & $\begin{array}{c}\text { Percent } \\
\text { Difference }\end{array}$ \\
\hline $1 \%$ & $3.391 \mathrm{E}-02$ & 26.10 & 32.46 & $-24.4 \%$ \\
\hline $5 \%$ & $4.176 \mathrm{E}-02$ & 32.13 & 32.46 & $-1.0 \%$ \\
\hline $10 \%$ & $4.185 \mathrm{E}-02$ & 32.20 & 32.46 & $-0.8 \%$ \\
\hline $25 \%$ & $4.183 \mathrm{E}-02$ & 32.18 & 32.46 & $-0.9 \%$ \\
\hline $50 \%$ & $4.155 \mathrm{E}-02$ & 31.97 & 32.46 & $-1.5 \%$ \\
\hline $75 \%$ & $4.158 \mathrm{E}-02$ & 32.00 & 32.46 & $-1.4 \%$ \\
\hline Baseline & $4.162 \mathrm{E}-02$ & 32.03 & 32.46 & $-1.4 \%$ \\
\hline $150 \%$ & $4.107 \mathrm{E}-02$ & 31.60 & 32.46 & $-2.7 \%$ \\
\hline $175 \%$ & $4.058 \mathrm{E}-02$ & 31.22 & 32.46 & $-4.0 \%$ \\
\hline $200 \%$ & $4.003 \mathrm{E}-02$ & 30.81 & 32.46 & $-5.4 \%$ \\
\hline
\end{tabular}

Historical Number of Tornadoes 1950-1995:

Bin Total $=1493$ Average per Year: CONUS $=769.5$ 
Table 10.2

Wind Speeds (mph) for 7 Generic Sites at Various Exceedance Probabilities

\begin{tabular}{|c|c|c|c|c|c|}
\hline Location & Prob. $=10^{-3}$ & Prob. $=10^{-4}$ & Prob. $=10^{-5}$ & Prob. $=10^{-6}$ & Prob. $=10^{-7}$ \\
\hline Boston, MA & 84.65 & 164.69 & 240.51 & 303.52 & 356.65 \\
\hline $\begin{array}{c}\text { New Orleans, } \\
\text { LA }\end{array}$ & 109.55 & 188.48 & 255.98 & 319.16 & 364.07 \\
\hline Pierre, SD & 65.12 & 154.18 & 243.37 & 316.67 & 364.00 \\
\hline $\begin{array}{c}\text { Salt Lake City, } \\
\text { UT }\end{array}$ & 65.12 & 104.21 & 176.75 & 250.59 & 316.78 \\
\hline Detroit, MI & 99.41 & 176.14 & 246.49 & 313.11 & 361.02 \\
\hline $\begin{array}{c}\text { Oklahoma } \\
\text { City, OK }\end{array}$ & 116.09 & 191.97 & 260.65 & 325.78 & 364.00 \\
\hline $\begin{array}{l}\text { Washington } \\
\text { D.C. }\end{array}$ & 67.48 & 136.67 & 195.20 & 247.91 & 296.71 \\
\hline
\end{tabular}


Figure 10-1: Hazard Curves Showing the Effects of Facility Size (compare with Figure 10-2)

\section{SRS Wind Hazard}

$300^{\prime} \times 300^{\prime}$ Area at 33.25ON 81.63"W

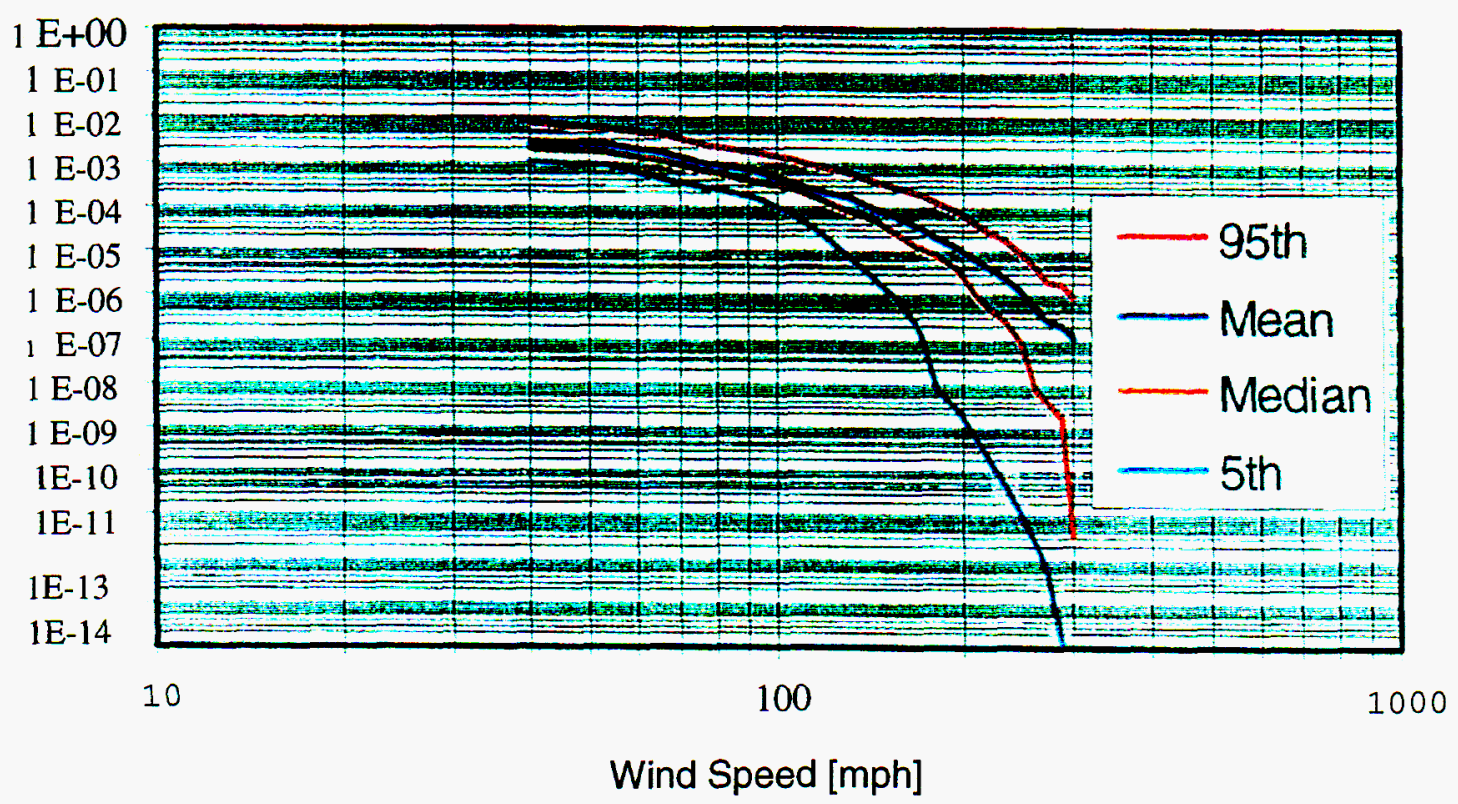


Figure 10-2: Hazard Curves Showing the Effects of Facility Orientation

SRS N36W \& S54W Wind Hazard

\section{$200^{\prime} \times 800^{\prime}$ Areas at $33.250 \mathrm{~N} 81.630 \mathrm{~W}$}

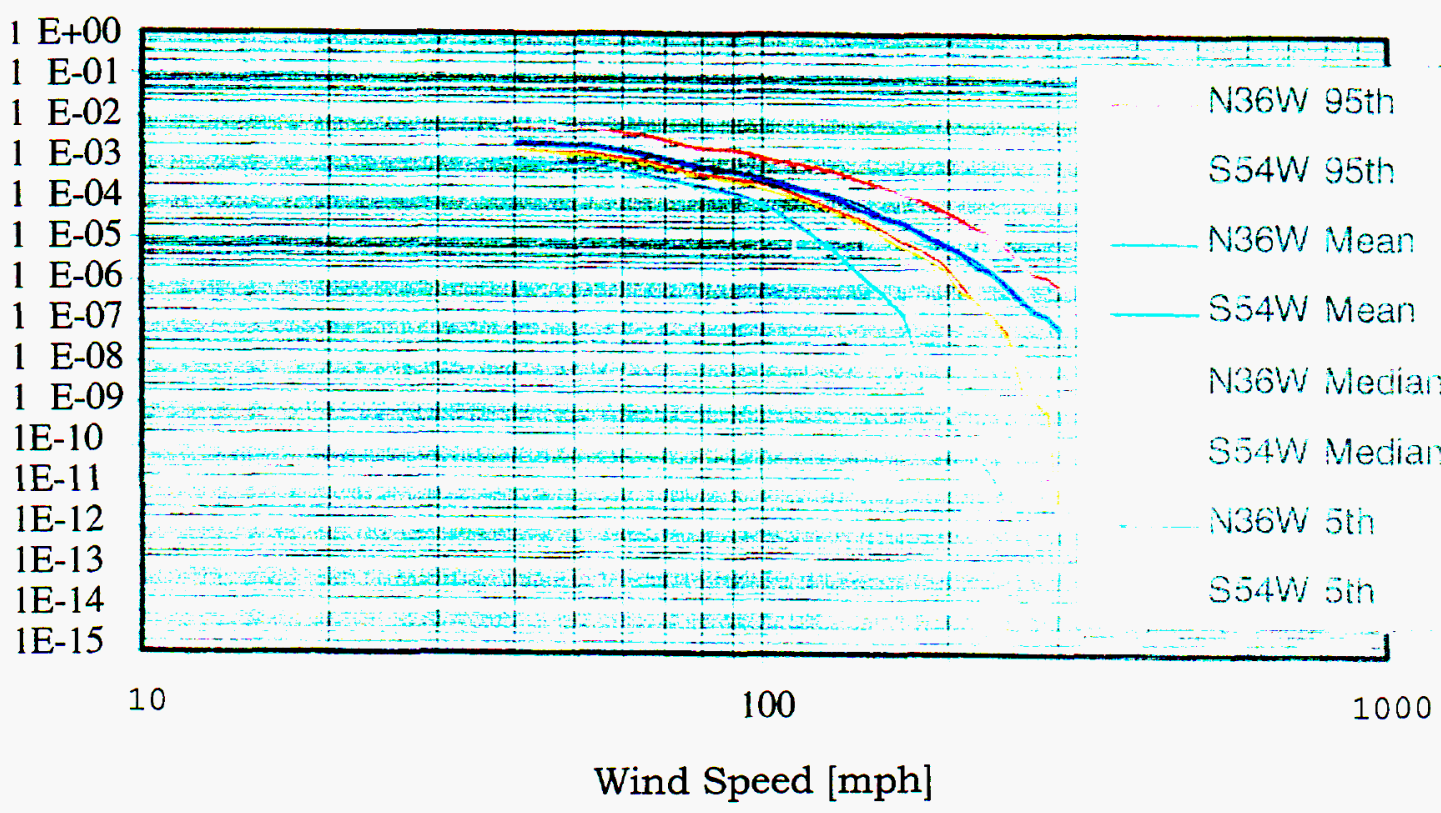




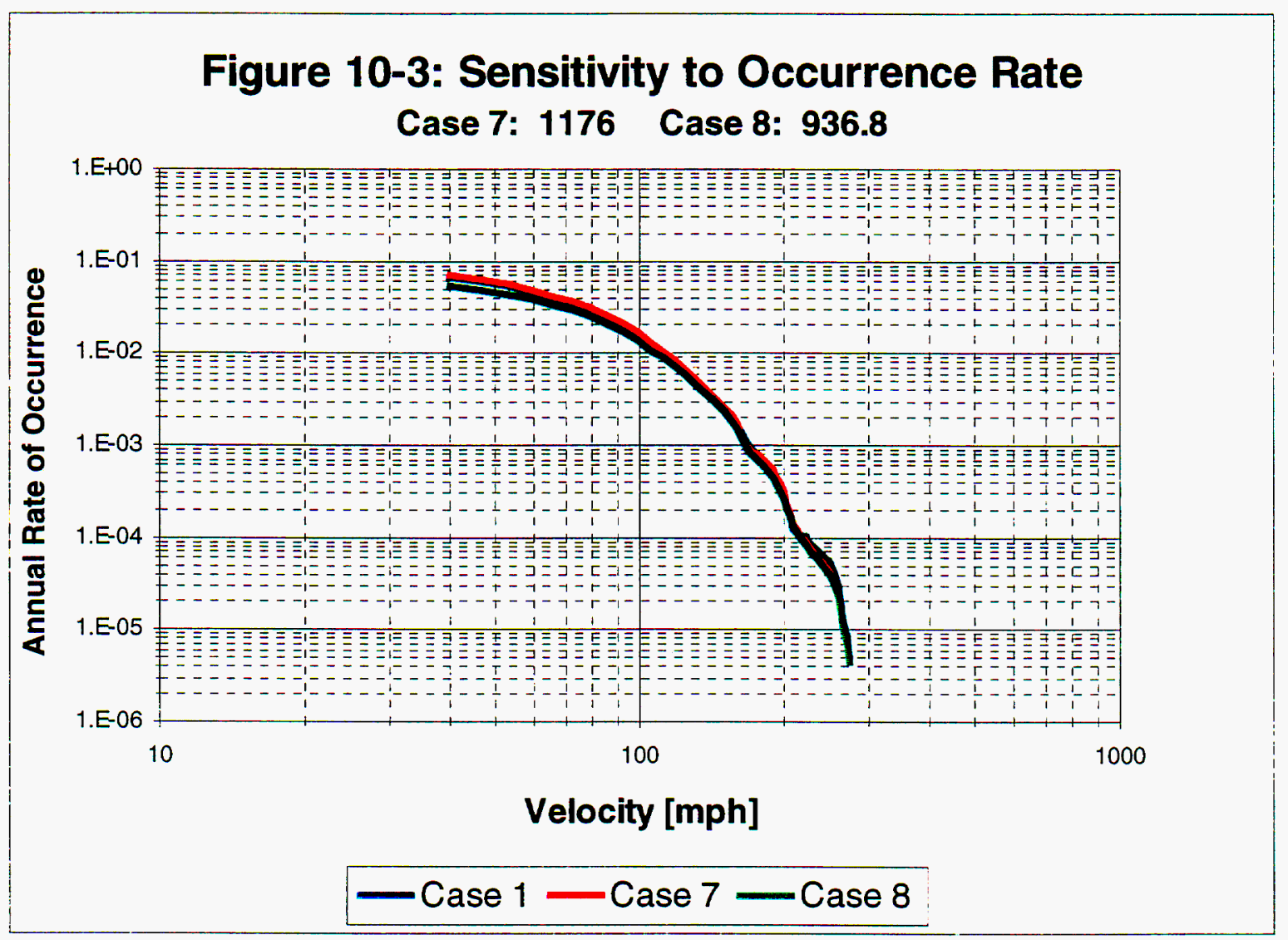







Figure 10-5: INEEL Using CONUS Intensity Distribution

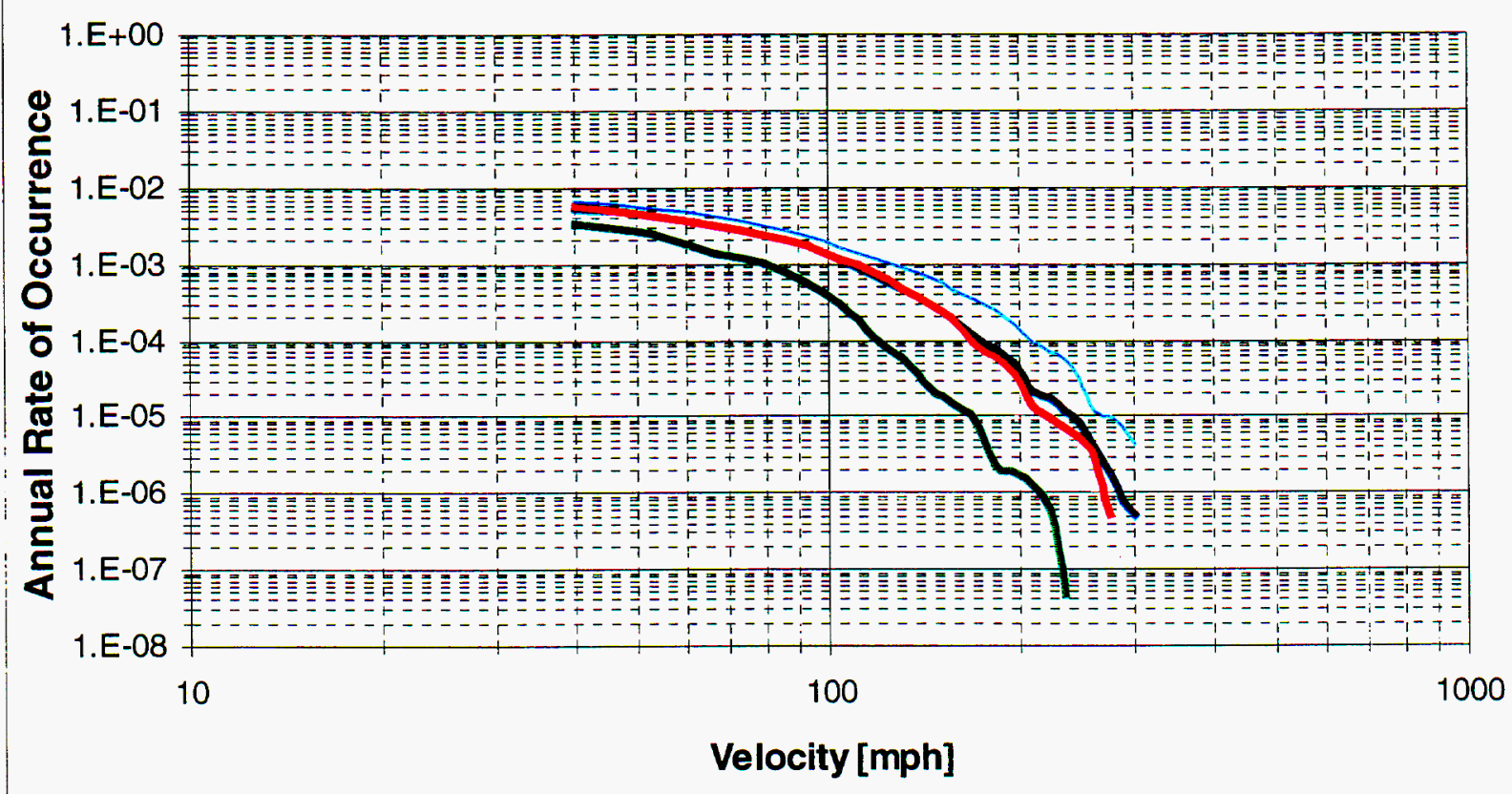

- Mean — Median — 5th Pct — 95th Pct 


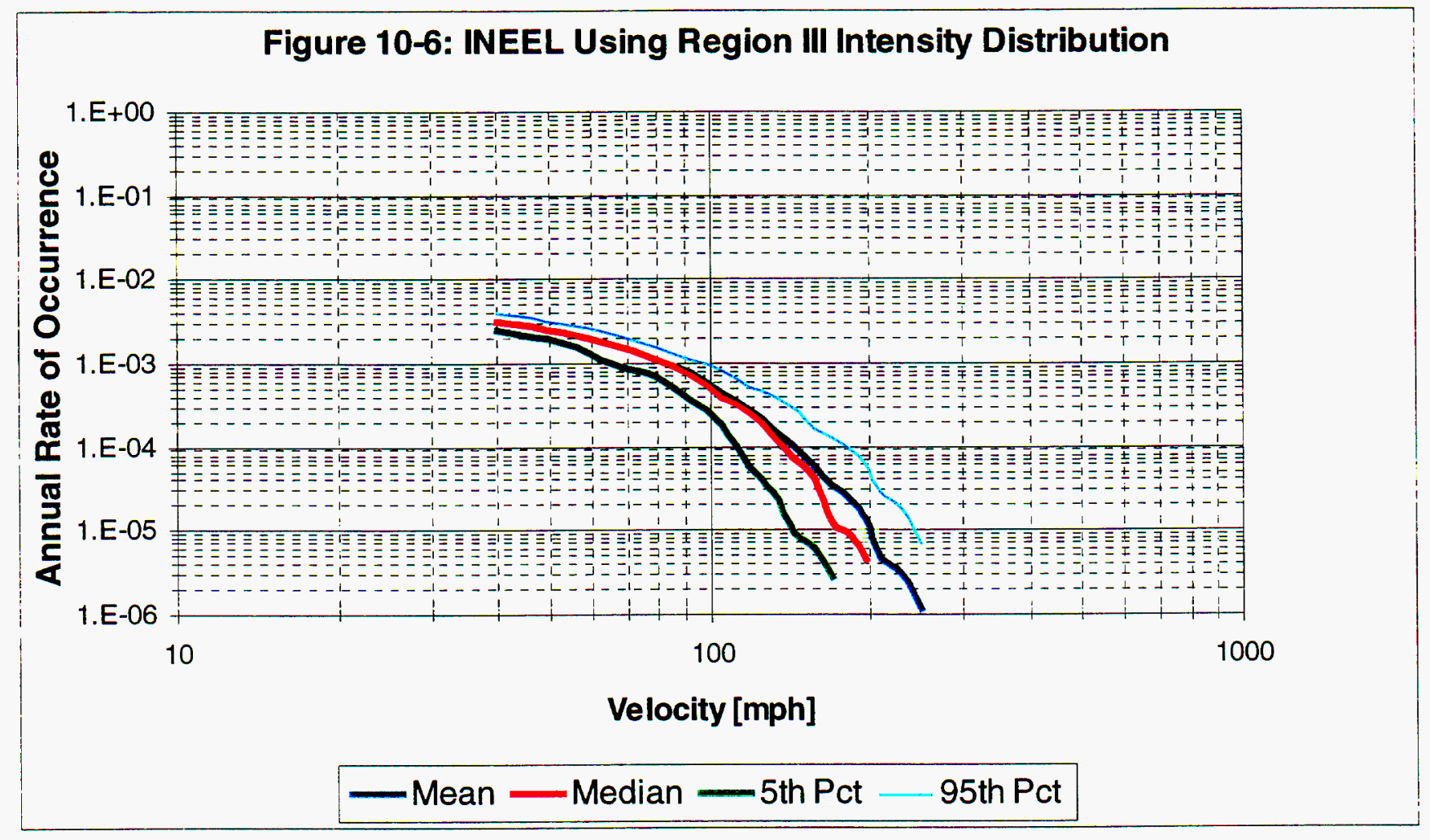









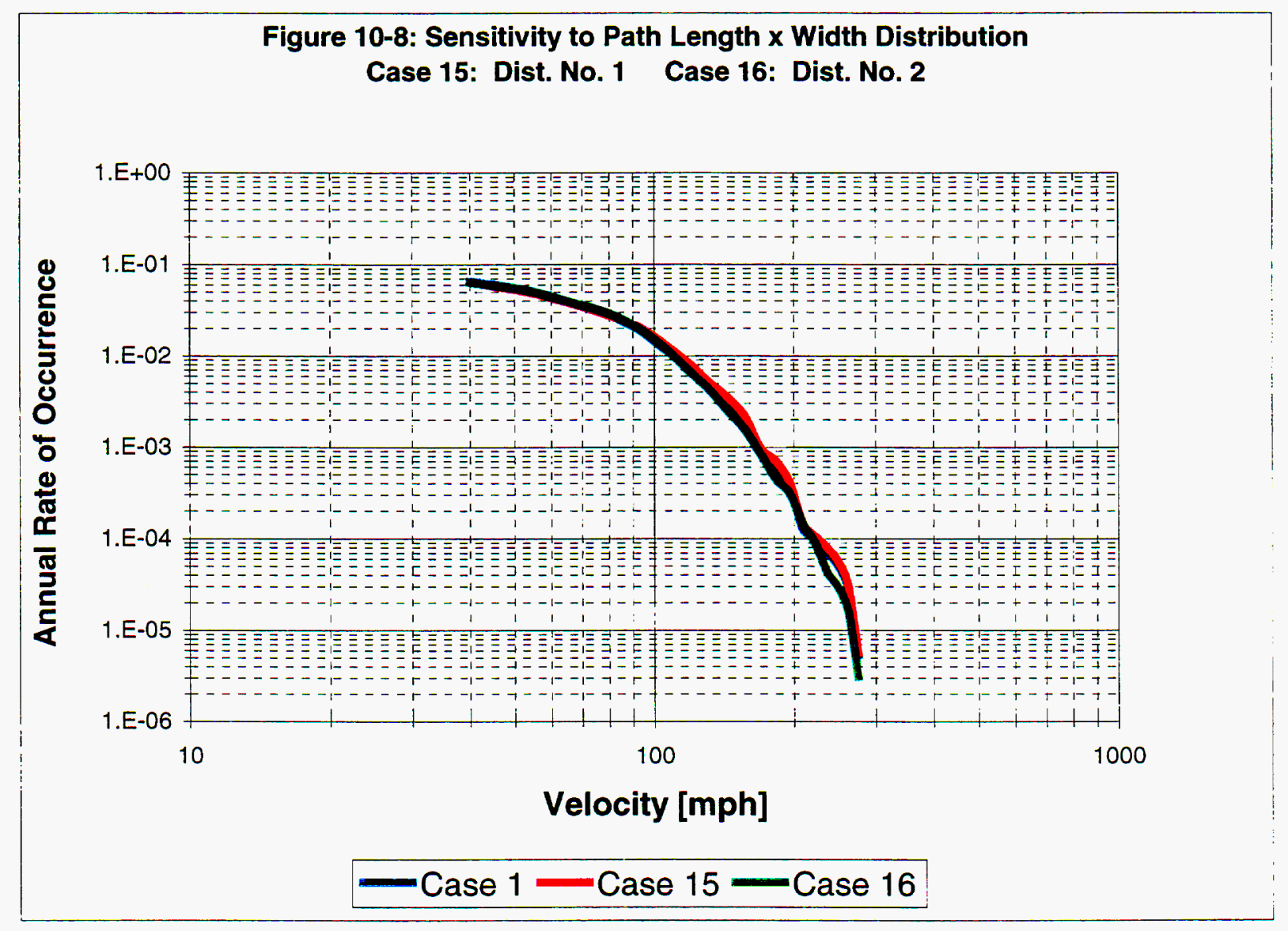




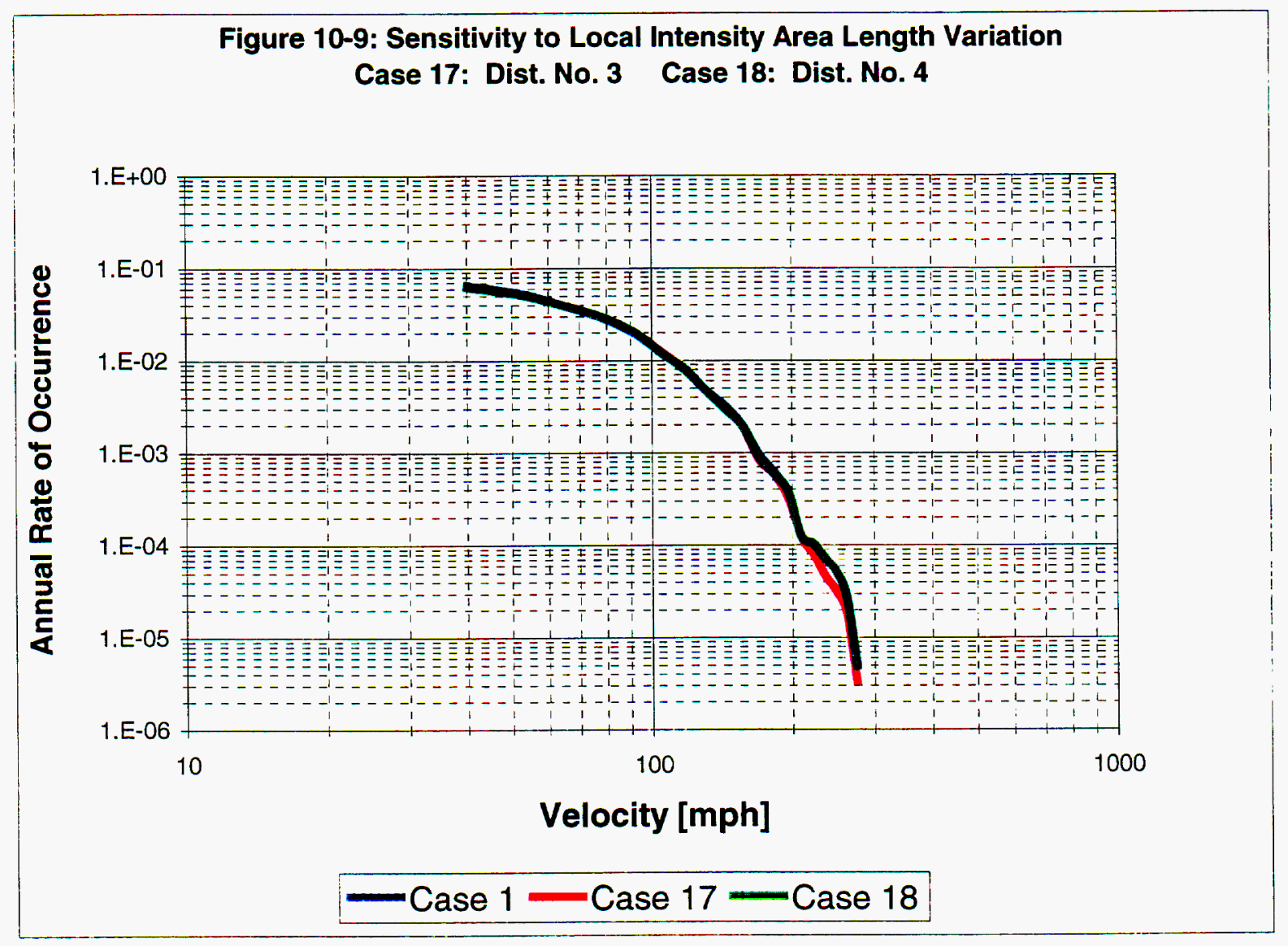




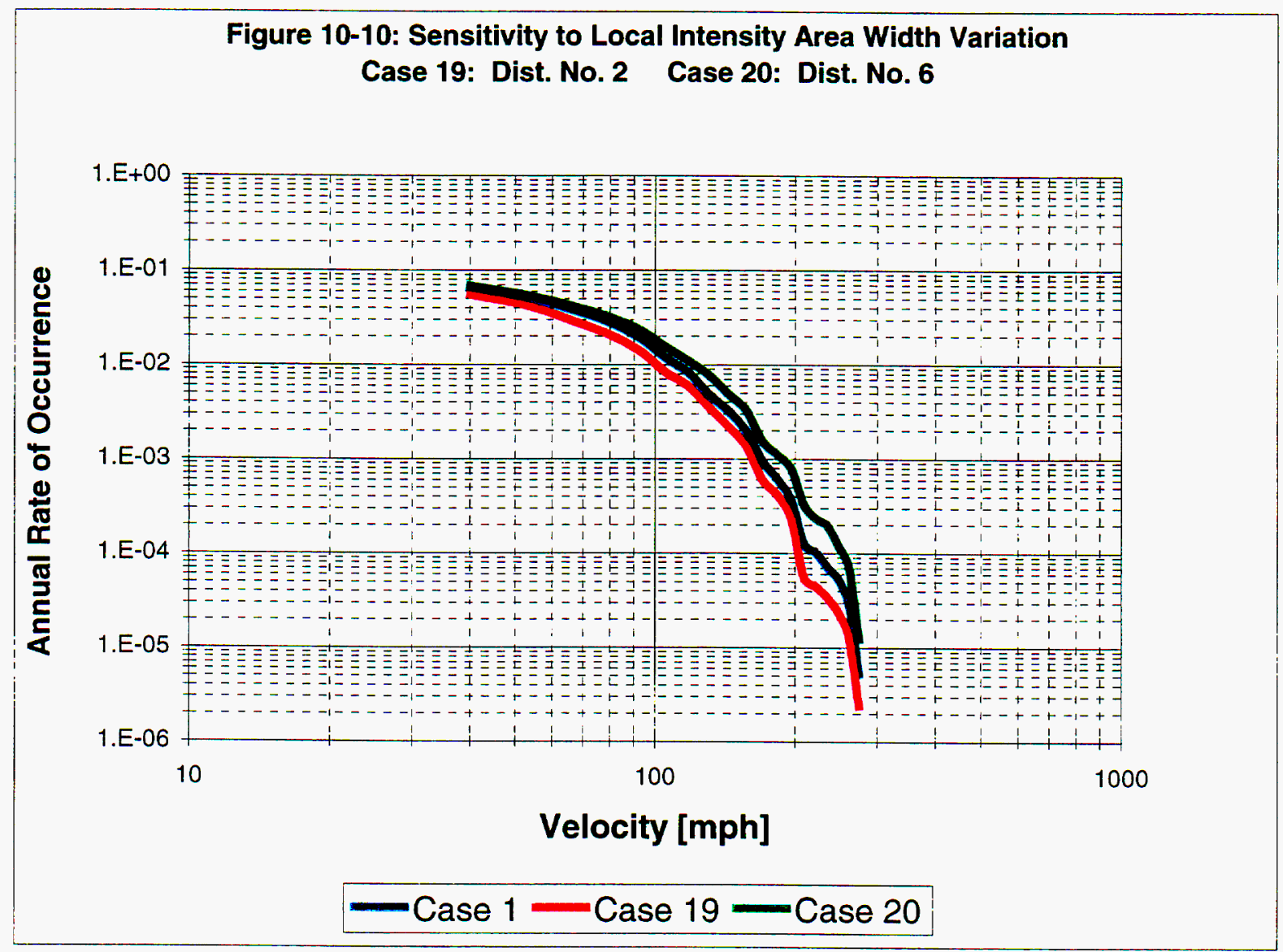




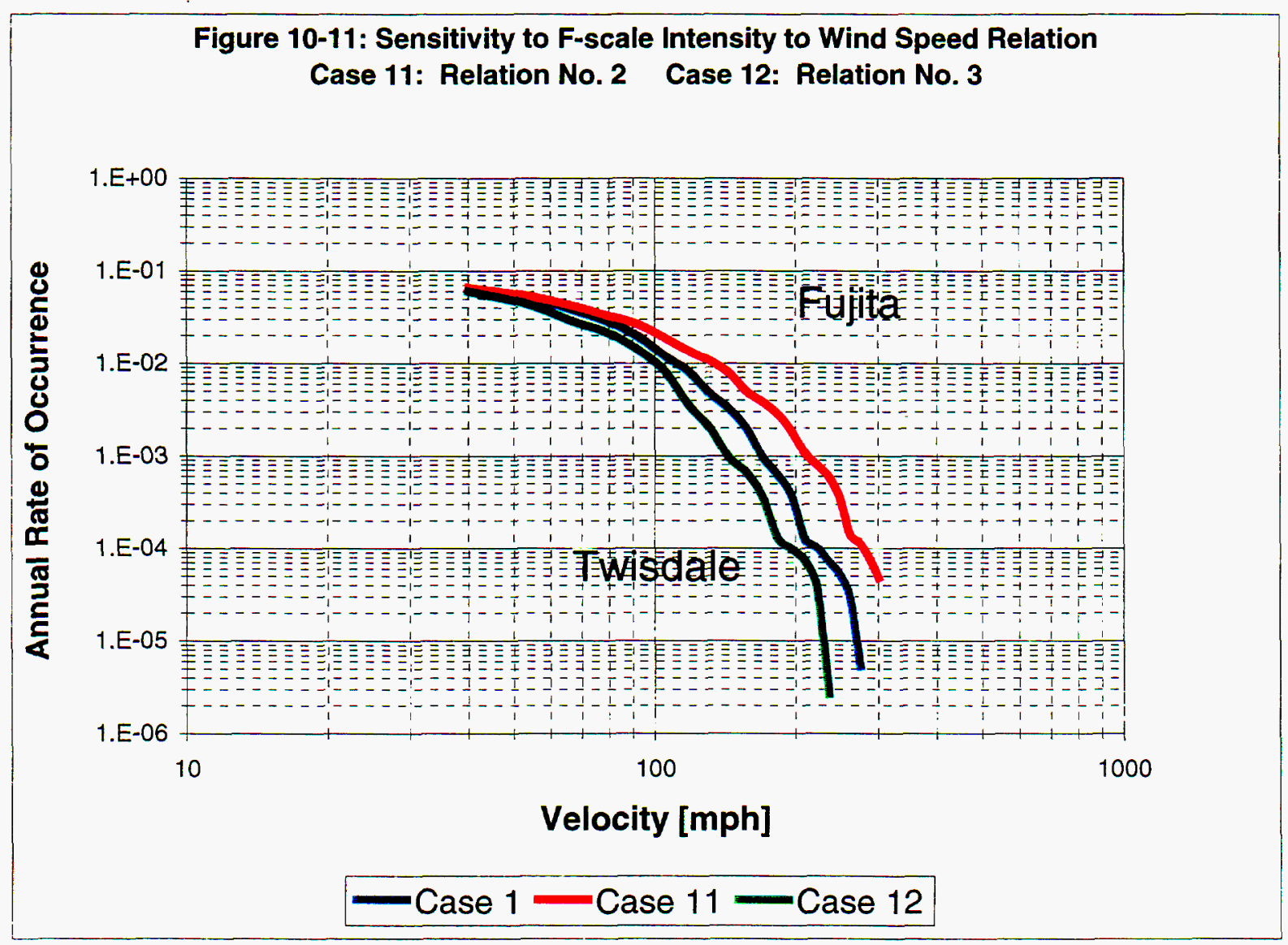


Figure 10-12: CONUS Map Showing Actual Touchdown Locations (1950-'95)

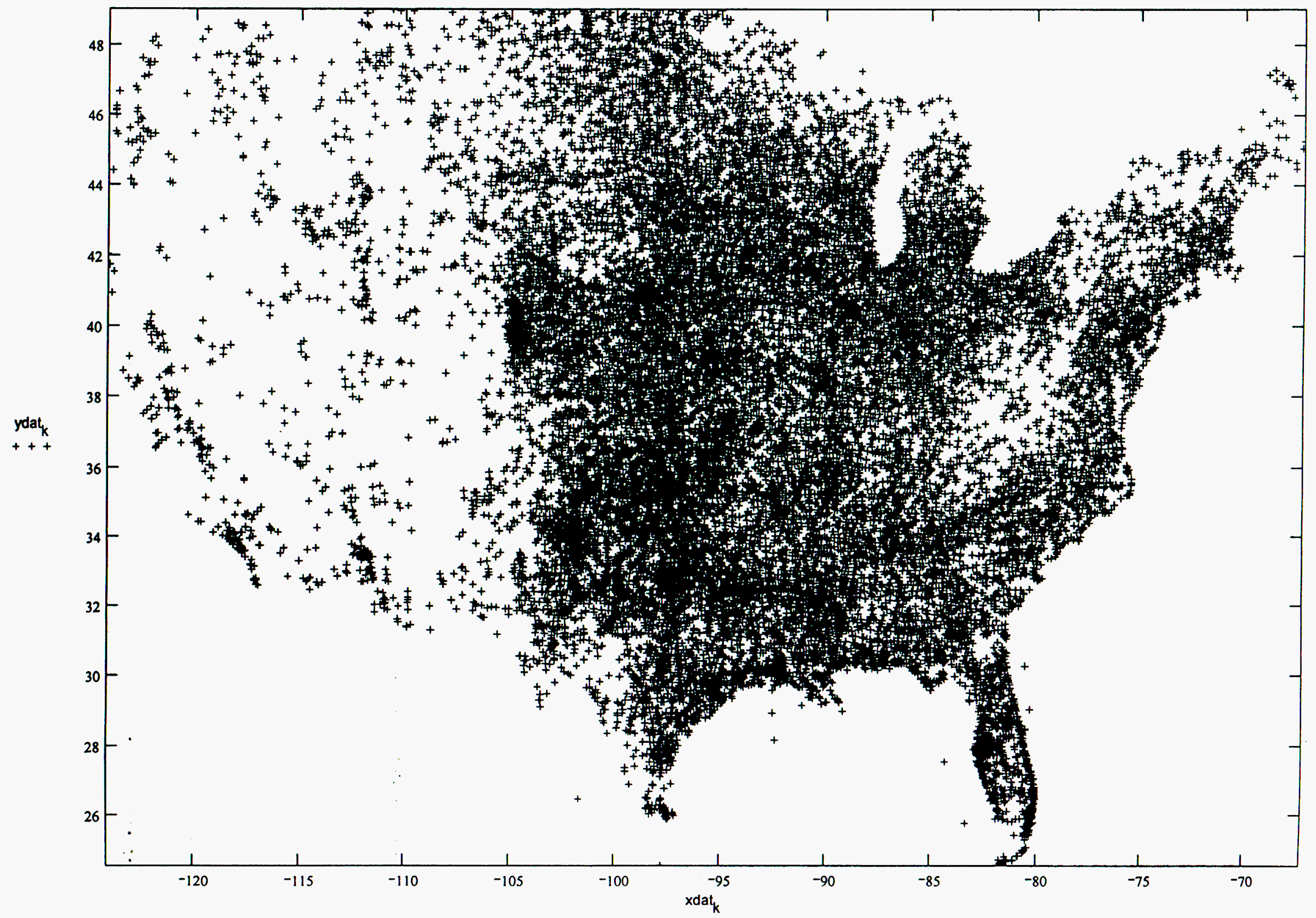






2

Figure 10-13: Contour Map Showing Density Estimation wih $h_{x}=1.5, h_{y}=0.9$ 


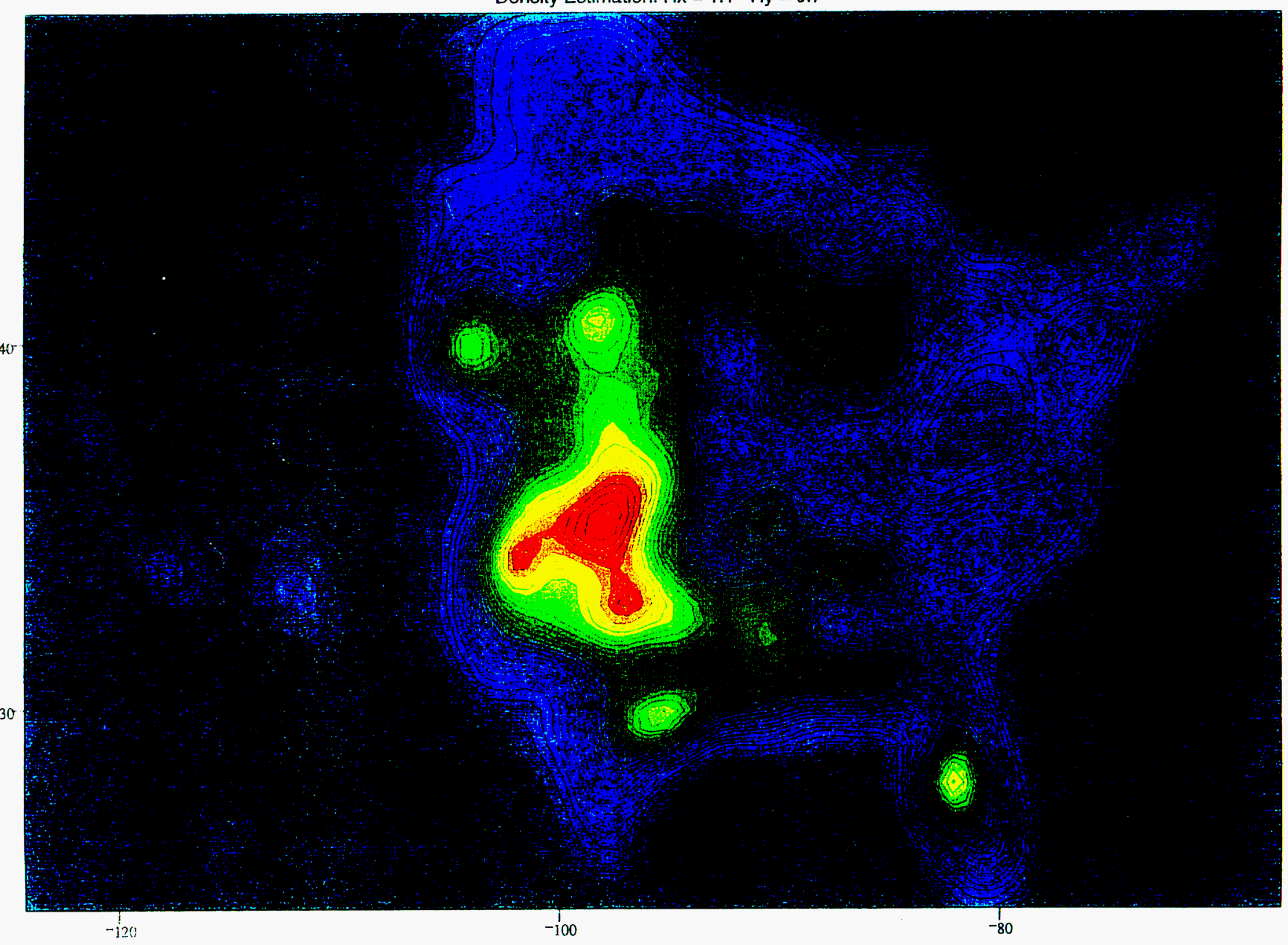




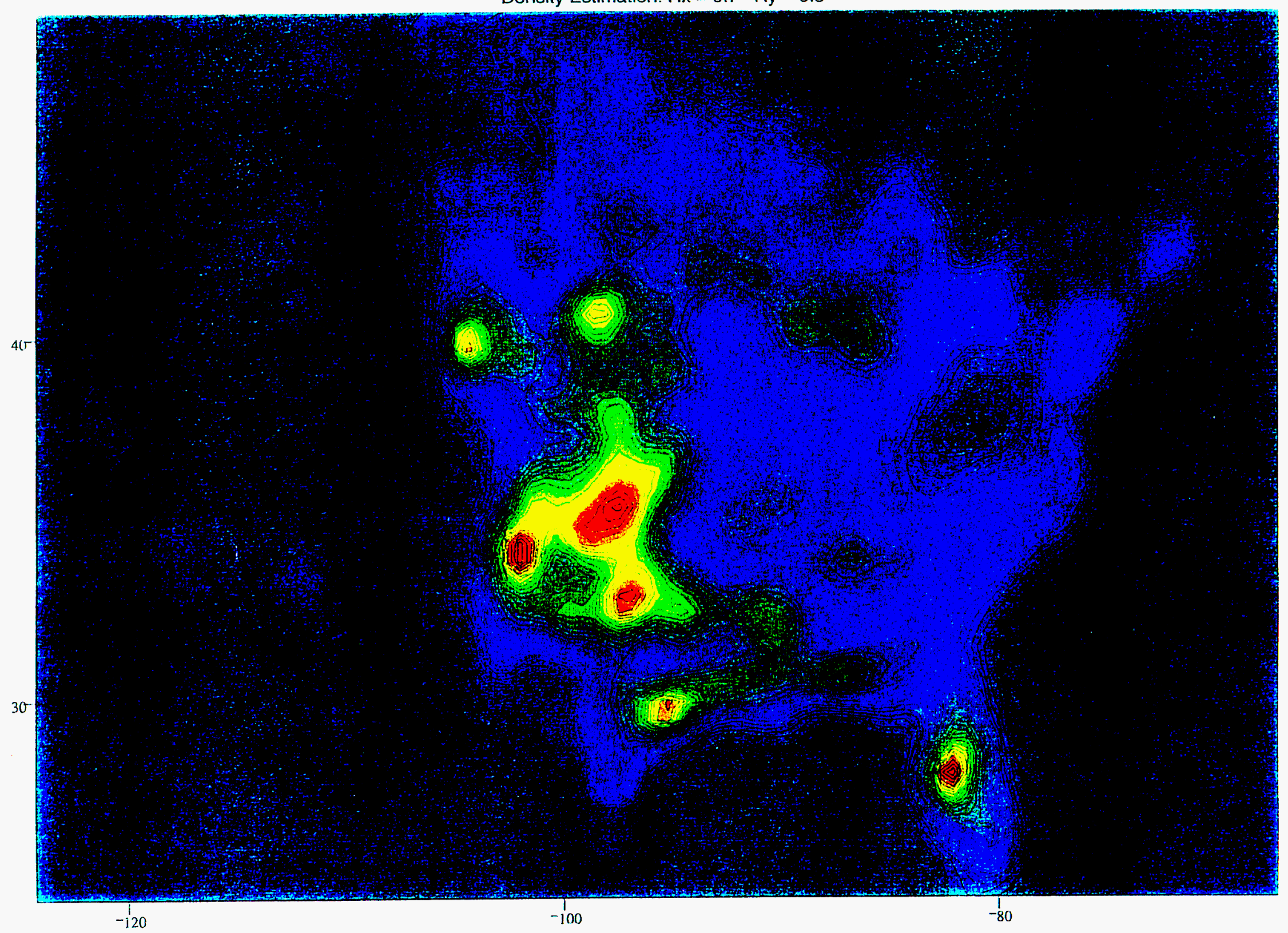

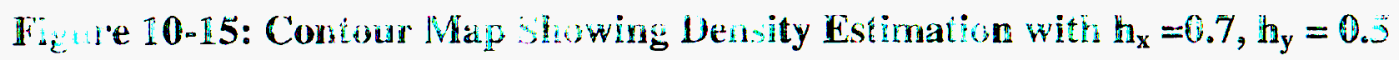


Figure 10-16

\section{Wind Hazard for 7 Generic Locations Nominal Case}

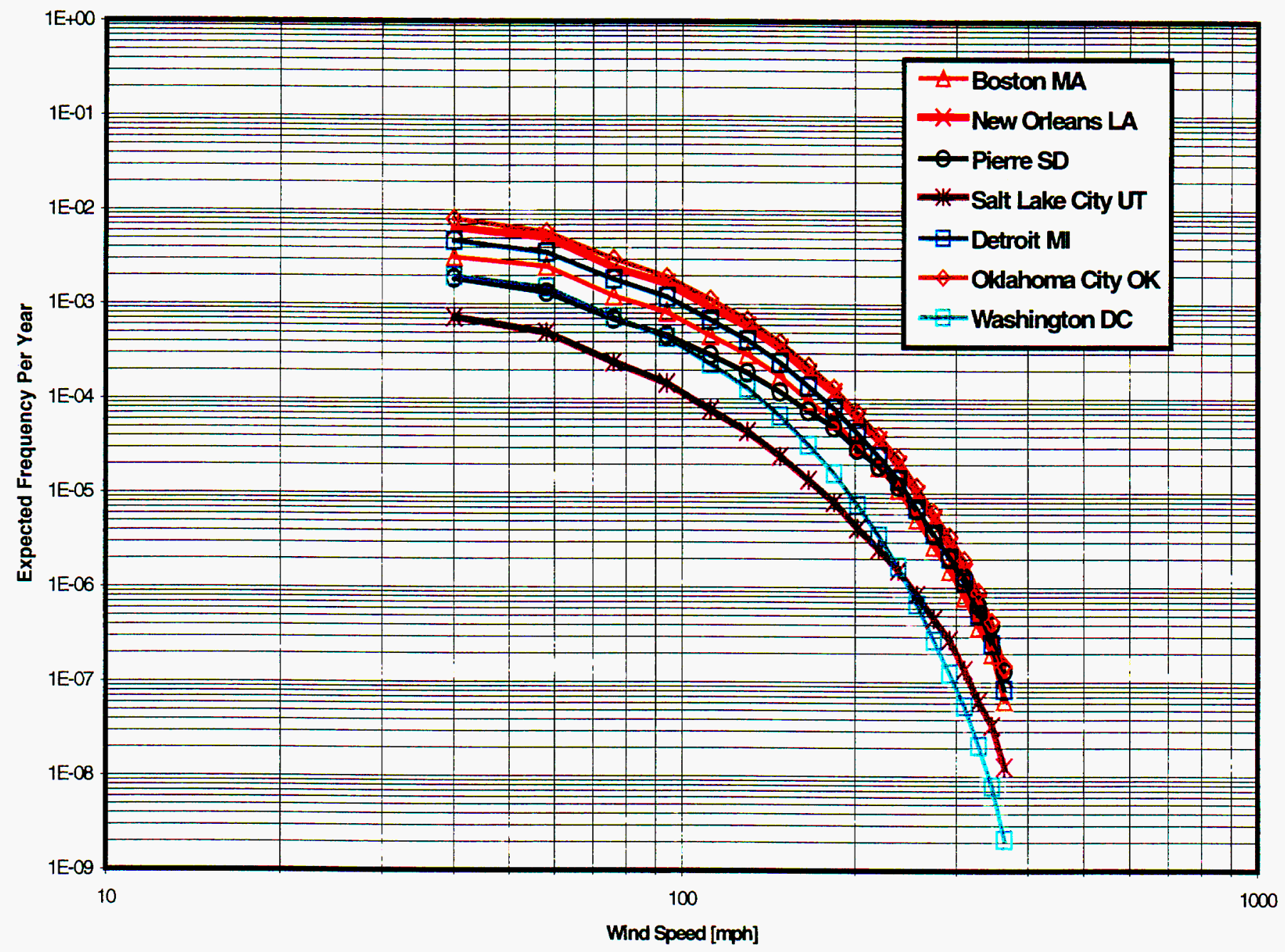


Figure 10-17: Full Set of Tornado Hazard Curves for Locations Evaluated

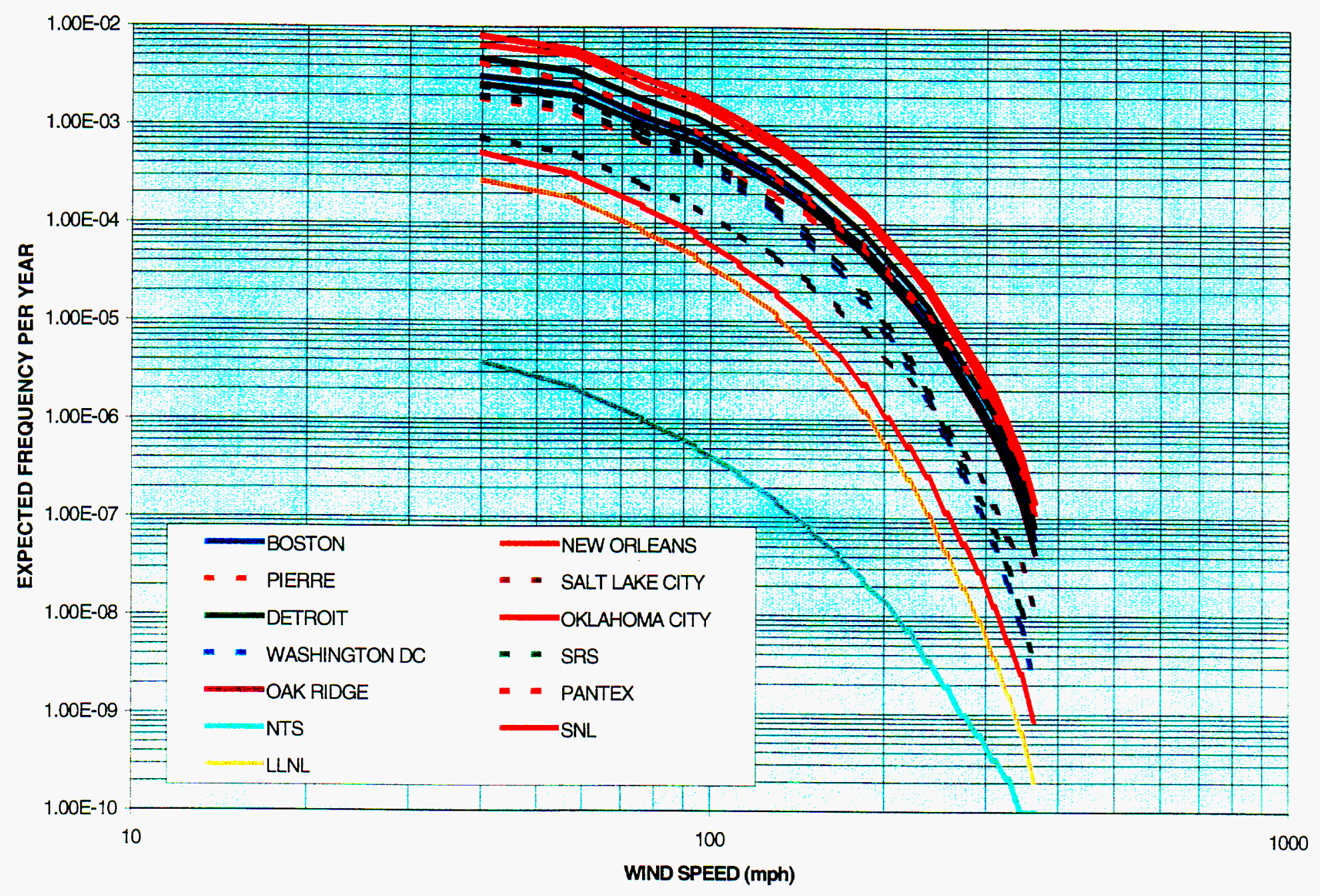


Figure 10-18: Tornado Hazard Curves for Three DOE Sites East of the Rockies

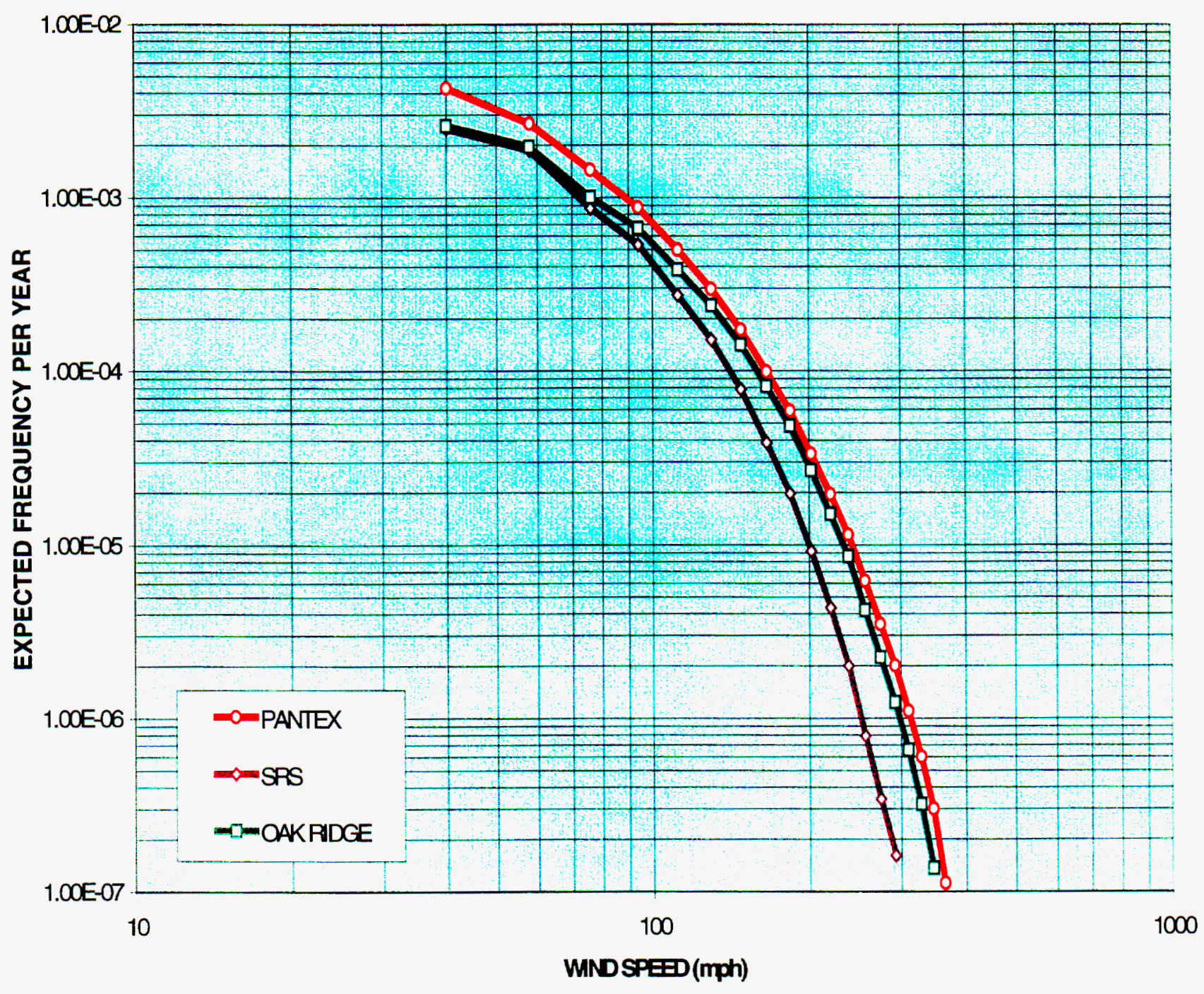


Figure 10-19: Tornado Hazard Curves for Three DOE and Two Generic Western



Sites 
Figure 10-20: Tornado Hazard Comparison of SRS with Three Generic Eastern

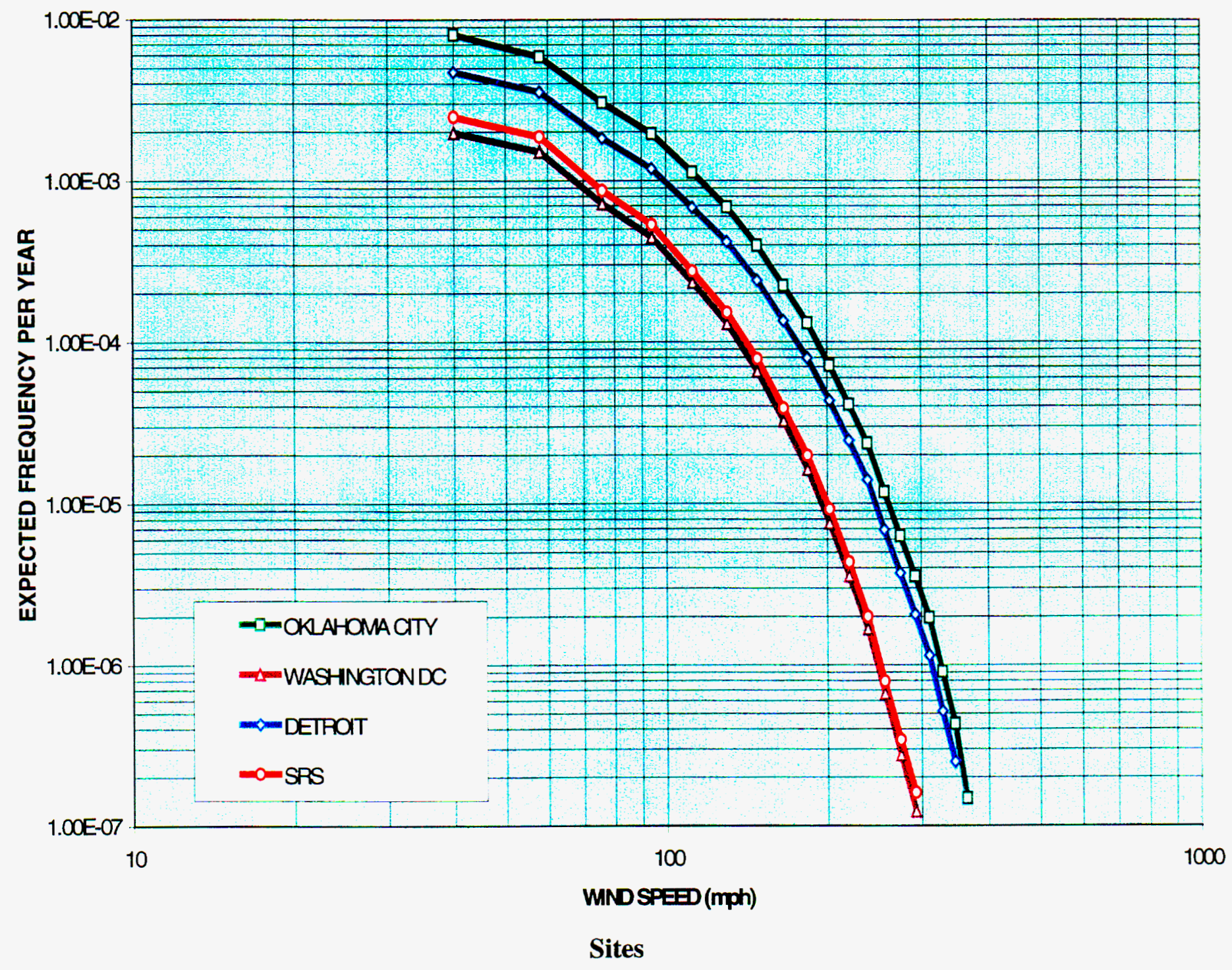


Figure 10-21: Tornado Hazard Comparison of PANTEX with Three Generic



Eastern Sites 
Figure 10-22: Tornado Hazard Comparison of OAKRIDGE with Three Generic Eastern Sites

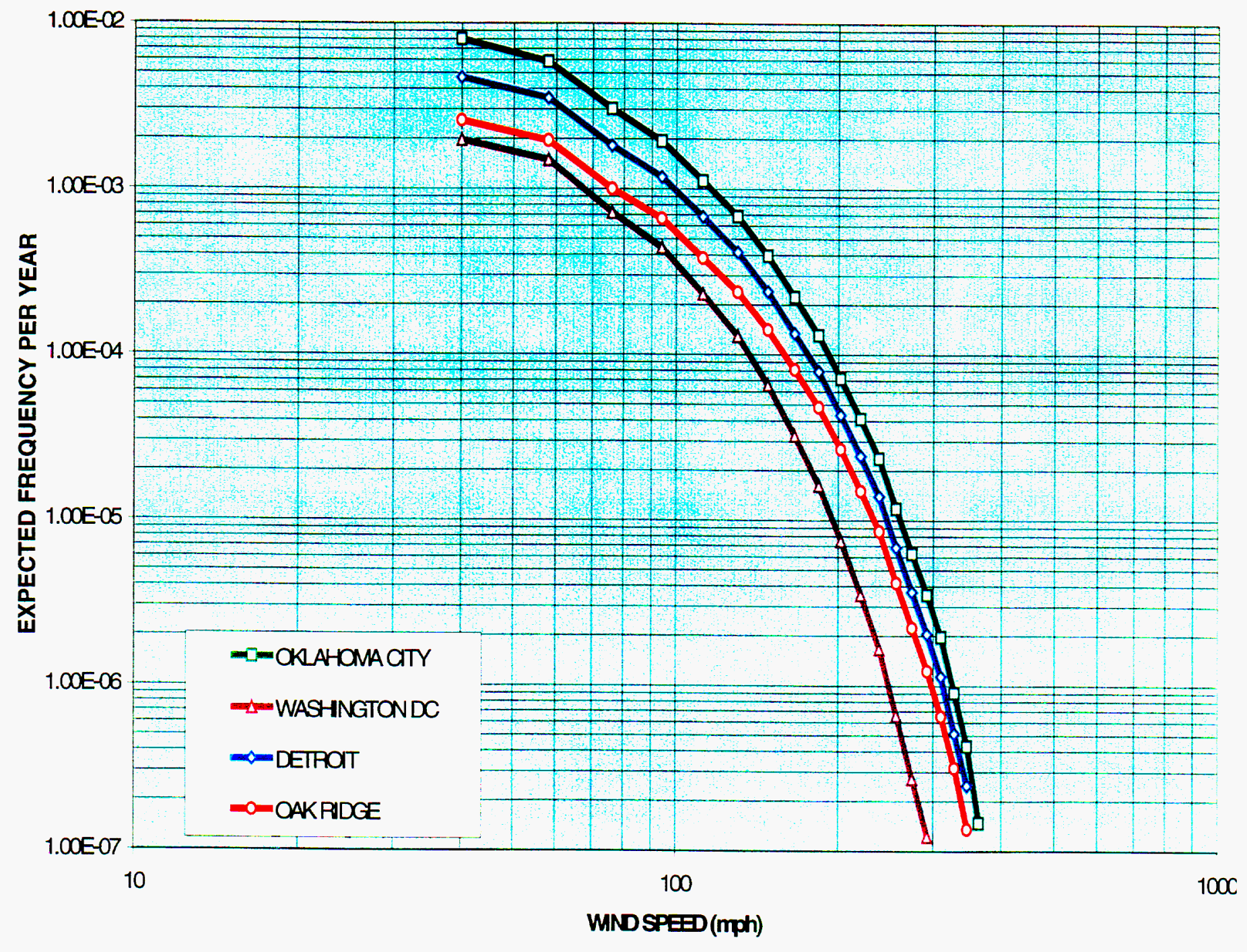


Figure 10-23: Tornado Hazard Comparison of Three Generic Eastern Sites

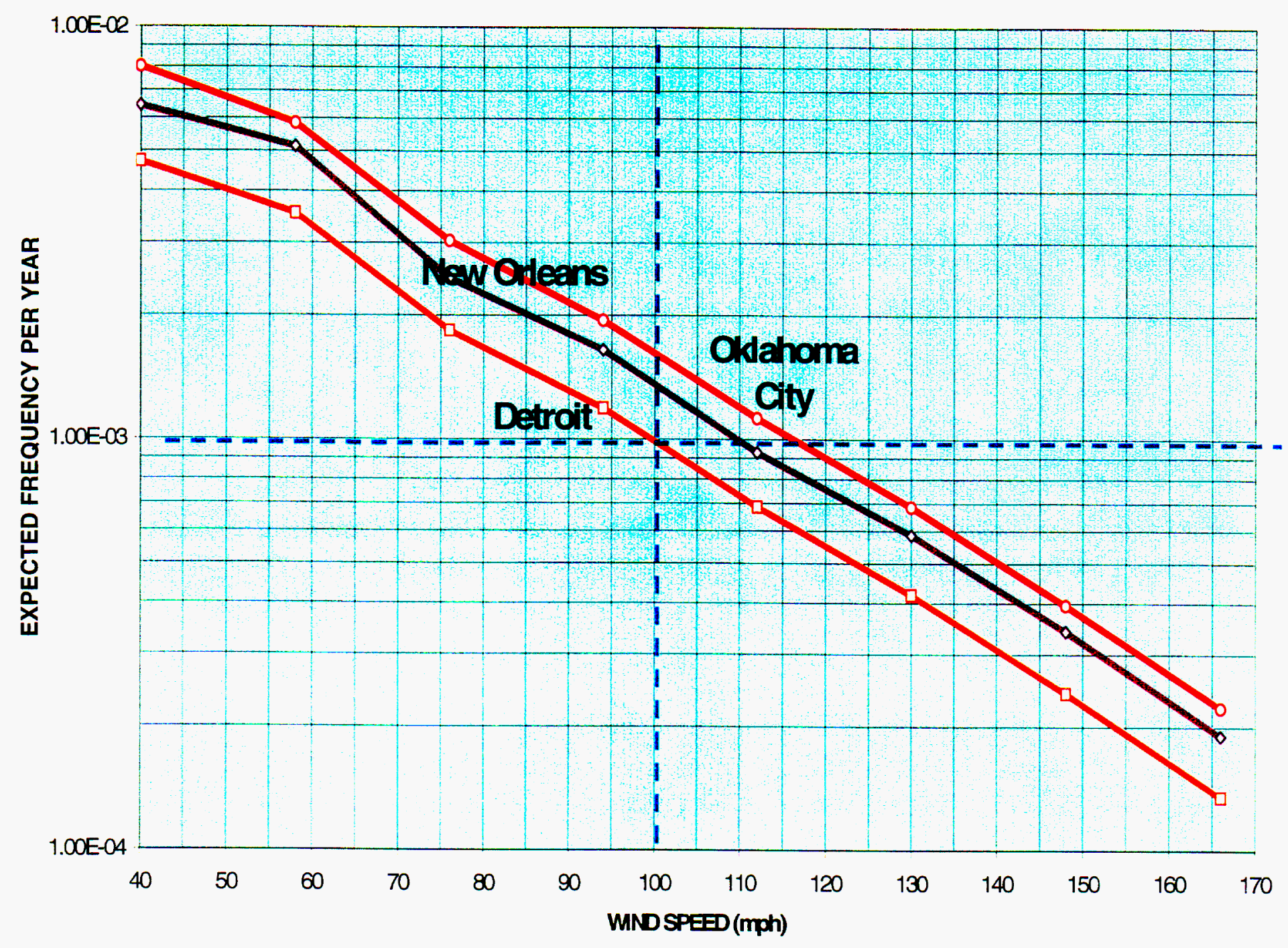


Figure 10-24: PANTEX Wind Hazard Sensitivity to Wind Speed Relationships

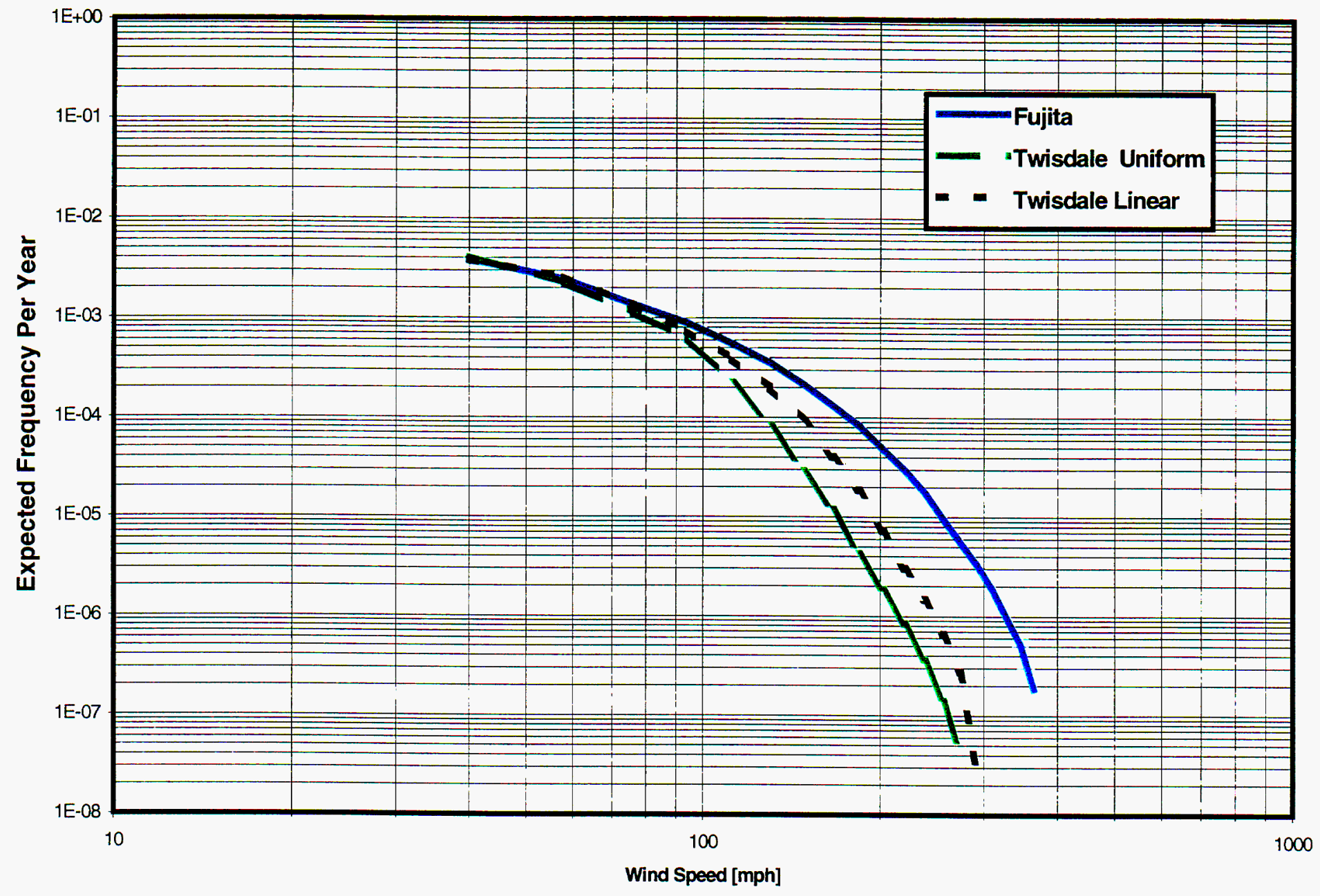


Figure 10-25: NTS Wind Hazard Sensitivity to Wind Speed Relationships

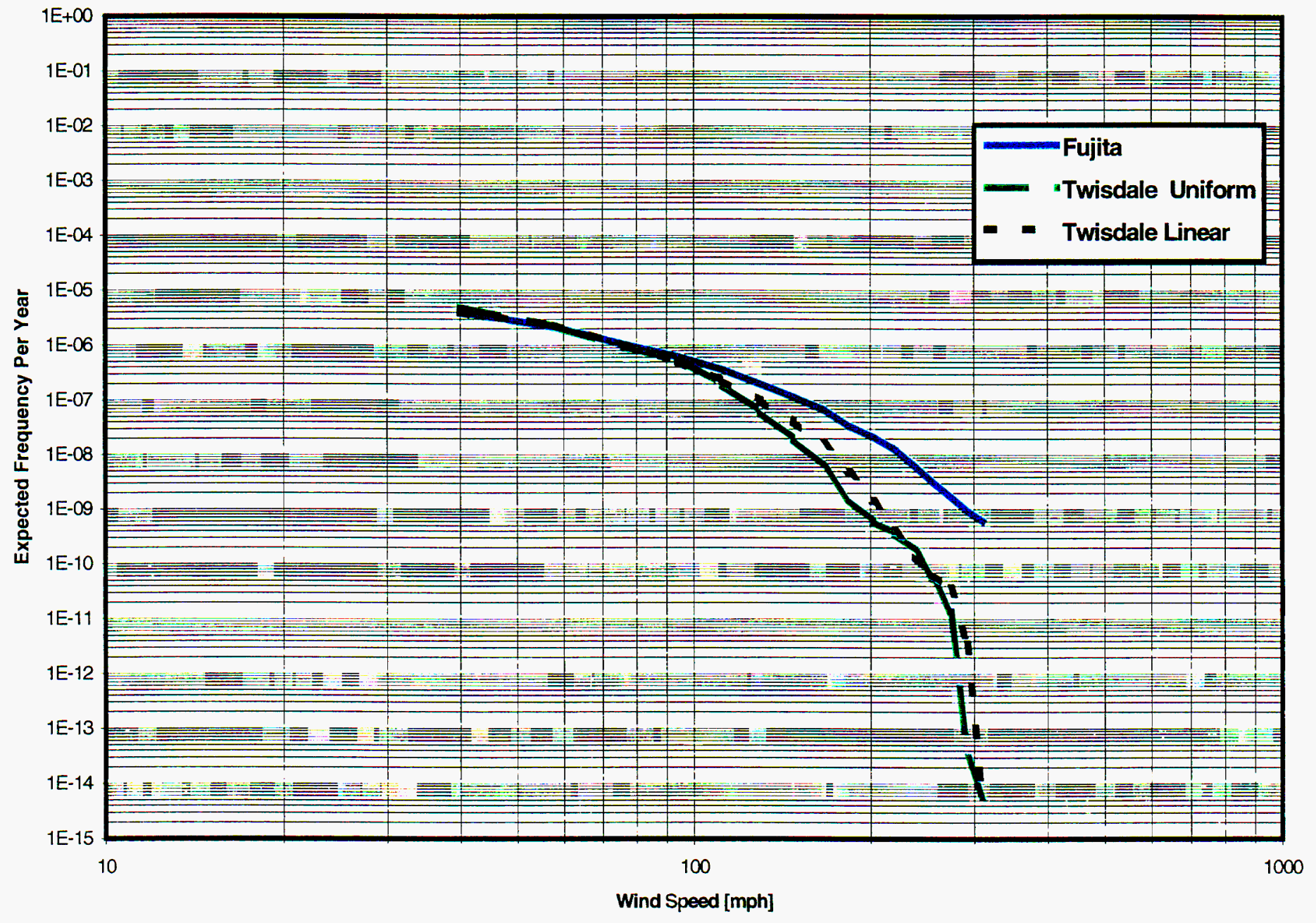


Figure 10-26: OAKRIDGE Wind Hazard Sensitivity to Wind Speed Relationships




Figure 10-27: SRS Wind Hazard Sensitivity to Wind Speed Relationships

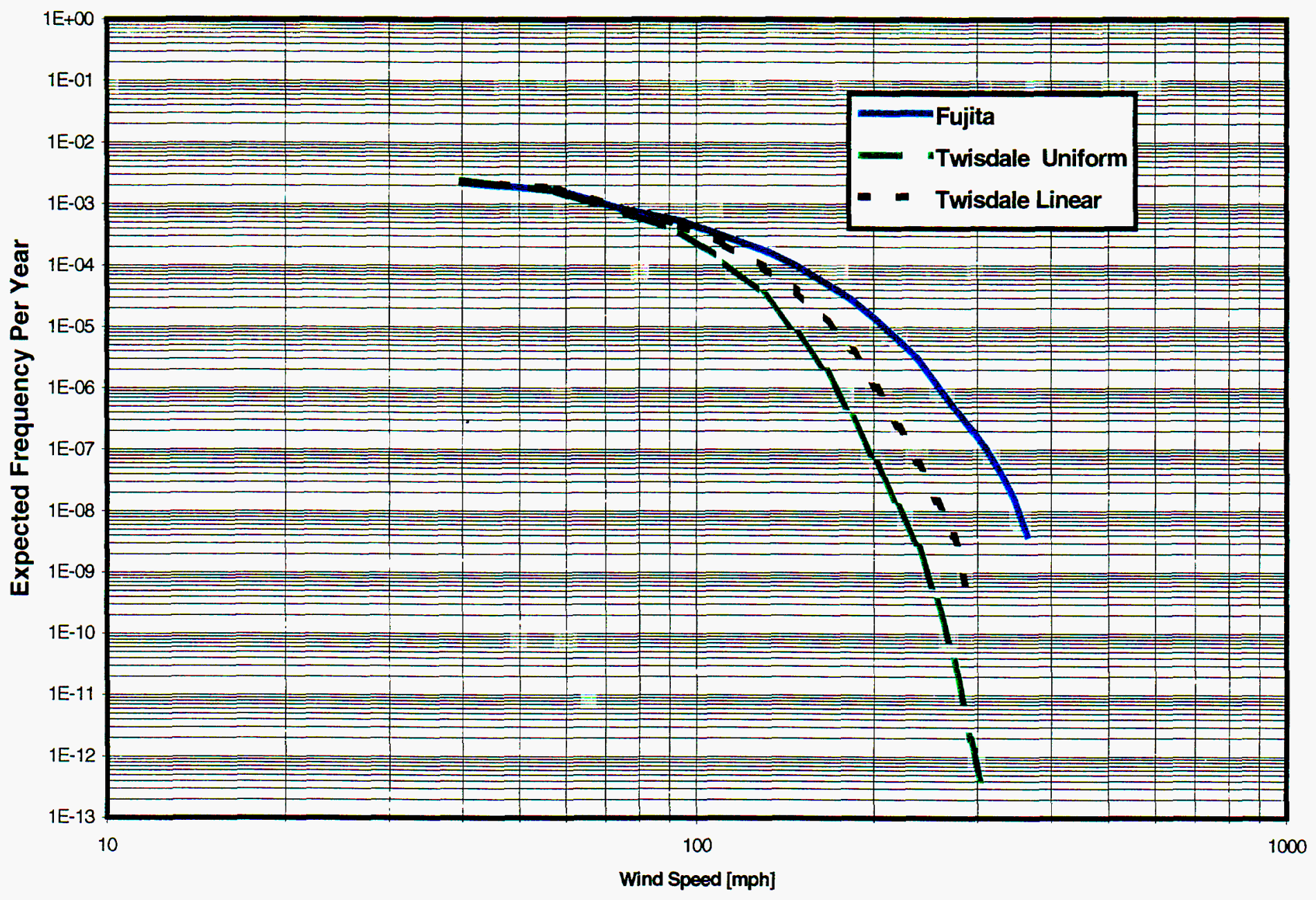


Figure 10-28

\section{Wind Hazard for 4 different Site Effect Areas (SEA) for Pantex}

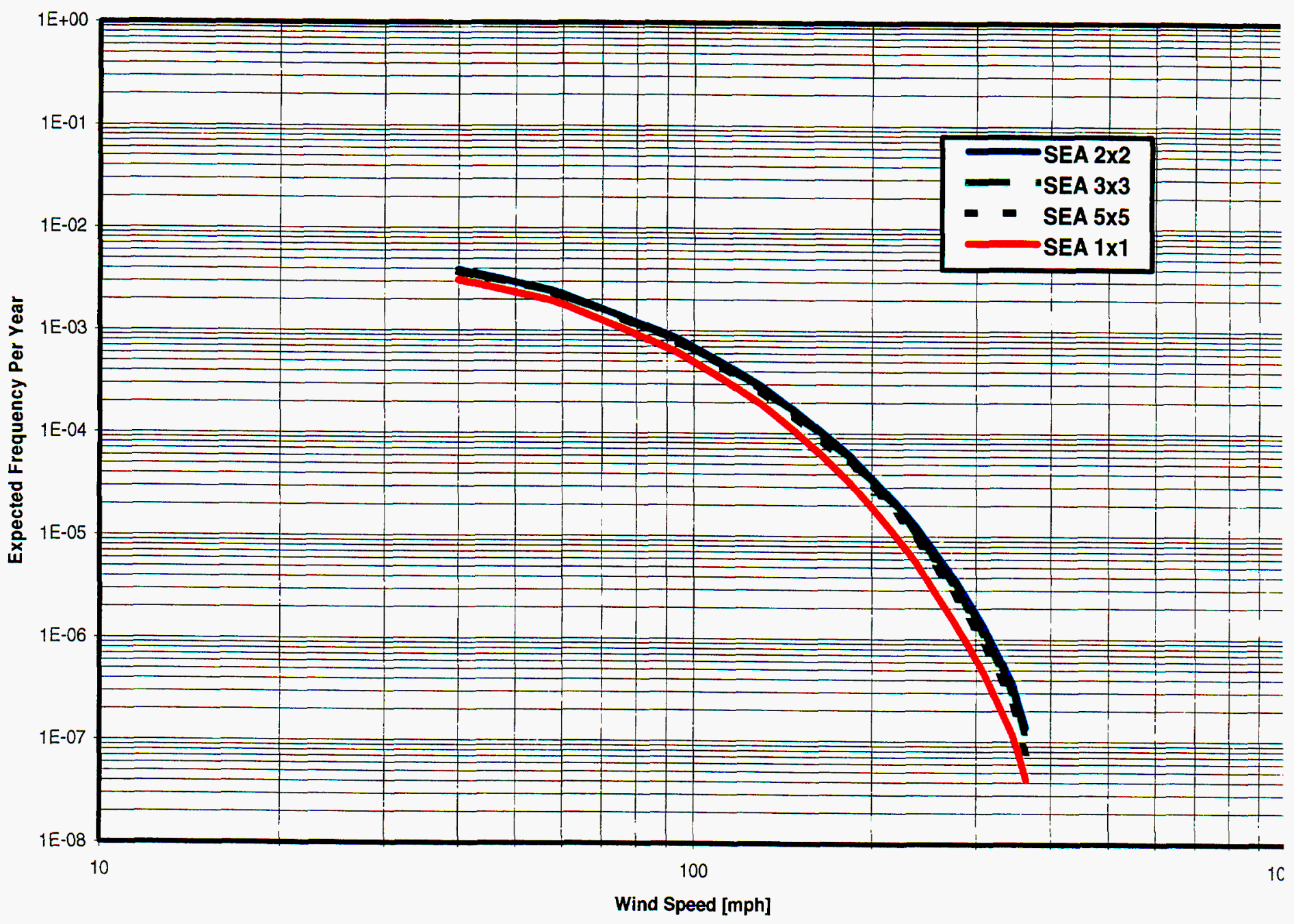


Figure 10-29: NTS Wind Hazard for 3 different Site Effect Areas (SEA)




Figure 10-30: OAKRIDGE Wind Hazard for 3 different Site Effect Areas (SEA)

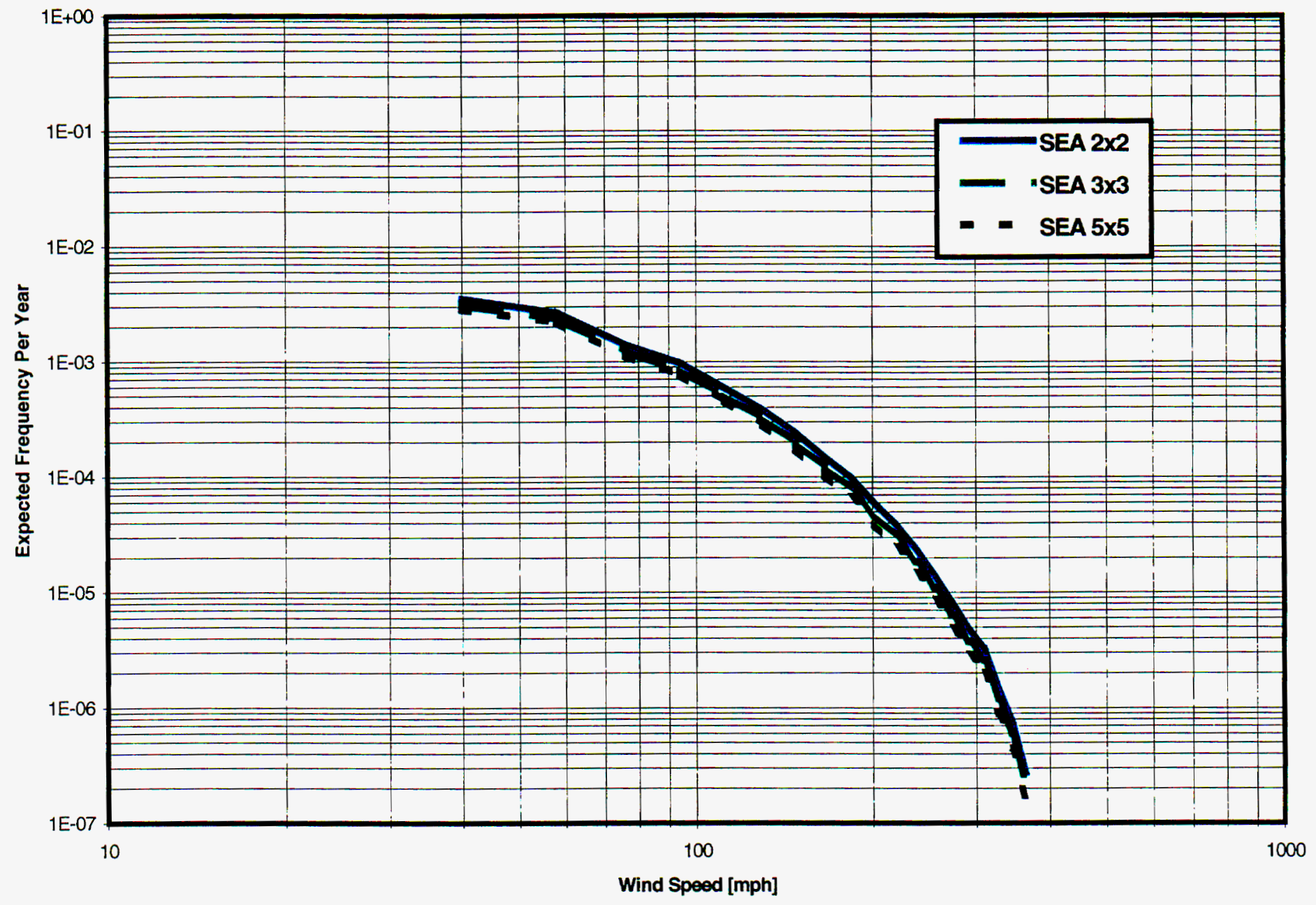


Figure 10-31: SRS Wind Hazard for 3 different Site Effect Areas (SEA)






\subsection{Test Application of TORNADO to DOE Sites}

\subsection{Test Cases}

To critically review the methodology developed and its implementation in the software code, TORNADO, a number of trial application runs of the TORNADO code were made for the following seven DOE sites

- Pantex Site in Texas

- Savannah River Site (SRS) in South Carolina

- Nevada Test Site (NTS) in Nevada

- Oak Ridge Site in Tennessee

- Los Alamos National Laboratory (LANL) Site in New Mexico

- Lawrence Livermore National Laboratory (LLNL) Site in California

- Sandia National Laboratory (SNL) Site in New Mexico

These sites provided a variety of locations throughout the contiguous U.S. Pantex is in the 'tornado belt'. Because of the Cumberland Plateau, Oak Ridge is somewhat sheltered. Most of the tornadoes in Tennessee occur to the west. SRS is in the Southeast, another area of tornado activity. The other three sites, NTS, LANL, LLNL and SNL are in the West, where there is limited tornado activity.

The results (i.e., hazard curves and tabulated values) provided in this section below are based on the hazard model and TORNADO code version before these were modified on the basis of revised inputs from the Expert Panel members and are superseded by those in Section 13 (see Sections 12 and 13 for details).

\subsection{Results}

Tornado wind hazard curves, assuming a 300'x300' facility at each of the seven sites, are shown in Figures 11-1 through 11-7. The tornado wind hazard curves for a 200'x800' building at SRS is shown in Figure 11-8. The facility at each location is centered at the respective latitude, longitude location for the site. The figures are log-log plots of the expected frequency of winds exceeding a specified wind speed, in mph, versus the wind speed. In recognition of the uncertainties associated with estimating tornado wind hazards, each Figure includes 4 curves. The lower and upper curves correspond to envelop curves of a low percentile (e.g., the $5^{\text {th }}$ percentile) and an upper percentile (e.g., the $95^{\text {th }}$ percentile). The center two curves correspond to the median, i.e., $50^{\text {th }}$ percentile, envelope curve and the mean envelope curve. Development of these uncertainty envelope curves is described in Section 7. The mean and median curves are usually plotted to allow the user more flexibility in assessing the hazard for design, safety assessments, etc. Based on the paradigm of decision theory (Lindley, 1985), the mean envelope curve is considered the estimated tornado wind hazard for each facility. 


\subsection{Comparisons with Previous Model Results}

The tornado wind velocities for each of the sites listed above corresponding to four nonexceedance probability values (taken from Figures 11-1 through 11-7) are presented in Tables 11-1 through 11-7, and compared with those obtained from USNRC's NUREG/CR-4461 (Ramsdell, 1986), USNRC's ONRR Staff Position (ONRR, 1988), and DOE-STD-1020-94 (DOE, 1996). ONRR values given in these tables (in parenthesis) are those recommended by the NRC staff for design; these are regional values based on, but not identical to, NUREG/CR-4461 wind speeds given for $5^{\circ} \times 5^{\circ}$ grids. For exceedance probabilities $1 \times \mathbf{1 0}^{-5}$ and $1 \times \mathbf{1 0}^{-6}$, the values shown under NUREG are mean values. For exceedance probability $1 \times \mathbf{1 0}^{-7}$, the values are estimated from the upper end of the $90 \%$ strike probability confidence interval. 
Table 11-1:Tornado Wind Speed Comparison for Pantex Site

\begin{tabular}{|c|c|c|c|}
\hline \multirow{2}{*}{$\begin{array}{l}\text { Mean Probability } \\
\text { of Exceedance }\end{array}$} & \multicolumn{3}{|c|}{ Tornado Wind Speed (mph) } \\
\cline { 2 - 4 } & TORNADO & NUREG (ONRR) & DOE-STD-1020 \\
\hline $2 \times 10^{-5}$ & 219 & 235 & 150 \\
\hline $2 \times 10^{-6}$ & 292 & - & 202 \\
\hline $1 \times 10^{-6}$ & 313 & 273 & - \\
\hline $1 \times 10^{-7}$ & 366 & $296(330)$ & - \\
\hline
\end{tabular}

Table 11-2:Tornado Wind Speed Comparison for Savannah River Site

\begin{tabular}{|c|c|c|c|}
\hline \multirow{2}{*}{$\begin{array}{l}\text { Mean Probability } \\
\text { of Exceedance }\end{array}$} & \multicolumn{3}{|c|}{ Tornado Wind Speed (mph) } \\
\cline { 2 - 4 } & TORNADO & NUREG (ONRR) & DOE-STD-1020 \\
\hline $2 \times 10^{-5}$ & 184 & 240 & 155 \\
\hline $2 \times 10^{-6}$ & 238 & - & 212 \\
\hline $1 \times 10^{-6}$ & 251 & 276 & - \\
\hline $1 \times 10^{-7}$ & 303 & $306(300)$ & - \\
\hline
\end{tabular}

Table 11-3:Tornado Wind Speed Comparison for Nevada Test Site

\begin{tabular}{|c|c|c|c|}
\hline \multirow{2}{*}{$\begin{array}{l}\text { Mean Probability } \\
\text { of Excedance }\end{array}$} & \multicolumn{3}{|c|}{ Tornado Wind Speed (mph) } \\
\cline { 2 - 4 } & TORNADO & NUREG (ONRR) & DOE-STD-1020 \\
\hline $2 \times 10^{-5}$ & $<40$ & - & - \\
\hline $2 \times 10^{-6}$ & $\mathbf{5 9}$ & - & - \\
\hline $1 \times 10^{-6}$ & $\mathbf{7 6}$ & 131 & - \\
\hline $1 \times 10^{-7}$ & 141 & $198(220)$ & - \\
\hline
\end{tabular}

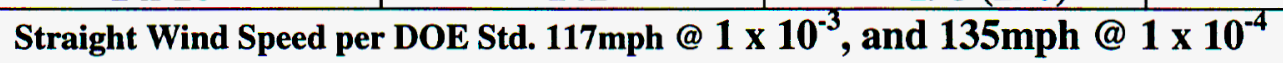


Table 11-4:Tornado Wind Speed Comparison for Oak Ridge Site

\begin{tabular}{|c|c|c|c|}
\hline \multirow{2}{*}{$\begin{array}{l}\text { Mean Probability } \\
\text { of Exceedance }\end{array}$} & \multicolumn{3}{|c|}{ Tornado Wind Speed (mph) } \\
\cline { 2 - 4 } & TORNADO & NUREG (ONRR) & DOE-STD-1020 \\
\hline $1 \times 10^{-5}$ & & 244 & \\
\hline $2 \times 10^{-5}$ & 211 & - & 130 \\
\hline $2 \times 10^{-6}$ & 277 & - & 192 \\
\hline $1 \times 10^{-6}$ & 298 & 282 & - \\
\hline $1 \times 10^{-7}$ & 351 & $316(330)$ & - \\
\hline
\end{tabular}

Table 11-5:Tornado Wind Speed Comparison for LANL Site

\begin{tabular}{|c|c|c|c|}
\hline \multirow{2}{*}{$\begin{array}{l}\text { Mean Probability } \\
\text { of Exceedance }\end{array}$} & \multicolumn{3}{|c|}{ Tornado Wind Speed (mph) } \\
\cline { 2 - 4 } & TORNADO & NUREG (ONRR) & DOE-STD-1020* \\
\hline $2 \times 10^{-5}$ & $\mathbf{7 1}$ & - & - \\
\hline $2 \times 10^{-6}$ & 142 & - & - \\
\hline $1 \times 10^{-6}$ & 163 & 137 & - \\
\hline $1 \times 10^{-7}$ & 210 & $198(220)$ & - \\
\hline
\end{tabular}

*Straight Wind Speed : $117 \mathrm{mph} @ 1 \times 10^{-3}$, and 135mph @ $1 \times 10^{-4}$

Table 11-6:Tornado Wind Speed Comparison for LLNL Site

\begin{tabular}{|c|c|c|c|}
\hline \multirow{2}{*}{$\begin{array}{l}\text { Mean Probability } \\
\text { of Exceedance }\end{array}$} & \multicolumn{3}{|c|}{ Tornado Wind Speed (mph) } \\
\cline { 2 - 4 } & TORNADO & NUREG (ONRR) & DOE-STD-1020* \\
\hline $2 \times 10^{-5}$ & 115 & - & - \\
\hline $2 \times 10^{-6}$ & 172 & - & - \\
\hline $1 \times 10^{-6}$ & 189 & 142 & - \\
\hline $1 \times 10^{-7}$ & $\mathbf{2 4 0}$ & $\mathbf{2 0 8}(220)$ & - \\
\hline
\end{tabular}

*Straight Wind Speed : $111 \mathrm{mph} @ 1 \times 10^{-3}$, and 128mph @ $1 \times 10^{-4}$ 
Table 11-7:Tornado Wind Speed Comparison for SNL Site

\begin{tabular}{|c|c|c|c|}
\hline \multirow{2}{*}{$\begin{array}{c}\text { Mean Probability } \\
\text { of Exceedance }\end{array}$} & \multicolumn{3}{|c|}{ Tornado Wind Speed (mph) } \\
\cline { 2 - 4 } & TORNADO & NUREG (ONRR) & DOE-STD-1020* \\
\hline $2 \times 10^{-5}$ & 129 & - & - \\
\hline $2 \times 10^{-6}$ & 187 & - & - \\
\hline $1 \times 10^{-6}$ & 204 & 137 & - \\
\hline $1 \times 10^{-7}$ & 259 & $198(220)$ & - \\
\hline
\end{tabular}

*Straight Wind Speed : 117mph @1 x 10 ${ }^{-3}$, and 135mph @ 1 x 10 
Table 11-8: Wind Hazard for LANL Site

\begin{tabular}{ccccc}
\hline $\begin{array}{c}\text { Wind Speed } \\
\text { (mph) }\end{array}$ & 5th & Median & Mean & 95th \\
\hline 40 & $1.82 \mathrm{E}-05$ & $4.05 \mathrm{E}-05$ & $5.11 \mathrm{E}-05$ & $1.22 \mathrm{E}-04$ \\
58 & $1.04 \mathrm{E}-05$ & $2.48 \mathrm{E}-05$ & $3.17 \mathrm{E}-05$ & $7.64 \mathrm{E}-05$ \\
76 & $4.76 \mathrm{E}-06$ & $1.42 \mathrm{E}-05$ & $1.72 \mathrm{E}-05$ & $4.23 \mathrm{E}-05$ \\
94 & $2.33 \mathrm{E}-06$ & $7.63 \mathrm{E}-06$ & $9.94 \mathrm{E}-06$ & $2.46 \mathrm{E}-05$ \\
112 & $9.28 \mathrm{E}-07$ & $3.93 \mathrm{E}-06$ & $5.54 \mathrm{E}-06$ & $1.54 \mathrm{E}-05$ \\
130 & $3.12 \mathrm{E}-07$ & $1.96 \mathrm{E}-06$ & $3.09 \mathrm{E}-06$ & $1.04 \mathrm{E}-05$ \\
148 & $7.60 \mathrm{E}-08$ & $1.01 \mathrm{E}-06$ & $1.67 \mathrm{E}-06$ & $6.15 \mathrm{E}-06$ \\
166 & $1.71 \mathrm{E}-08$ & $4.65 \mathrm{E}-07$ & $9.21 \mathrm{E}-07$ & $3.89 \mathrm{E}-06$ \\
184 & $2.06 \mathrm{E}-09$ & $2.17 \mathrm{E}-07$ & $4.91 \mathrm{E}-07$ & $2.24 \mathrm{E}-06$ \\
202 & $4.38 \mathrm{E}-10$ & $8.97 \mathrm{E}-08$ & $2.61 \mathrm{E}-07$ & $1.21 \mathrm{E}-06$ \\
220 & $6.92 \mathrm{E}-11$ & $3.72 \mathrm{E}-08$ & $1.39 \mathrm{E}-07$ & $7.03 \mathrm{E}-07$ \\
238 & $1.94 \mathrm{E}-11$ & $1.47 \mathrm{E}-08$ & $7.22 \mathrm{E}-08$ & $4.26 \mathrm{E}-07$ \\
256 & $3.94 \mathrm{E}-12$ & $3.58 \mathrm{E}-09$ & $3.71 \mathrm{E}-08$ & $2.39 \mathrm{E}-07$ \\
274 & $8.09 \mathrm{E}-13$ & $6.15 \mathrm{E}-10$ & $1.94 \mathrm{E}-08$ & $1.33 \mathrm{E}-07$ \\
292 & & $1.96 \mathrm{E}-10$ & $1.03 \mathrm{E}-08$ & $7.36 \mathrm{E}-08$ \\
310 & & $3.58 \mathrm{E}-11$ & $5.37 \mathrm{E}-09$ & $3.78 \mathrm{E}-08$ \\
328 & & $5.68 \mathrm{E}-12$ & $2.55 \mathrm{E}-09$ & $1.74 \mathrm{E}-08$ \\
346 & & $3.78 \mathrm{E}-13$ & $1.19 \mathrm{E}-09$ & $8.79 \mathrm{E}-09$ \\
364 & & $5.73 \mathrm{E}-14$ & $4.16 \mathrm{E}-10$ & $3.00 \mathrm{E}-09$ \\
382 & & & $1.14 \mathrm{E}-10$ & \\
400 & & & $2.53 \mathrm{E}-11$ & \\
\hline
\end{tabular}

\begin{tabular}{lc}
\hline Mean Hazard Level & $\begin{array}{c}\text { Wind } \\
\text { Speed } \\
\text { [mph] }\end{array}$ \\
\hline per year & \\
\hline & \\
$2.00 \mathrm{E}-05$ & 71 \\
$2.00 \mathrm{E}-06$ & 142 \\
$1.00 \mathrm{E}-06$ & 163 \\
$1.00 \mathrm{E}-07$ & 229 \\
\hline
\end{tabular}


Table 11-9: Wind Hazard for LLNL Site

\begin{tabular}{ccccc}
\hline $\begin{array}{c}\text { Wind Speed } \\
\text { (mph) }\end{array}$ & 5th & Median & Mean & 95th \\
\hline 40 & $1.05 \mathrm{E}-04$ & $2.16 \mathrm{E}-04$ & $2.72 \mathrm{E}-04$ & $6.14 \mathrm{E}-04$ \\
58 & $6.54 \mathrm{E}-05$ & $1.40 \mathrm{E}-04$ & $1.76 \mathrm{E}-04$ & $3.92 \mathrm{E}-04$ \\
76 & $2.63 \mathrm{E}-05$ & $6.63 \mathrm{E}-05$ & $8.35 \mathrm{E}-05$ & $1.86 \mathrm{E}-04$ \\
94 & $1.39 \mathrm{E}-05$ & $3.57 \mathrm{E}-05$ & $4.58 \mathrm{E}-05$ & $1.09 \mathrm{E}-04$ \\
112 & $4.52 \mathrm{E}-06$ & $1.59 \mathrm{E}-05$ & $2.26 \mathrm{E}-05$ & $6.30 \mathrm{E}-05$ \\
130 & $1.27 \mathrm{E}-06$ & $7.63 \mathrm{E}-06$ & $1.15 \mathrm{E}-05$ & $3.57 \mathrm{E}-05$ \\
148 & $2.96 \mathrm{E}-07$ & $3.29 \mathrm{E}-06$ & $5.54 \mathrm{E}-06$ & $2.02 \mathrm{E}-05$ \\
166 & $5.53 \mathrm{E}-08$ & $1.30 \mathrm{E}-06$ & $2.62 \mathrm{E}-06$ & $1.07 \mathrm{E}-05$ \\
184 & $1.15 \mathrm{E}-08$ & $5.52 \mathrm{E}-07$ & $1.24 \mathrm{E}-06$ & $5.47 \mathrm{E}-06$ \\
202 & $1.58 \mathrm{E}-09$ & $1.85 \mathrm{E}-07$ & $5.50 \mathrm{E}-07$ & $2.76 \mathrm{E}-06$ \\
220 & $8.35 \mathrm{E}-11$ & $6.51 \mathrm{E}-08$ & $2.51 \mathrm{E}-07$ & $1.43 \mathrm{E}-06$ \\
238 & $1.64 \mathrm{E}-11$ & $2.11 \mathrm{E}-08$ & $1.12 \mathrm{E}-07$ & $6.59 \mathrm{E}-07$ \\
256 & $2.90 \mathrm{E}-12$ & $4.72 \mathrm{E}-09$ & $4.49 \mathrm{E}-08$ & $3.12 \mathrm{E}-07$ \\
274 & $3.91 \mathrm{E}-13$ & $7.60 \mathrm{E}-10$ & $1.97 \mathrm{E}-08$ & $1.46 \mathrm{E}-07$ \\
292 & & $1.27 \mathrm{E}-10$ & $9.17 \mathrm{E}-09$ & $7.25 \mathrm{E}-08$ \\
310 & & $4.53 \mathrm{E}-12$ & $3.83 \mathrm{E}-09$ & $3.10 \mathrm{E}-08$ \\
328 & & $3.54 \mathrm{E}-13$ & $1.57 \mathrm{E}-09$ & $1.20 \mathrm{E}-08$ \\
346 & & & $6.60 \mathrm{E}-10$ & $5.44 \mathrm{E}-09$ \\
364 & & & $2.06 \mathrm{E}-10$ & $1.54 \mathrm{E}-09$ \\
382 & & & $4.98 \mathrm{E}-11$ & \\
400 & & & $9.67 \mathrm{E}-12$ & \\
\hline
\end{tabular}

\begin{tabular}{lc}
\hline Mean Hazard Level & $\begin{array}{c}\text { Wind } \\
\text { Speed } \\
\text { [mph] }\end{array}$ \\
\hline per year & 115 \\
$2.00 \mathrm{E}-05$ & 172 \\
$2.00 \mathrm{E}-06$ & 189 \\
$1.00 \mathrm{E}-06$ & 240 \\
\hline
\end{tabular}


Table 11-10: Wind Hazard for NTS Site

\begin{tabular}{ccccc}
\hline $\begin{array}{c}\text { Wind Speed } \\
(\mathbf{m p h})\end{array}$ & 5th & Median & Mean & 95th \\
\hline 40 & $1.17 \mathrm{E}-06$ & $2.81 \mathrm{E}-06$ & $3.90 \mathrm{E}-06$ & $1.02 \mathrm{E}-05$ \\
58 & $6.57 \mathrm{E}-07$ & $1.54 \mathrm{E}-06$ & $2.10 \mathrm{E}-06$ & $5.39 \mathrm{E}-06$ \\
76 & $2.33 \mathrm{E}-07$ & $7.59 \mathrm{E}-07$ & $1.01 \mathrm{E}-06$ & $2.55 \mathrm{E}-06$ \\
94 & $1.08 \mathrm{E}-07$ & $3.76 \mathrm{E}-07$ & $5.33 \mathrm{E}-07$ & $1.44 \mathrm{E}-06$ \\
112 & $3.49 \mathrm{E}-08$ & $2.01 \mathrm{E}-07$ & $2.79 \mathrm{E}-07$ & $8.97 \mathrm{E}-07$ \\
130 & $1.03 \mathrm{E}-08$ & $8.74 \mathrm{E}-08$ & $1.47 \mathrm{E}-07$ & $5.07 \mathrm{E}-07$ \\
148 & $1.98 \mathrm{E}-09$ & $3.95 \mathrm{E}-08$ & $7.77 \mathrm{E}-08$ & $2.95 \mathrm{E}-07$ \\
166 & $5.81 \mathrm{E}-10$ & $1.84 \mathrm{E}-08$ & $4.23 \mathrm{E}-08$ & $1.78 \mathrm{E}-07$ \\
184 & $3.52 \mathrm{E}-11$ & $7.43 \mathrm{E}-09$ & $2.32 \mathrm{E}-08$ & $1.19 \mathrm{E}-07$ \\
202 & $6.45 \mathrm{E}-12$ & $3.10 \mathrm{E}-09$ & $1.30 \mathrm{E}-08$ & $6.67 \mathrm{E}-08$ \\
220 & $4.25 \mathrm{E}-13$ & $1.23 \mathrm{E}-09$ & $7.11 \mathrm{E}-09$ & $3.97 \mathrm{E}-08$ \\
238 & $8.97 \mathrm{E}-14$ & $4.07 \mathrm{E}-10$ & $3.50 \mathrm{E}-09$ & $2.17 \mathrm{E}-08$ \\
256 & $1.55 \mathrm{E}-14$ & $9.61 \mathrm{E}-11$ & $1.93 \mathrm{E}-09$ & $1.25 \mathrm{E}-08$ \\
274 & $1.66 \mathrm{E}-15$ & $1.49 \mathrm{E}-11$ & $9.76 \mathrm{E}-10$ & $6.54 \mathrm{E}-09$ \\
292 & & $5.18 \mathrm{E}-12$ & $6.12 \mathrm{E}-10$ & $3.84 \mathrm{E}-09$ \\
310 & & $9.82 \mathrm{E}-13$ & $3.43 \mathrm{E}-10$ & $2.42 \mathrm{E}-09$ \\
328 & & $4.93 \mathrm{E}-13$ & $2.21 \mathrm{E}-10$ & $1.53 \mathrm{E}-09$ \\
346 & & $1.32 \mathrm{E}-13$ & $9.43 \mathrm{E}-11$ & $6.54 \mathrm{E}-10$ \\
364 & & & $3.13 \mathrm{E}-11$ & $2.11 \mathrm{E}-10$ \\
382 & & & $8.42 \mathrm{E}-12$ & \\
400 & & & $1.89 \mathrm{E}-12$ & \\
\hline
\end{tabular}

\begin{tabular}{lc}
\hline $\begin{array}{l}\text { Mean Hazard Level } \\
\text { per year }\end{array}$ & $\begin{array}{c}\text { Wind Speed } \\
{[\mathrm{mph}]}\end{array}$ \\
\hline & \multicolumn{2}{c}{ Less than 40} \\
$2.00 \mathrm{E}-05$ & 59 \\
$2.00 \mathrm{E}-06$ & 76 \\
$1.00 \mathrm{E}-06$ & 141 \\
$1.00 \mathrm{E}-07$ & \\
\hline
\end{tabular}


Table 11-11: Wind Hazard for PANTEX Site

\begin{tabular}{ccccc}
\hline $\begin{array}{c}\text { Wind Speed } \\
\text { (mph) }\end{array}$ & 5th & Median & Mean & 95th \\
\hline 40 & $1.68 \mathrm{E}-03$ & $3.22 \mathrm{E}-03$ & $4.27 \mathrm{E}-03$ & $1.03 \mathrm{E}-02$ \\
58 & $9.85 \mathrm{E}-04$ & $2.07 \mathrm{E}-03$ & $2.67 \mathrm{E}-03$ & $6.39 \mathrm{E}-03$ \\
76 & $4.79 \mathrm{E}-04$ & $1.15 \mathrm{E}-03$ & $1.45 \mathrm{E}-03$ & $3.25 \mathrm{E}-03$ \\
94 & $2.62 \mathrm{E}-04$ & $6.90 \mathrm{E}-04$ & $8.79 \mathrm{E}-04$ & $2.12 \mathrm{E}-03$ \\
112 & $1.06 \mathrm{E}-04$ & $3.66 \mathrm{E}-04$ & $5.03 \mathrm{E}-04$ & $1.35 \mathrm{E}-03$ \\
130 & $3.94 \mathrm{E}-05$ & $2.14 \mathrm{E}-04$ & $2.99 \mathrm{E}-04$ & $8.44 \mathrm{E}-04$ \\
148 & $1.10 \mathrm{E}-05$ & $1.10 \mathrm{E}-04$ & $1.74 \mathrm{E}-04$ & $5.51 \mathrm{E}-04$ \\
166 & $3.87 \mathrm{E}-06$ & $5.91 \mathrm{E}-05$ & $9.99 \mathrm{E}-05$ & $3.69 \mathrm{E}-04$ \\
184 & $7.19 \mathrm{E}-07$ & $3.20 \mathrm{E}-05$ & $5.94 \mathrm{E}-05$ & $2.34 \mathrm{E}-04$ \\
202 & $2.16 \mathrm{E}-07$ & $1.47 \mathrm{E}-05$ & $3.37 \mathrm{E}-05$ & $1.47 \mathrm{E}-04$ \\
220 & $1.97 \mathrm{E}-08$ & $6.93 \mathrm{E}-06$ & $1.97 \mathrm{E}-05$ & $9.45 \mathrm{E}-05$ \\
238 & $7.26 \mathrm{E}-09$ & $3.34 \mathrm{E}-06$ & $1.15 \mathrm{E}-05$ & $5.86 \mathrm{E}-05$ \\
256 & $2.44 \mathrm{E}-09$ & $7.81 \mathrm{E}-07$ & $6.21 \mathrm{E}-06$ & $3.53 \mathrm{E}-05$ \\
274 & $5.86 \mathrm{E}-10$ & $1.32 \mathrm{E}-07$ & $3.49 \mathrm{E}-06$ & $2.12 \mathrm{E}-05$ \\
292 & & $4.96 \mathrm{E}-08$ & $2.01 \mathrm{E}-06$ & $1.22 \mathrm{E}-05$ \\
310 & & $1.65 \mathrm{E}-09$ & $1.10 \mathrm{E}-06$ & $6.59 \mathrm{E}-06$ \\
328 & & $2.89 \mathrm{E}-10$ & $6.01 \mathrm{E}-07$ & $3.68 \mathrm{E}-06$ \\
346 & & $2.66 \mathrm{E}-11$ & $3.01 \mathrm{E}-07$ & $1.92 \mathrm{E}-06$ \\
364 & & $4.46 \mathrm{E}-13$ & $1.13 \mathrm{E}-07$ & $7.22 \mathrm{E}-07$ \\
382 & & & & \\
400 & & & & \\
\hline
\end{tabular}

\begin{tabular}{ll}
\hline $\begin{array}{l}\text { Mean Hazard Level } \\
\text { per year }\end{array}$ & $\begin{array}{c}\text { Wind Speed } \\
{[\mathrm{mph}]}\end{array}$ \\
\hline & \\
$2.00 \mathrm{E}-05$ & 219 \\
$2.00 \mathrm{E}-06$ & 292 \\
$1.00 \mathrm{E}-06$ & 313 \\
$1.00 \mathrm{E}-07$ & 366 \\
\hline
\end{tabular}


Table 11-12: Wind Hazard for SNL Site

\begin{tabular}{ccccc}
\hline $\begin{array}{c}\text { Wind Speed } \\
\text { (mph) }\end{array}$ & 5th & Median & Mean & 95th \\
\hline 40 & $1.98 \mathrm{E}-04$ & $4.15 \mathrm{E}-04$ & $5.22 \mathrm{E}-04$ & $1.18 \mathrm{E}-03$ \\
58 & $1.04 \mathrm{E}-04$ & $2.46 \mathrm{E}-04$ & $3.08 \mathrm{E}-04$ & $7.18 \mathrm{E}-04$ \\
76 & $3.98 \mathrm{E}-05$ & $1.16 \mathrm{E}-04$ & $1.48 \mathrm{E}-04$ & $3.54 \mathrm{E}-04$ \\
94 & $1.88 \mathrm{E}-05$ & $5.92 \mathrm{E}-05$ & $7.80 \mathrm{E}-05$ & $2.01 \mathrm{E}-04$ \\
112 & $6.20 \mathrm{E}-06$ & $2.67 \mathrm{E}-05$ & $3.81 \mathrm{E}-05$ & $1.07 \mathrm{E}-04$ \\
130 & $1.57 \mathrm{E}-06$ & $1.28 \mathrm{E}-05$ & $1.93 \mathrm{E}-05$ & $6.12 \mathrm{E}-05$ \\
148 & $3.74 \mathrm{E}-07$ & $5.76 \mathrm{E}-06$ & $9.44 \mathrm{E}-06$ & $3.40 \mathrm{E}-05$ \\
166 & $7.78 \mathrm{E}-08$ & $2.25 \mathrm{E}-06$ & $4.58 \mathrm{E}-06$ & $1.99 \mathrm{E}-05$ \\
184 & $1.24 \mathrm{E}-08$ & $9.76 \mathrm{E}-07$ & $2.32 \mathrm{E}-06$ & $1.07 \mathrm{E}-05$ \\
202 & $1.89 \mathrm{E}-09$ & $3.67 \mathrm{E}-07$ & $1.08 \mathrm{E}-06$ & $5.18 \mathrm{E}-06$ \\
220 & $2.06 \mathrm{E}-10$ & $1.45 \mathrm{E}-07$ & $5.40 \mathrm{E}-07$ & $3.05 \mathrm{E}-06$ \\
238 & $4.46 \mathrm{E}-11$ & $5.76 \mathrm{E}-08$ & $2.68 \mathrm{E}-07$ & $1.49 \mathrm{E}-06$ \\
256 & $8.35 \mathrm{E}-12$ & $1.32 \mathrm{E}-08$ & $1.15 \mathrm{E}-07$ & $7.23 \mathrm{E}-07$ \\
274 & $2.33 \mathrm{E}-12$ & $2.41 \mathrm{E}-09$ & $5.58 \mathrm{E}-08$ & $3.63 \mathrm{E}-07$ \\
292 & & $6.40 \mathrm{E}-10$ & $2.87 \mathrm{E}-08$ & $1.97 \mathrm{E}-07$ \\
310 & & $2.14 \mathrm{E}-10$ & $1.28 \mathrm{E}-08$ & $8.73 \mathrm{E}-08$ \\
328 & & $8.22 \mathrm{E}-11$ & $5.49 \mathrm{E}-09$ & $3.99 \mathrm{E}-08$ \\
346 & & $2.89 \mathrm{E}-11$ & $2.58 \mathrm{E}-09$ & $1.89 \mathrm{E}-08$ \\
364 & & $9.96 \mathrm{E}-12$ & $8.73 \mathrm{E}-10$ & $6.17 \mathrm{E}-09$ \\
382 & & & $2.22 \mathrm{E}-10$ & \\
400 & & & $4.43 \mathrm{E}-11$ & \\
\hline
\end{tabular}

\begin{tabular}{lc}
\hline $\begin{array}{l}\text { Mean Hazard Level } \\
\text { per year }\end{array}$ & $\begin{array}{c}\text { Wind Speed } \\
\text { [mph] }\end{array}$ \\
\hline & \\
$2.00 \mathrm{E}-05$ & 129 \\
$2.00 \mathrm{E}-06$ & 187 \\
$1.00 \mathrm{E}-06$ & 204 \\
$1.00 \mathrm{E}-07$ & 259 \\
\hline
\end{tabular}


Table 11-13: Wind Hazard for SRS Site

\begin{tabular}{ccccc}
\hline $\begin{array}{c}\text { Wind Speed } \\
\text { (mph) }\end{array}$ & 5th & Median & Mean & 95th \\
\hline 40 & $9.96 \mathrm{E}-04$ & $1.89 \mathrm{E}-03$ & $2.49 \mathrm{E}-03$ & $6.06 \mathrm{E}-03$ \\
58 & $7.31 \mathrm{E}-04$ & $1.44 \mathrm{E}-03$ & $1.87 \mathrm{E}-03$ & $4.48 \mathrm{E}-03$ \\
76 & $3.00 \mathrm{E}-04$ & $6.84 \mathrm{E}-04$ & $8.70 \mathrm{E}-04$ & $2.00 \mathrm{E}-03$ \\
94 & $1.64 \mathrm{E}-04$ & $4.15 \mathrm{E}-04$ & $5.36 \mathrm{E}-04$ & $1.32 \mathrm{E}-03$ \\
112 & $5.78 \mathrm{E}-05$ & $1.96 \mathrm{E}-04$ & $2.75 \mathrm{E}-04$ & $7.60 \mathrm{E}-04$ \\
130 & $1.63 \mathrm{E}-05$ & $1.00 \mathrm{E}-04$ & $1.52 \mathrm{E}-04$ & $4.58 \mathrm{E}-04$ \\
148 & $2.96 \mathrm{E}-06$ & $4.83 \mathrm{E}-05$ & $7.88 \mathrm{E}-05$ & $2.76 \mathrm{E}-04$ \\
166 & $6.17 \mathrm{E}-07$ & $2.05 \mathrm{E}-05$ & $3.89 \mathrm{E}-05$ & $1.59 \mathrm{E}-04$ \\
184 & $5.49 \mathrm{E}-08$ & $9.19 \mathrm{E}-06$ & $1.98 \mathrm{E}-05$ & $8.80 \mathrm{E}-05$ \\
202 & $7.13 \mathrm{E}-09$ & $3.24 \mathrm{E}-06$ & $9.24 \mathrm{E}-06$ & $4.84 \mathrm{E}-05$ \\
220 & $5.72 \mathrm{E}-10$ & $1.13 \mathrm{E}-06$ & $4.34 \mathrm{E}-06$ & $2.28 \mathrm{E}-05$ \\
238 & $8.21 \mathrm{E}-11$ & $3.74 \mathrm{E}-07$ & $2.00 \mathrm{E}-06$ & $1.12 \mathrm{E}-05$ \\
256 & $8.32 \mathrm{E}-12$ & $6.61 \mathrm{E}-08$ & $7.92 \mathrm{E}-07$ & $5.01 \mathrm{E}-06$ \\
274 & $6.87 \mathrm{E}-13$ & $8.50 \mathrm{E}-09$ & $3.43 \mathrm{E}-07$ & $2.08 \mathrm{E}-06$ \\
292 & $2.65 \mathrm{E}-14$ & $1.97 \mathrm{E}-09$ & $1.62 \mathrm{E}-07$ & $9.03 \mathrm{E}-07$ \\
310 & & $4.52 \mathrm{E}-10$ & $7.58 \mathrm{E}-08$ & $4.19 \mathrm{E}-07$ \\
328 & & $1.38 \mathrm{E}-10$ & $3.17 \mathrm{E}-08$ & $1.96 \mathrm{E}-07$ \\
346 & & $3.87 \mathrm{E}-11$ & $1.17 \mathrm{E}-08$ & $8.43 \mathrm{E}-08$ \\
364 & & $8.00 \mathrm{E}-12$ & $3.31 \mathrm{E}-09$ & $1.93 \mathrm{E}-08$ \\
382 & & & $7.42 \mathrm{E}-10$ & \\
400 & & & $1.37 \mathrm{E}-10$ & \\
\hline
\end{tabular}

\begin{tabular}{lc}
\hline $\begin{array}{l}\text { Mean Hazard Level } \\
\text { per year }\end{array}$ & $\begin{array}{c}\text { Wind Speed } \\
\text { [mph] }\end{array}$ \\
\hline & \\
$2.00 \mathrm{E}-05$ & 184 \\
$2.00 \mathrm{E}-06$ & 238 \\
$1.00 \mathrm{E}-06$ & 251 \\
$1.00 \mathrm{E}-07$ & 303 \\
\hline
\end{tabular}


Table 11-14: Wind Hazard for OAKRIDGE Site

\begin{tabular}{ccccc}
\hline $\begin{array}{c}\text { Wind Speed } \\
\text { (mph) }\end{array}$ & 5th & Median & Mean & 95th \\
\hline 40 & $1.01 \mathrm{E}-03$ & $2.03 \mathrm{E}-03$ & $2.60 \mathrm{E}-03$ & $6.29 \mathrm{E}-03$ \\
58 & $7.48 \mathrm{E}-04$ & $1.55 \mathrm{E}-03$ & $1.97 \mathrm{E}-03$ & $4.58 \mathrm{E}-03$ \\
76 & $3.44 \mathrm{E}-04$ & $8.00 \mathrm{E}-04$ & $1.01 \mathrm{E}-03$ & $2.29 \mathrm{E}-03$ \\
94 & $2.03 \mathrm{E}-04$ & $5.38 \mathrm{E}-04$ & $6.68 \mathrm{E}-04$ & $1.56 \mathrm{E}-03$ \\
112 & $8.21 \mathrm{E}-05$ & $2.92 \mathrm{E}-04$ & $3.86 \mathrm{E}-04$ & $1.00 \mathrm{E}-03$ \\
130 & $3.28 \mathrm{E}-05$ & $1.73 \mathrm{E}-04$ & $2.40 \mathrm{E}-04$ & $6.76 \mathrm{E}-04$ \\
148 & $8.84 \mathrm{E}-06$ & $9.19 \mathrm{E}-05$ & $1.42 \mathrm{E}-04$ & $4.40 \mathrm{E}-04$ \\
166 & $2.71 \mathrm{E}-06$ & $4.79 \mathrm{E}-05$ & $8.17 \mathrm{E}-05$ & $2.88 \mathrm{E}-04$ \\
184 & $5.22 \mathrm{E}-07$ & $2.44 \mathrm{E}-05$ & $4.86 \mathrm{E}-05$ & $1.83 \mathrm{E}-04$ \\
202 & $1.25 \mathrm{E}-07$ & $1.09 \mathrm{E}-05$ & $2.70 \mathrm{E}-05$ & $1.14 \mathrm{E}-04$ \\
220 & $7.32 \mathrm{E}-09$ & $4.87 \mathrm{E}-06$ & $1.51 \mathrm{E}-05$ & $7.14 \mathrm{E}-05$ \\
238 & $2.10 \mathrm{E}-09$ & $2.03 \mathrm{E}-06$ & $8.61 \mathrm{E}-06$ & $4.33 \mathrm{E}-05$ \\
256 & $4.93 \mathrm{E}-10$ & $4.12 \mathrm{E}-07$ & $4.20 \mathrm{E}-06$ & $2.15 \mathrm{E}-05$ \\
274 & $1.02 \mathrm{E}-10$ & $6.14 \mathrm{E}-08$ & $2.25 \mathrm{E}-06$ & $1.16 \mathrm{E}-05$ \\
292 & & $1.84 \mathrm{E}-08$ & $1.24 \mathrm{E}-06$ & $7.22 \mathrm{E}-06$ \\
310 & & $5.53 \mathrm{E}-09$ & $6.58 \mathrm{E}-07$ & $3.63 \mathrm{E}-06$ \\
328 & & $2.37 \mathrm{E}-09$ & $3.20 \mathrm{E}-07$ & $1.93 \mathrm{E}-06$ \\
346 & & $9.24 \mathrm{E}-10$ & $1.37 \mathrm{E}-07$ & $8.33 \mathrm{E}-07$ \\
364 & & $2.65 \mathrm{E}-10$ & $4.50 \mathrm{E}-08$ & $3.04 \mathrm{E}-07$ \\
382 & & & $1.18 \mathrm{E}-08$ & \\
400 & & & $2.55 \mathrm{E}-09$ & \\
\hline
\end{tabular}

\begin{tabular}{ll}
\hline $\begin{array}{l}\text { Mean Hazard Level } \\
\text { per year }\end{array}$ & $\begin{array}{c}\text { Wind Speed } \\
\text { [mph] }\end{array}$ \\
\hline & \\
$2.00 \mathrm{E}-05$ & 211 \\
$2.00 \mathrm{E}-06$ & 277 \\
$1.00 \mathrm{E}-06$ & 298 \\
$1.00 \mathrm{E}-07$ & 351 \\
\hline
\end{tabular}


Figure 11-1

\section{LANL Wind Hazard \\ $300^{\prime} \times 300^{\prime}$ Areas at $37.68^{\circ} \mathrm{N} 121.70^{\circ} \mathrm{W}$}

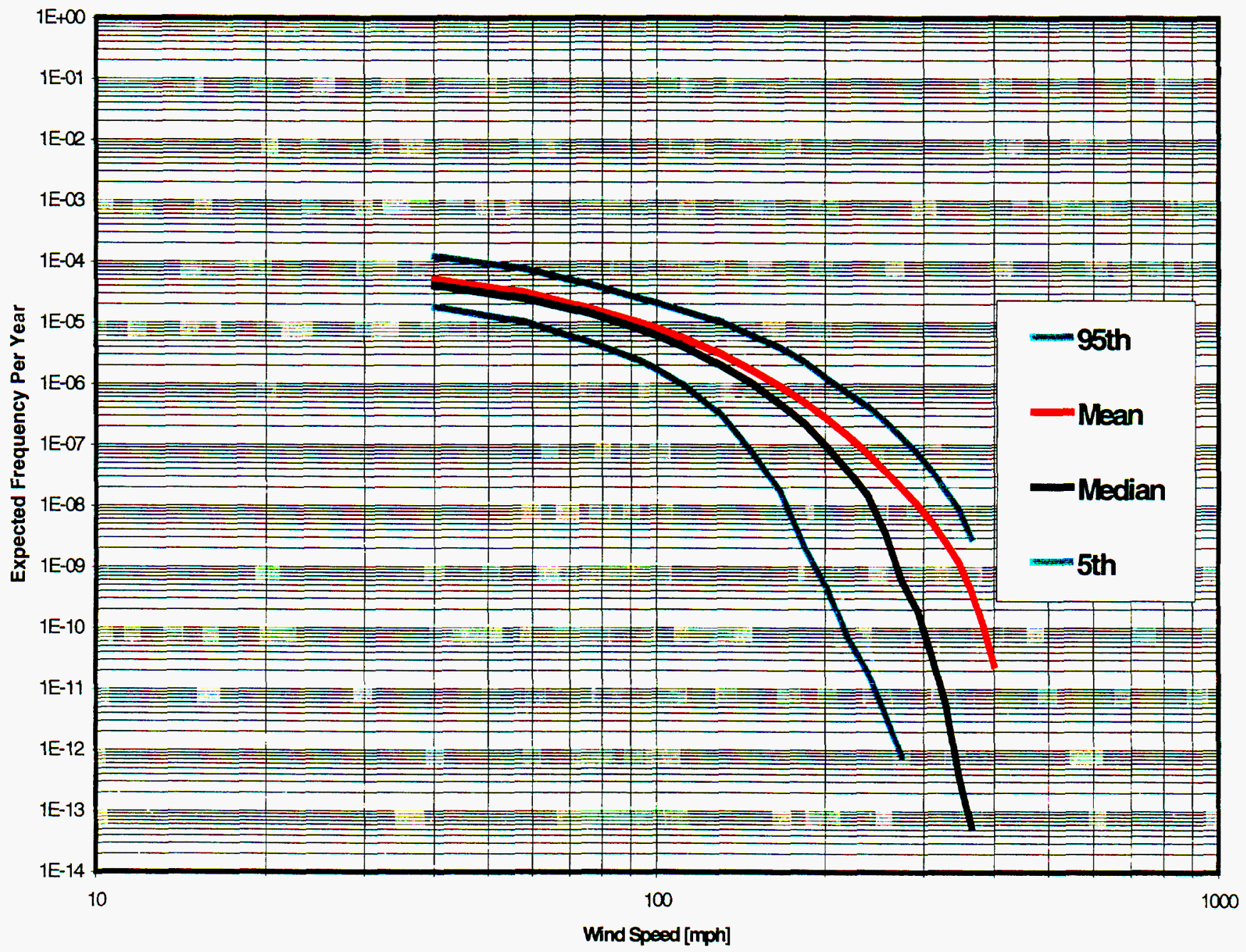


Figure 11-2

\section{UNL Wind Hazerd \\ $300^{\prime} \times 300^{\prime}$ Areas at $37.68^{\circ} \mathrm{N} 121.70^{\circ} \mathrm{W}$}

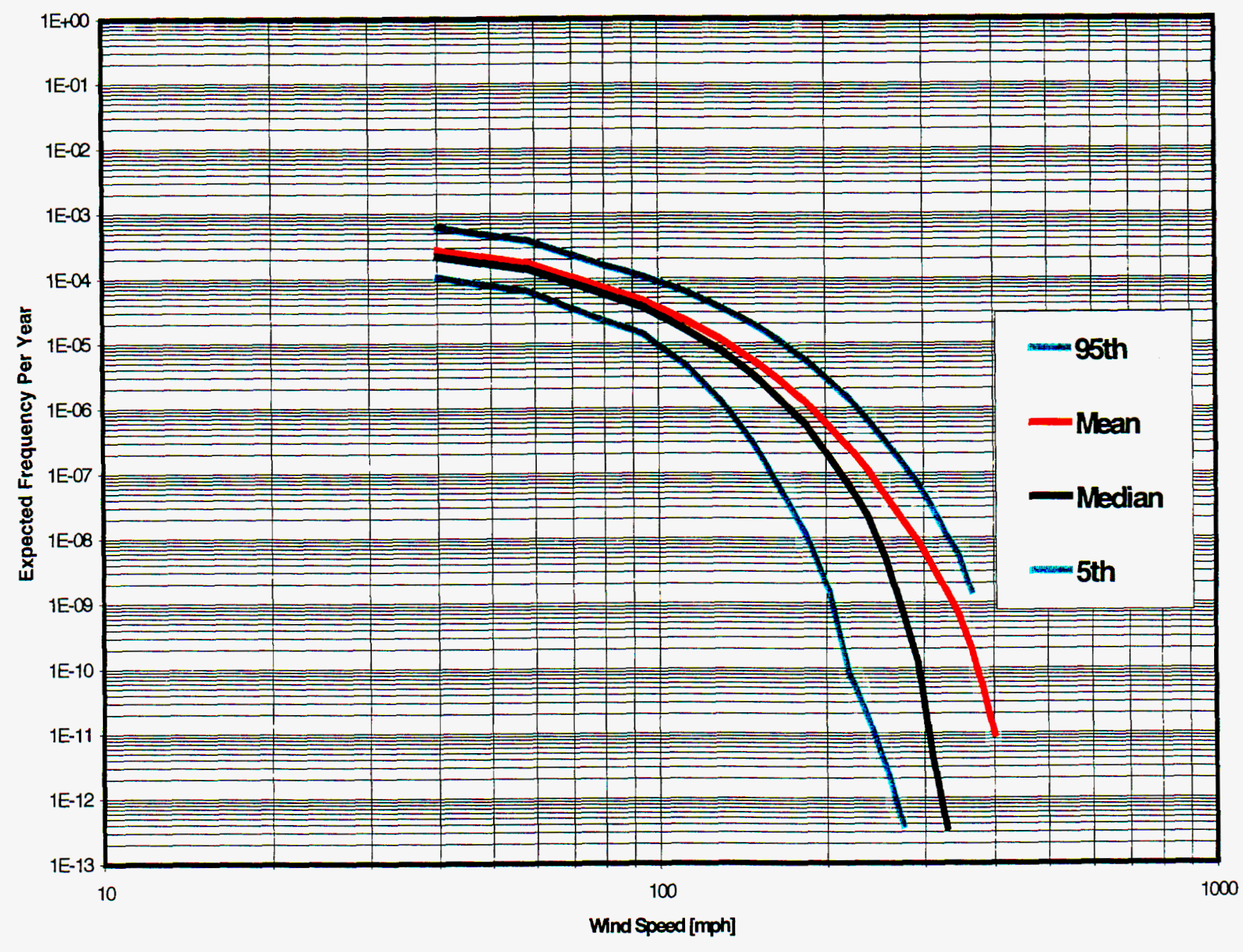


Figure 11-3

\section{NTS Wind Hazard \\ $300^{\circ} \times 300^{\prime}$ Areas at $36.78^{\circ} \mathrm{N} 116.12^{\circ} \mathrm{W}$}

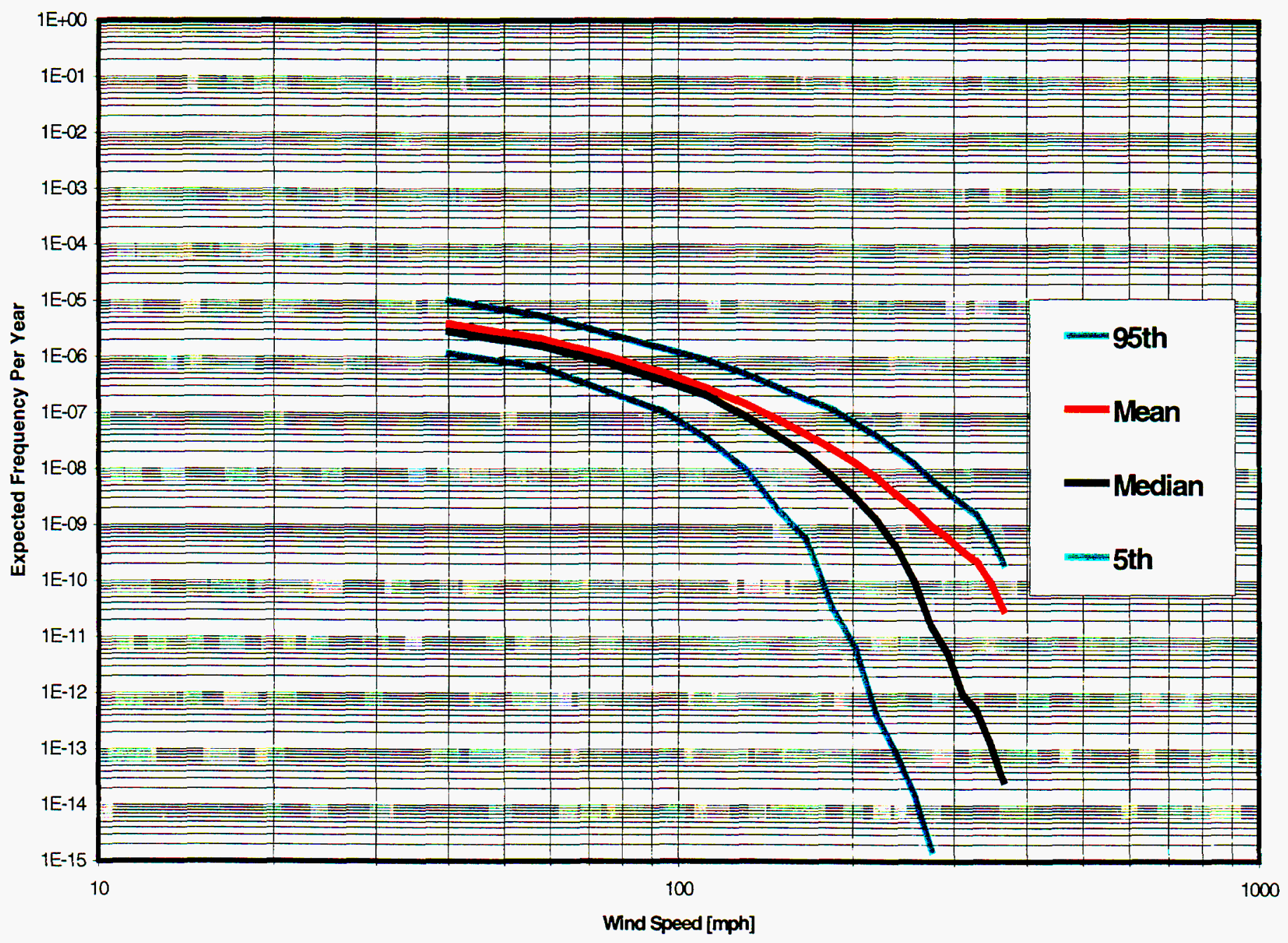


Figure 11-4

\section{Pantex Wind Hazard}

$300^{\prime} \times 300^{\prime}$ Areas at $35.32^{\circ} \mathrm{N} 101.56^{\circ} \mathrm{W}$




Figure 11-5

\section{SNL Wind Hazerd \\ $300^{\prime} \times 300^{\prime}$ Areas at $35.00^{\circ} \mathrm{N} 106.53^{\circ} \mathrm{W}$}




Figure 11-6

\section{SRS Wind Hazard \\ $300^{\prime} \times 300^{\prime}$ Areas at $33.25^{\circ} \mathrm{N} 81.63^{\circ} \mathrm{W}$}

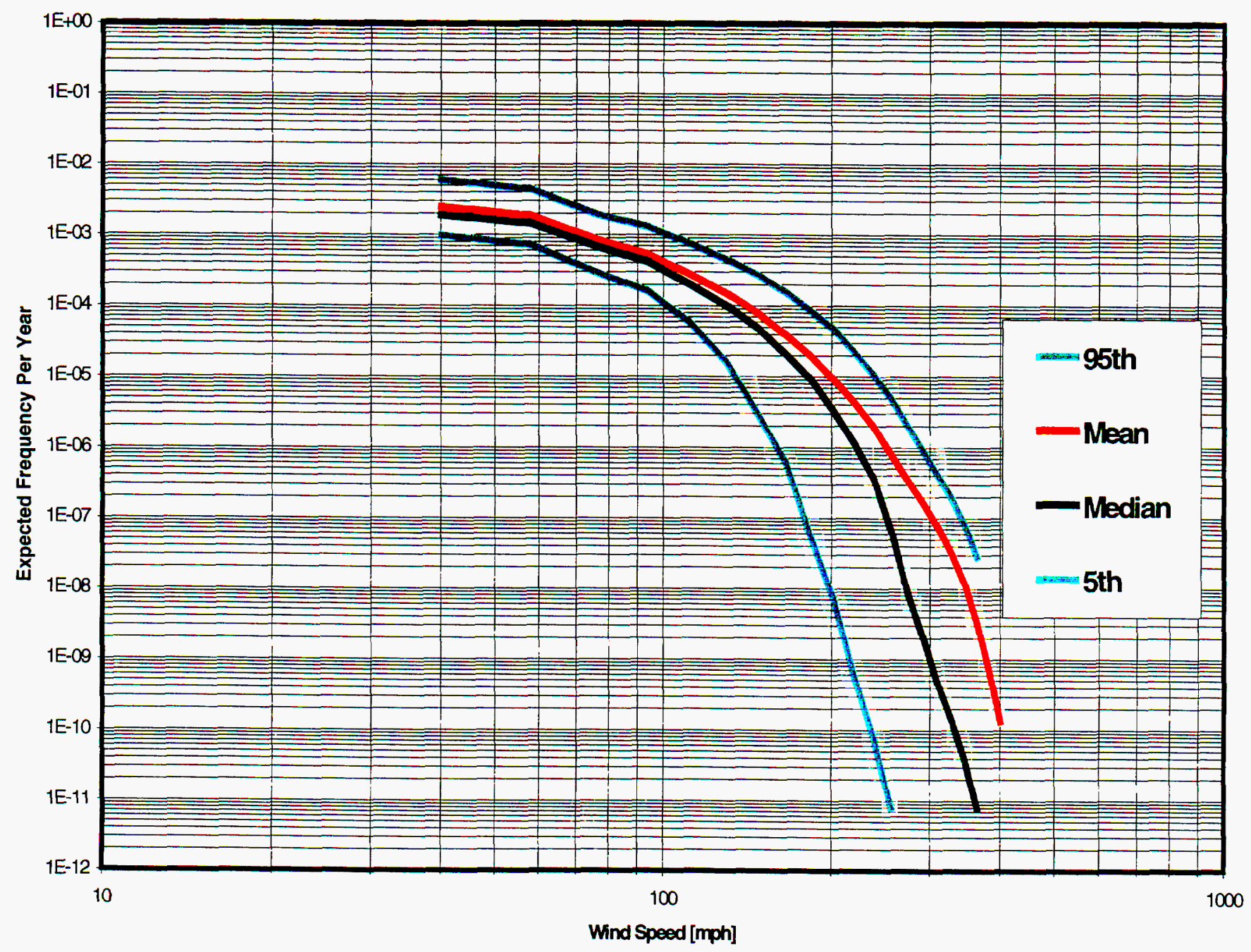


Figure 11-7

\section{Oakridge Wind Hazard \\ $300^{\prime} \times 300^{\prime}$ Areas at $35.95^{\circ} \mathrm{N} 84.32^{\circ} \mathrm{W}$}

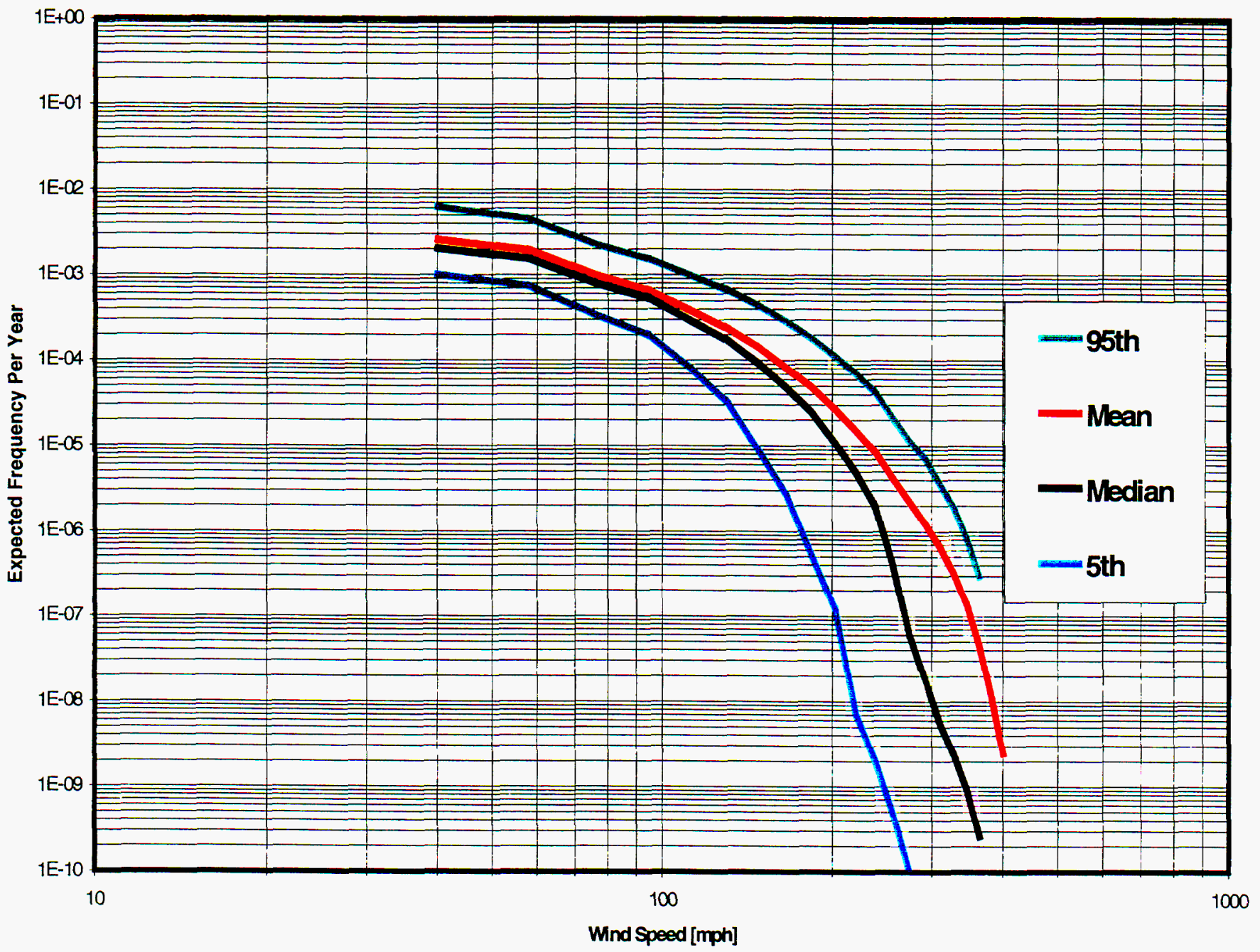




\section{0 Third DOE/LLNL Tornado Wind Hazard Workshop}

\subsection{Purpose of Workshop}

The Third DOE/LLNL Tornado Wind Hazard Workshop was held in Washington DC on April 3 and 4, 2000. The purpose of the workshop included (1) resolution of the experts' comments on the Draft Final Report (2) presentation and review of the results of several sensitivity analyses (3) review and discussion of the experts' initial judgements about the model parameters (4) elicitation of revisions to the experts' judgements about the model parameters and (5) elicitation of future model enhancements. A detailed summary of the workshop proceedings is included in Appendix IX, which also includes the workshop purpose, agenda and attendees.

\subsection{Summary of Workshop Proceedings}

\subsubsection{Resolution of Experts' Comments}

The LLNL Team submitted the initial draft of the Final Report, dated Sept. 9, 1999, to the panel members for their review and comments. After accumulating the comments from all reviewers, the LLNL Team prepared an updated version of the Draft Final Report, dated March 24, 2000, which represented the Team's resolution of the initial comments. This revision was submitted to the panel prior to the workshop for their review. In the first session of the workshop the panel members provided their reactions and critiques of the revised Draft Report. Several open issues and unresolved comments were identified and discussed. The issues identified are included in the workshop summary in Appendix IX. Agreement was reached on the resolution of these open issues. The current version of the Final Report reflects the resolution of these issues.

\subsubsection{Review of Sensitivity Analyses}

As part of the testing, analysis and verification of the model and TORNADO code, tornado wind hazard curves were developed for a number of DOE and other generic sites throughout the U.S. Also, a series of analyses were run to assess the sensitivity of the hazard to variation in each of the model parameters. In these analyses, separate runs were made with one parameter at an extreme value with the remaining parameters at a nominal value. Thus, the sensitivity of the hazard to the range of values, derived from the experts' judgements about the model parameters, of each parameter was assessed. The results of these test runs were presented to the panel for discussion.

One parameter identified as being significant was the size of the area used to develop the site-specific intensity distribution. Of particular concern was the possibility that using large areas, e.g., $5^{\circ} \times 5^{\circ}$, resulted in unrealistically high intensity events being associated with some sites. This could occur at sites at which the geographical and/or meteorological environments would not support the occurrence of such severe tornadoes. This raised the 
more general question of how to identify and model the existence of physical 'barriers' to the occurrence of tornadoes or tornadoes of higher intensities. Although this is recognized as an important issue to developing realistic tornado wind hazard curves at some locations, it could be a complex issue with no ready solution. It has been identified for future enhancements to the model.

Another issue identified in the review of the sensitivity analyses was the impact of the number and quality of the information in the database of historical tornadoes. This was highlighted by an analysis, provided by Joe Schaeffer, of the relative frequency of intensities over time. A significant change occurs around 1978, when there was a change in the sources of the intensity estimates. This led the panel to recommend that the time periods of historical tornadoes used to estimate some of the model parameters be different for the different intensities. This is further described below in the discussion of review and re-elicitation of the experts' judgements about the model parameters.

\subsubsection{Discussion of the Experts' Initial Judgements About the Model Parameters}

The first model parameter considered was the expected value of the annual frequency of tornadoes occurring in the contiguous U.S. In the review it was emphasized that it is important to distinguish between (1) the realized number of tornadoes each year, which represents the year to year variation of the assumed Poisson process and (2) the parameter of the Poisson process, the expected number per year. The value of the latter is what is being elicited. A good estimate of the expected value is the 'long-term' per year average number of historical events. Any uncertainty in estimating this parameter should reflect the uncertainties associated with using the historical data as a basis of estimation.

The next two parameters considered were the size of the area surrounding a site used to estimate the site-specific intensity distribution and the time period of historical events to use for the estimation. Regarding the former, it was generally agreed that, because of the number of historical events, smaller areas would be appropriate for sites in the East and larger areas are necessary for sites in the West. An important observation made by Joe Schaeffer was that the relative frequencies between low and high intensity historical events changes in the mid-seventies, about the time of a change in the source of the estimates. Based on this observation and the recognition that there are relatively few historical high intensity events, the panel suggested that separate time periods be considered for intensities F0-F2 and F3-F5.

The next parameter discussed was the misclassification matrix and the associated models of the random encounter errors and direct classification errors. It was generally agreed that the current models for the random encounter errors, in which the true intensity could be any level higher than the recorded intensity, were unrealistic. The general perception was that a better model would limit the true intensity to be no more than two levels higher than the recorded intensity. The panel proposed that such a model be considered. Thus, such a model was developed and is included in the revised default model parameter and distribution file. 
The F-scale intensity to wind speed relation was the next parameter considered. Two general perceptions arose during the discussion. One was that the wind speeds associated with the higher intensities were too high in the Fujita relation and too low in the two Twisdale relations. The second issue discussed was the ranges of wind speeds associated with the intensity values. In general, it was perceived that the greater the damage the greater the uncertainty in determining the velocities of the winds causing the damage. Thus, it was perceived that the ranges of wind speeds should increase with increasing intensity. Based on these perceptions, the panel proposed a revised relation:

\begin{tabular}{|c|c|}
\hline Intensity & $\begin{array}{c}\text { Wind Speeds } \\
(\mathrm{mph})\end{array}$ \\
\hline F0 & $(40,75]$ \\
\hline F1 & $(75,105]$ \\
\hline F2 & $(105,135]$ \\
\hline F3 & $(135,170]$ \\
\hline F4 & $(170,215]$ \\
\hline F5 & $(215,270]$ \\
\hline F6 & $(270,330]$ \\
\hline
\end{tabular}

This relation, labeled P2000, replaced the Twisdale-uniform relation in the re-elicitation.

The next parameter discussed was the damage area (length, width) distribution. The LLNL Team proposed the following set of bins for developing the empirical joint distributions of (length, width):

\begin{tabular}{|l|l|}
\hline Length (miles) & Width (feet) \\
\hline$(0,1]$ & $(0,10]$ \\
\hline$(1,5]$ & $(10,100]$ \\
\hline$(5,15]$ & $(100,500]$ \\
\hline$(15,25]$ & $(500,1320]$ \\
\hline$(25,100]$ & $(1320,5280]$ \\
\hline$(100,400]$ & $(5280,21120]$ \\
\hline
\end{tabular}

The panel also recognized the need to consider different time periods for developing the damage area (length, width) distributions for different intensity levels. This is reflected in the revised default mode parameter input files.

There were no significant issues identified related to the tornado path heading distribution and wind field within the damage area parameters.

\subsection{Second Elicitation of the Experts' Judgements About the Model Parameters}

Following the discussion of the experts' initial inputs about the model parameters, a follow-up questionnaire was provided to the panelists to give them the opportunity to revise their initial judgements about the model parameters. This was done in an open 
format in which questions could be raised and issues discussed as deemed appropriate. This provided the benefit of questionable issues being clarified immediately and also provided everyone the opportunity to have their views heard by everyone. However, in the end the responses provided by each expert was his own. This method of elicitation proved to be an efficient way to perform the second round of elicitation.

\subsection{Summary and Application of Elicited Inputs}

A summary of the experts' responses to the questions regarding the input parameters for the tornado wind hazard model is included as an Attachment to the Third Tornado Wind Hazard Workshop Summary included in the Report as Appendix IX. Overall, there is much more consistency in the experts' judgements about the parameters compared to the original elicitation. Certainly, the presentation of the results and sensitivity analyses, as well as the resulting discussion, at the third workshop contributed to this convergence of judgements among the panel. Thus, it bears out the importance of the follow-up workshop and the desirability of giving the experts' an opportunity to reflect on their initial judgements, given the chance to see the impact of their initial views about the model parameters.

The inputs elicited from the panel were combined to develop uncertainty distributions, i.e., in most cases, weights associated with alternative values of the model parameters and probability distributions, for each of the model parameters. The experts' judgements were combined based on equal weighting of the panelists. Default input files, included in Appendix X, were developed based on the uncertainty distributions derived from the elicited judgements. Avoiding any major change in the TORNADO code, the revised input files were structured to have the same format and number of alternative values of the model parameters. As discussed below, this precluded full implementation of some of the suggested modifications to the model discussed at the workshop. It also required some analyst's judgement to interpret the experts' inputs, based on the modifications, and to apply the inputs to the current version of TORNADO.

The following subsections summarize the uncertainty distributions, based on the revised elicited judgements, as applied to developing the default-input files for the current version of TORNADO. 


\subsubsection{Expected Frequency of Tornadoes (per year)}

\begin{tabular}{|l|l|}
\hline $\begin{array}{l}\text { Expected } \\
\text { Frequency, } \mathrm{v}\end{array}$ & $\mathrm{P}($ Exp. Freq. <= v) \\
\hline 600 & 0.00 \\
\hline 700 & 0.01 \\
\hline 800 & 0.03 \\
\hline 900 & 0.13 \\
\hline 1000 & 0.30 \\
\hline 1100 & 0.57 \\
\hline 1200 & 0.74 \\
\hline 1300 & 0.88 \\
\hline 1400 & 0.95 \\
\hline 1500 & 0.99 \\
\hline 1600 & 1.00 \\
\hline
\end{tabular}

\subsubsection{Size of the Site-Specific Intensity Distribution Area}

Separate distributions for the area size were developed for locations in the East and West. In recognition of the potential effect of the Rocky Mountains on the touch down locations and travel paths of tornadoes, the division of the contiguous U.S. into east and west was redefined by roughly following the Continental Divide.

\begin{tabular}{|c|c|c|}
\hline & East & West \\
\hline Size (degree) & \multicolumn{2}{|c|}{ Probability } \\
\hline $2 \times 2$ & 0.82 & \\
\hline $3 \times 3$ & 0.18 & 0.22 \\
\hline $5 \times 5$ & & 0.78 \\
\hline
\end{tabular}

\subsubsection{Time Period of Historical Tornadoes Used to Develop the Site Specific Intensity Distribution}

This is not used in the current code, which is hard-wired to use all the historical events in the available database. The panel decided the distributions of the time periods should depend on the intensity level of the tornadoes, as indicated in the following table.

\begin{tabular}{|l|l|l|}
\hline & F0-F2 & F3-F5 \\
\hline Time Period & \multicolumn{2}{|c|}{ Probability } \\
\hline $1950-98$ & & 1.00 \\
\hline $1970-98$ & 0.12 & \\
\hline $1978-98$ & 0.64 & \\
\hline $1990-98$ & 0.24 & \\
\hline
\end{tabular}




\subsubsection{Misclassification Matrix}

The random encounter error matrix based on the limitation imposed by the panel at the workshop is labeled D1.

\begin{tabular}{|l|l|}
\hline Matrix Pair & Probability \\
\hline $\mathrm{A} 1, \mathrm{~A} 2(0.9)$ & 0.05 \\
\hline $\mathrm{C} 1, \mathrm{~A} 2$ & 0.21 \\
\hline $\mathrm{D} 1, \mathrm{~A} 2$ & 0.74 \\
\hline
\end{tabular}

\subsubsection{F-Scale Intensity to Wind Speed Relation}

Only the Fujita and the relation developed by the panel, labeled P2000, were given weights by the panelists.

\begin{tabular}{|l|l|}
\hline Relation & Probability \\
\hline Fujita & 0.16 \\
\hline P2000 & 0.84 \\
\hline
\end{tabular}

\subsubsection{Path Heading}

Because there is a difference of judgements among the experts whether the path heading distribution is regionally dependent, two types of distributions, one regional and the second common to both regions, are applied at a site. The uncertainty distributions associated with this parameter are given in the table below.

\begin{tabular}{|l|l|l|}
\hline Time Period & Type & Probability \\
\hline $1953-98$ & CONUS & 0.192 \\
\hline & East/West & 0.288 \\
\hline $1960-98$ & CONUS & 0.064 \\
\hline & East/West & 0.096 \\
\hline $1978-98$ & CONUS & 0.144 \\
\hline & East/West & 0.216 \\
\hline
\end{tabular}

\subsubsection{Damage Area (Length, Width) Distribution}

Again, because of the numbers and perceived quality of historical damage area data, it was considered appropriate to use different time periods for the different intensity levels: 


\begin{tabular}{|l|l|l|l|}
\hline & F0-F1 & F2-F3 & F4-F5 \\
\hline Time Period & \multicolumn{3}{|c|}{ Probability } \\
\hline $1950-98$ & 0.02 & 0.02 & 0.84 \\
\hline $1960-98$ & 0.02 & 0.15 & 0.04 \\
\hline $1970-98$ & 0.34 & 0.60 & 0.12 \\
\hline $1978-98$ & 0.62 & 0.23 & \\
\hline
\end{tabular}

Because the current version of TORNADO limits the inputs to three sets of length, width distributions, the following combinations were developed for the revised default file.

\begin{tabular}{|l|l|l|l|}
\hline F0-F1 & F2-F3 & F4-F5 & Probability \\
\hline \multicolumn{3}{|c|}{ Time Period } & \\
\hline $1978-98$ & $1978-98$ & $1950-98$ & 0.271 \\
\hline $1978-98$ & $1973-98$ & $1950-98$ & 0.706 \\
\hline $1973-98$ & $1960-98$ & $1960-98$ & 0.023 \\
\hline
\end{tabular}

\subsubsection{Wind Field Distribution}

\begin{tabular}{|l|l|}
\hline $\begin{array}{l}\text { Length, Width } \\
\text { Matrices }\end{array}$ & Probability \\
\hline L1, W2 & 0.284 \\
\hline L1, W4 & 0.124 \\
\hline L1, W6 & 0.042 \\
\hline L2, W2 & 0.124 \\
\hline L2, W4 & 0.198 \\
\hline L2, W6 & 0.118 \\
\hline L3, W2 & 0.052 \\
\hline L3, W4 & 0.038 \\
\hline L3, W6 & 0.020 \\
\hline
\end{tabular}

Because the current version of TORNADO requires that the uncertainty distributions for the length and width matrices be independent, the following distributions were developed for the default-input files.

\begin{tabular}{|l|l|l|l|}
\hline Matrix & Probability & Matrix & Probability \\
\hline L1 & 0.45 & W2 & 0.46 \\
\hline L2 & 0.44 & W4 & 0.36 \\
\hline L3 & 0.11 & W6 & 0.18 \\
\hline
\end{tabular}




\subsection{Estimated Tornado Wind Hazard at Selected DOE Sites and US Cities}

Most of the changes in the hazard model and in the TORNADO code that were necessary to incorporate the revised inputs from the Expert panel members (received from the second elicitation during the Third Workshop) were made (see Section 12 above) and the hazards for the selected DOE sites and cities in the continental United States (see Sections 10.4.1 and 11.0) were recalculated. The resulting hazard curves are shown in Figures 13-1 through 13-14. Tornado wind speeds at different hazard or annual exceedance probability levels are given in Tables 13-1 and 13-2. 
Table 13-1

Tornado Wind Speed (mph) for Selected DOE Sites

\begin{tabular}{|c|c|c|c|c|c|c|c|}
\hline $\begin{array}{c}\text { Hazard } \\
\text { Freq.* }\end{array}$ & LANL & LLNL & NTS & Oakridge & Pantex & SNL & SRS \\
\hline 1.0E-01 & N/A & N/A & N/A & N/A & N/A & N/A & N/A \\
\hline 1.0E-02 & N/A & N/A & N/A & N/A & N/A & N/A & N/A \\
\hline 1.0E-03 & N/A & N/A & N/A & 83.2 & 89.9 & N/A & 79.2 \\
\hline 1.0E-04 & N/A & 73.3 & N/A & 155.3 & 153.4 & 80.6 & 136.1 \\
\hline 1.0E-05 & 76.6 & 121.7 & N/A & 217.0 & 210.8 & 125.7 & 182.7 \\
\hline 1.0E-06 & 129.3 & 160.5 & 74.7 & 270.9 & 262.7 & 164.9 & 227.9 \\
\hline 1.0E-07 & 173.8 & 195.7 & 121.8 & 315.1 & 304.5 & $\mathbf{2 0 2 . 8}$ & $\mathbf{2 7 1 . 4}$ \\
\hline
\end{tabular}

*Annual Exceedance Probability

Table 13-2

Tornado Wind Speed (mph) for Selected Cities in the Continental United States

\begin{tabular}{|c|c|c|c|c|c|c|c|}
\hline $\begin{array}{c}\text { Hazard } \\
\text { Freq.* }\end{array}$ & Boston & Detroit & $\begin{array}{c}\text { New } \\
\text { Orleans }\end{array}$ & $\begin{array}{c}\text { Oaklahoma } \\
\text { City }\end{array}$ & Pierre & $\begin{array}{c}\text { Salt } \\
\text { Lake } \\
\text { City }\end{array}$ & $\begin{array}{c}\text { Wash. } \\
\text { DC }\end{array}$ \\
\hline 1.0E-01 & N/A & N/A & N/A & N/A & N/A & N/A & N/A \\
\hline 1.0E-02 & N/A & N/A & N/A & 40.5 & N/A & N/A & N/A \\
\hline 1.0E-03 & 76.4 & 101.9 & 90.1 & 11.4 & 40.9 & N/A & 73.3 \\
\hline 1.0E-04 & 141.1 & 167.5 & 141.3 & 178.8 & 115.6 & 93.4 & 130.4 \\
\hline 1.0E-05 & 202.5 & 230.7 & 185.3 & 239.0 & 178.7 & 134.9 & 176.1 \\
\hline 1.0E-06 & 252.9 & 292.8 & 227.6 & 298.0 & $\mathbf{2 4 4 . 4}$ & $\mathbf{1 7 1 . 3}$ & $\mathbf{2 2 1 . 9}$ \\
\hline 1.0E-07 & 300.4 & 330 & 268.7 & 330 & 309.7 & $\mathbf{2 0 8 . 0}$ & $\mathbf{2 6 7 . 5}$ \\
\hline
\end{tabular}

* Annual Exceedance Probability 
Figure 13-1

\section{LOS ALAMOS NATIONAL LABORATORY Wind Hazard}

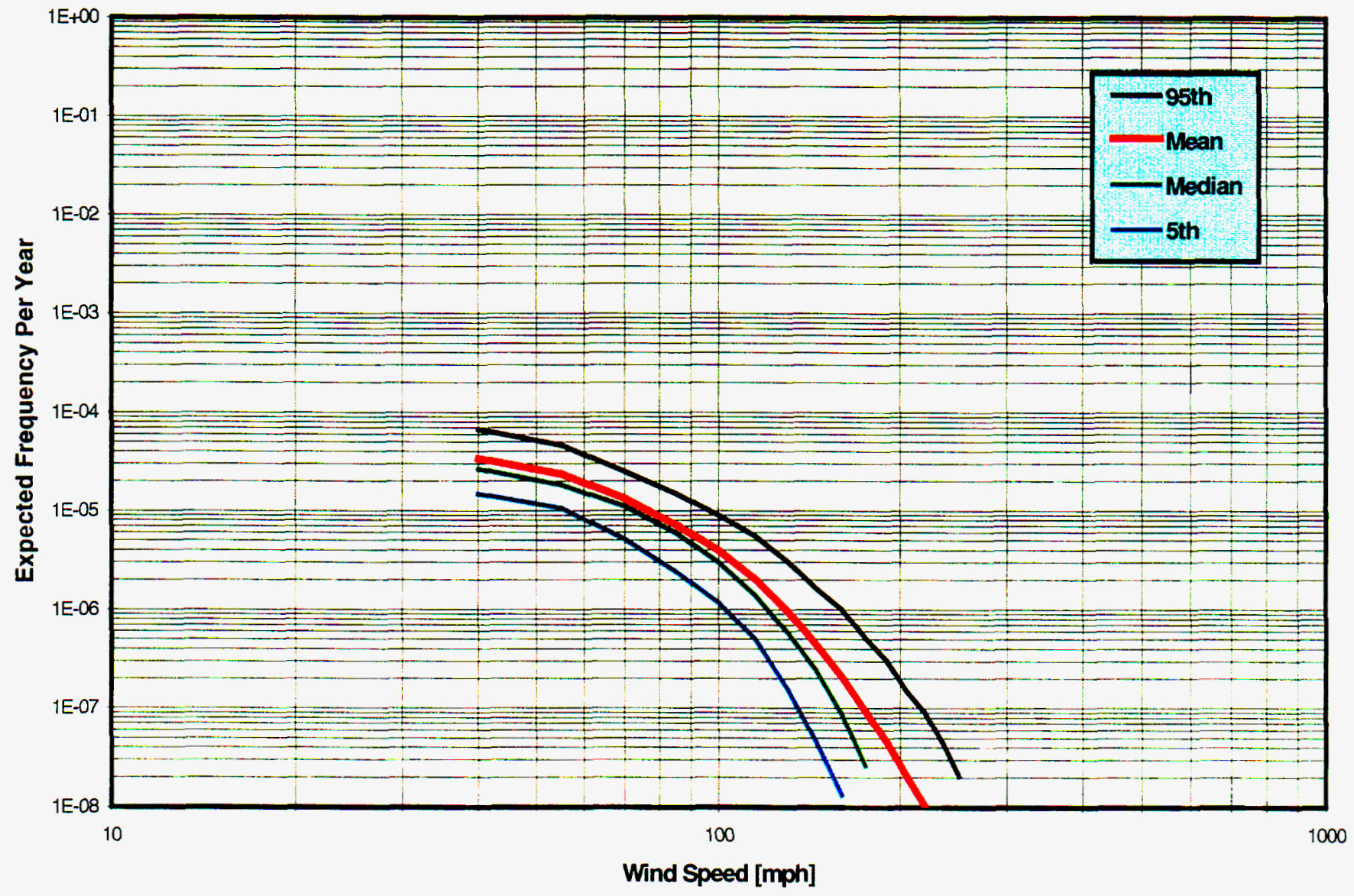


Figure 13-2

\section{LAWRENCEUMEMMOPENATIONAL LABORATORY Wind Hezard}

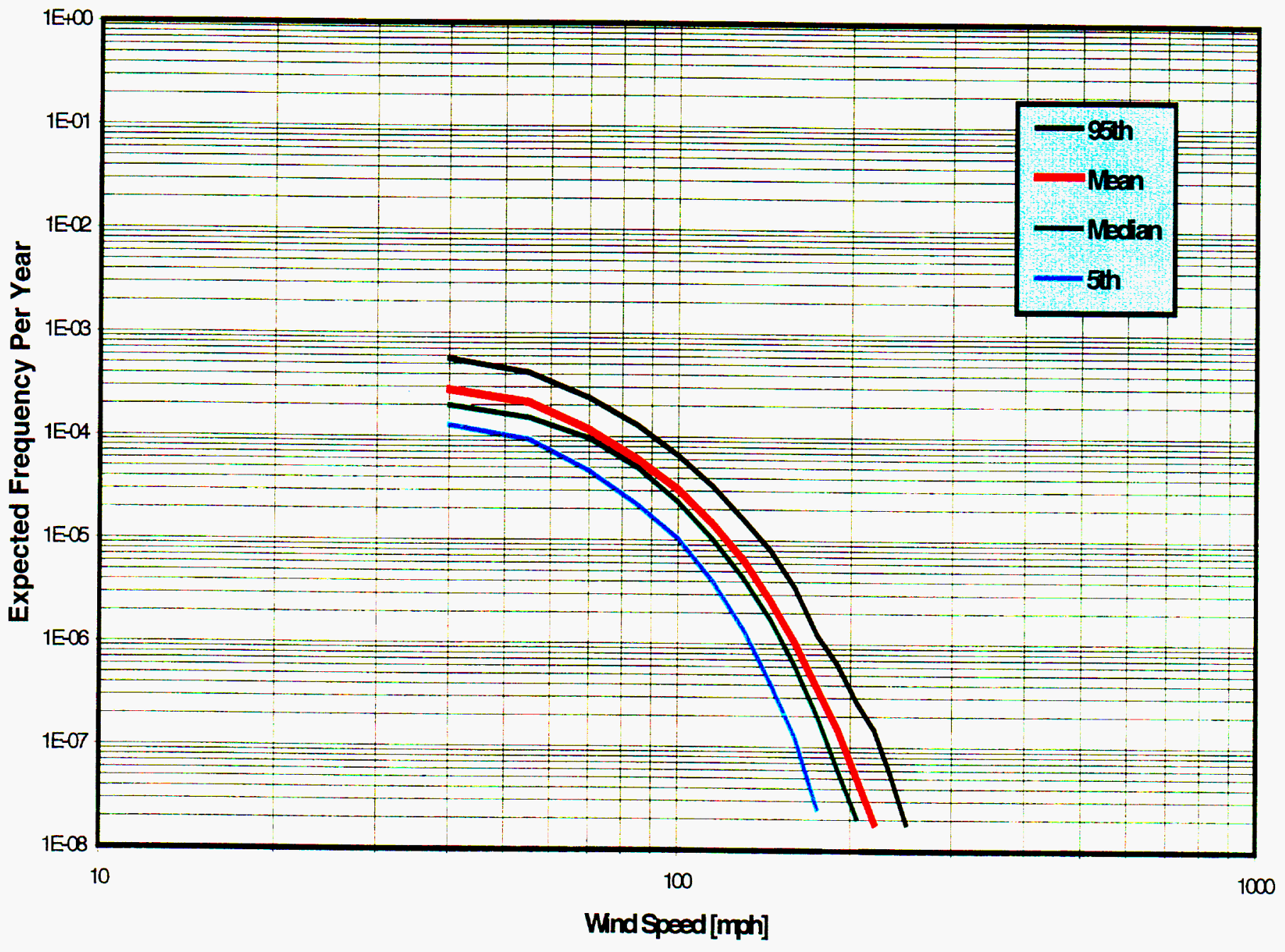


Figure 13-3

\section{NEVADA TEST STTE \\ Wind Hazard}




Figure 13-4

OAKRIDGE, TN

Wind Hazard

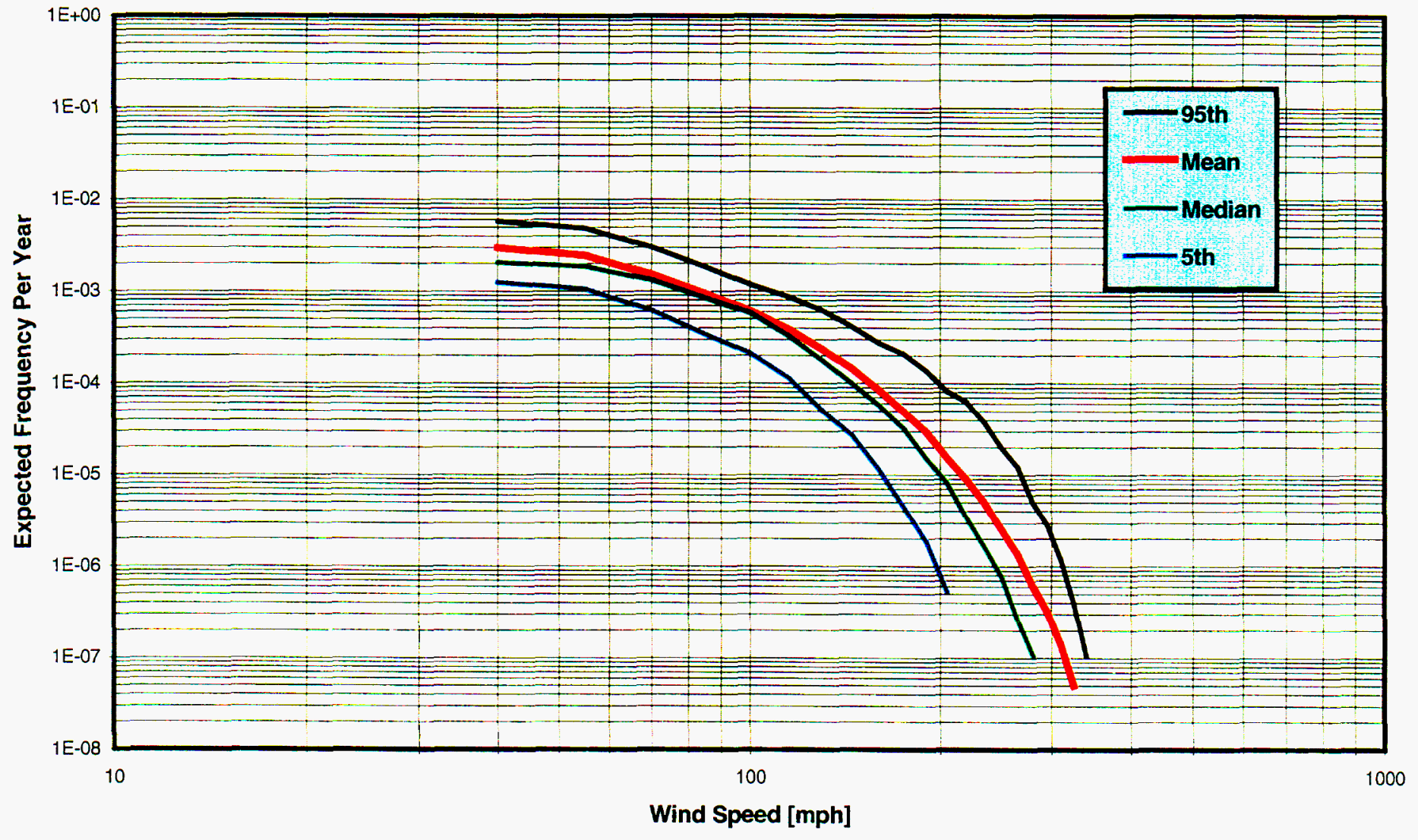


Figure 13-5

\section{PANTEX, TX \\ Wind Hazard}

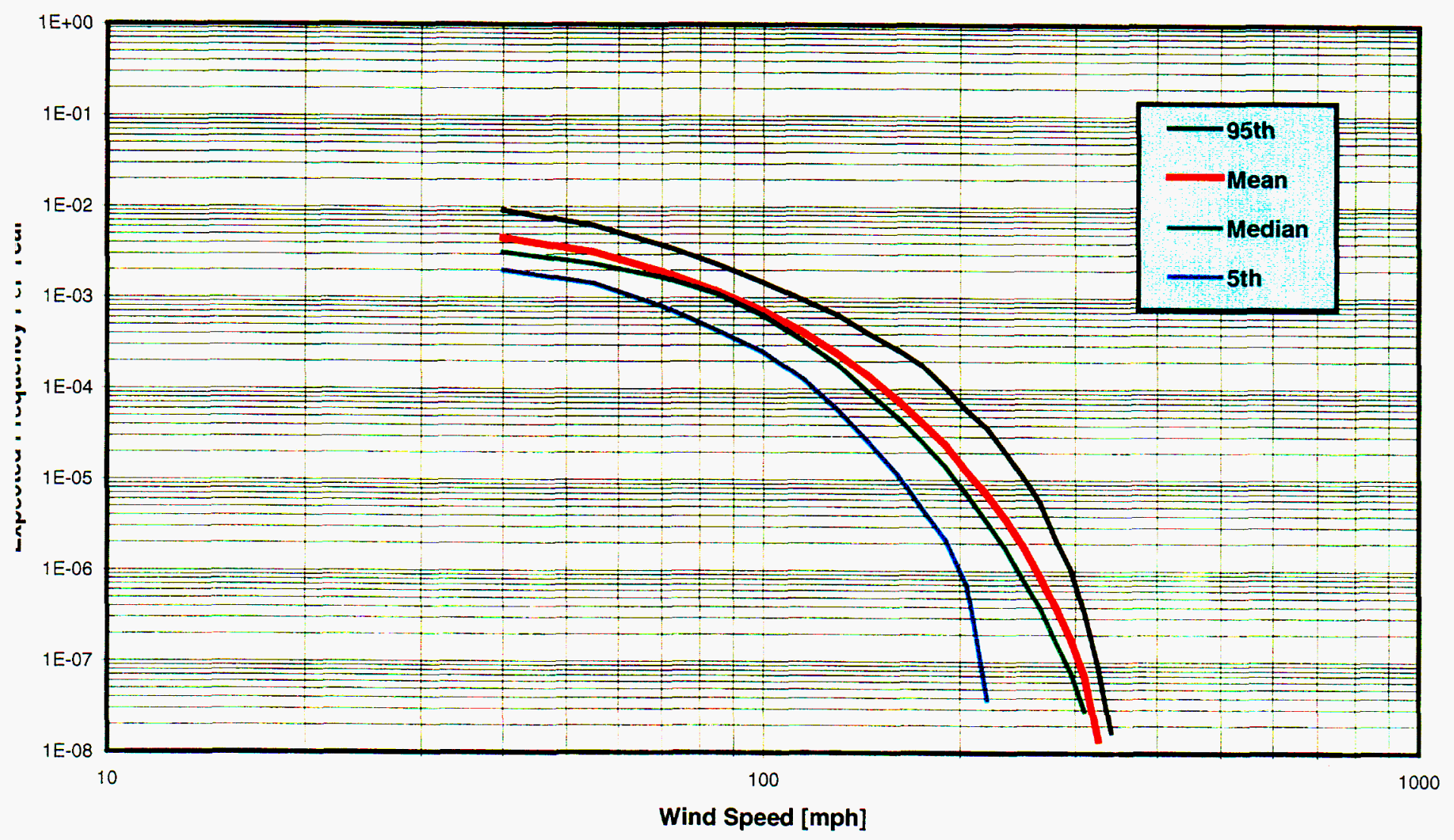


Figure 13-6

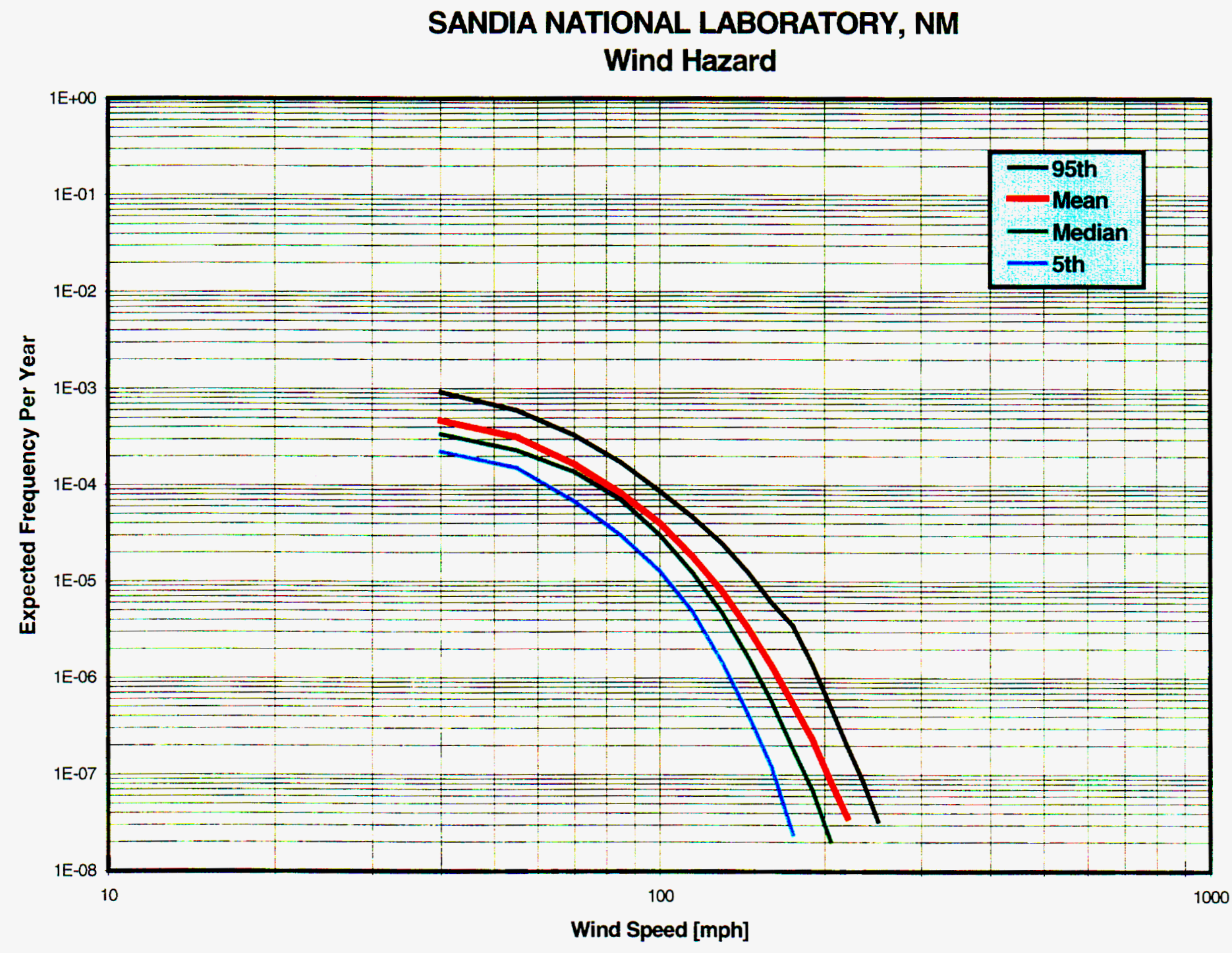


Figure 13-7

\section{SAVANNAH RIVER SITE, SC \\ Wind Hazard}

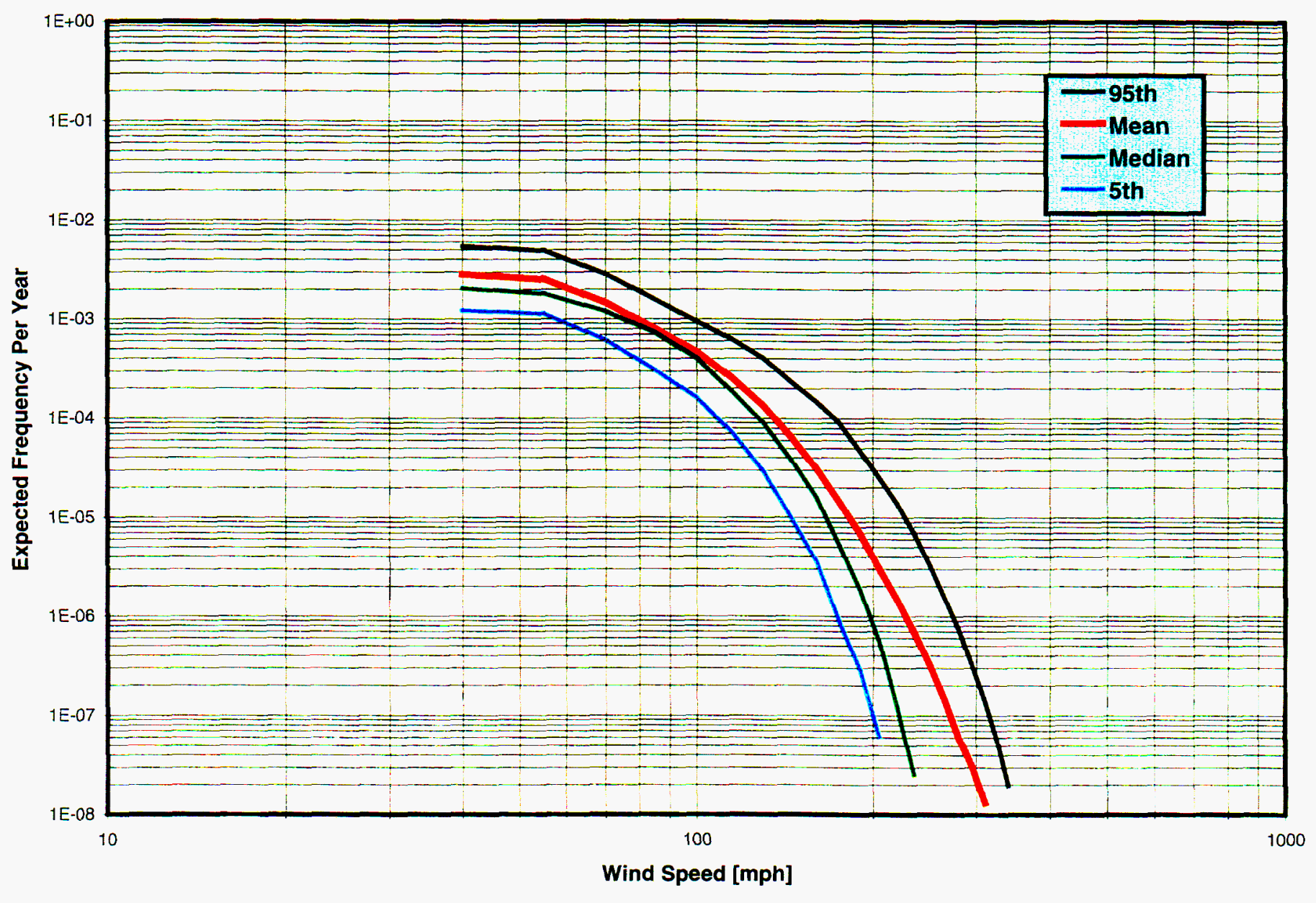


Figure 13-8

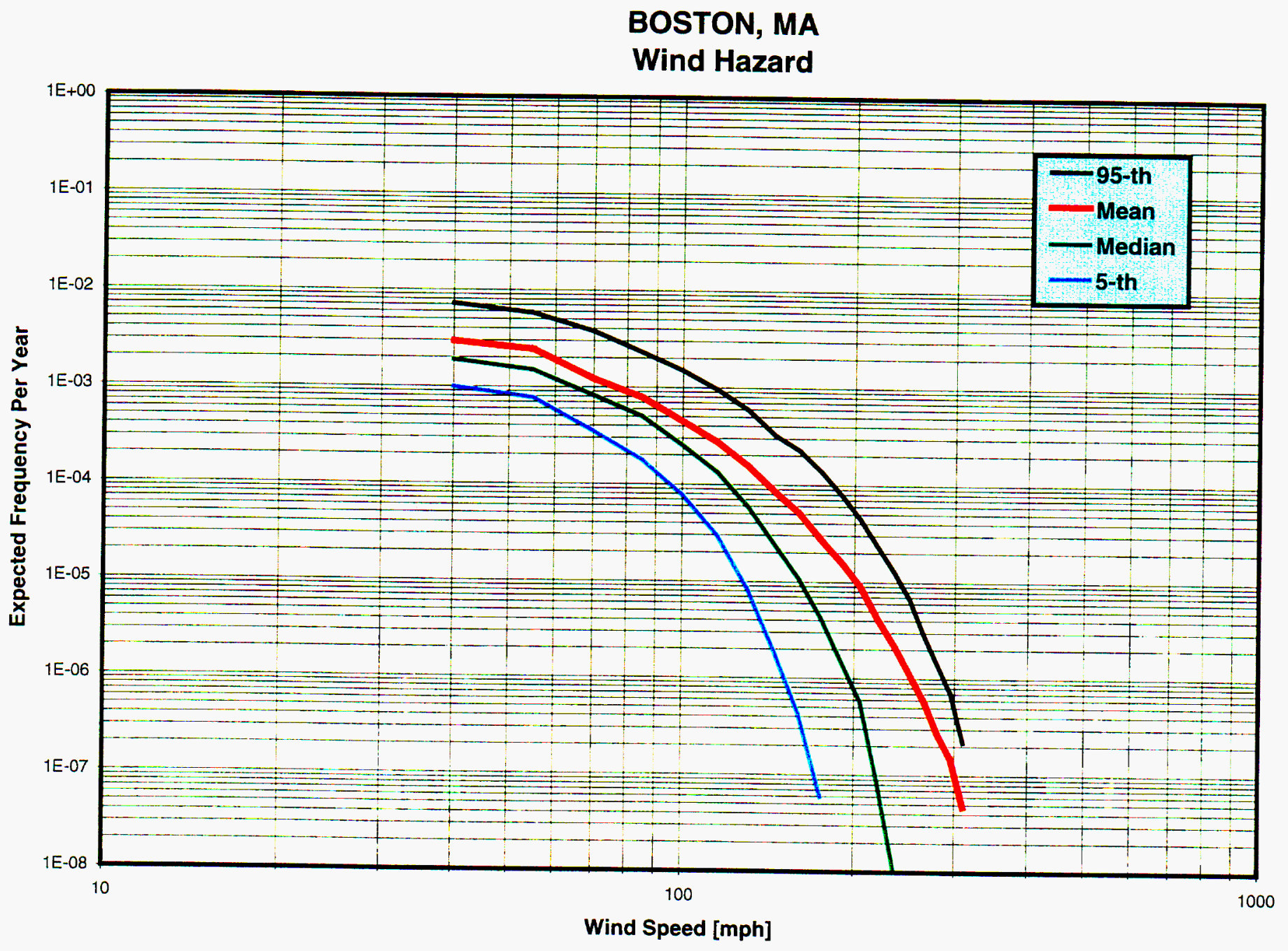


Figure 13-9

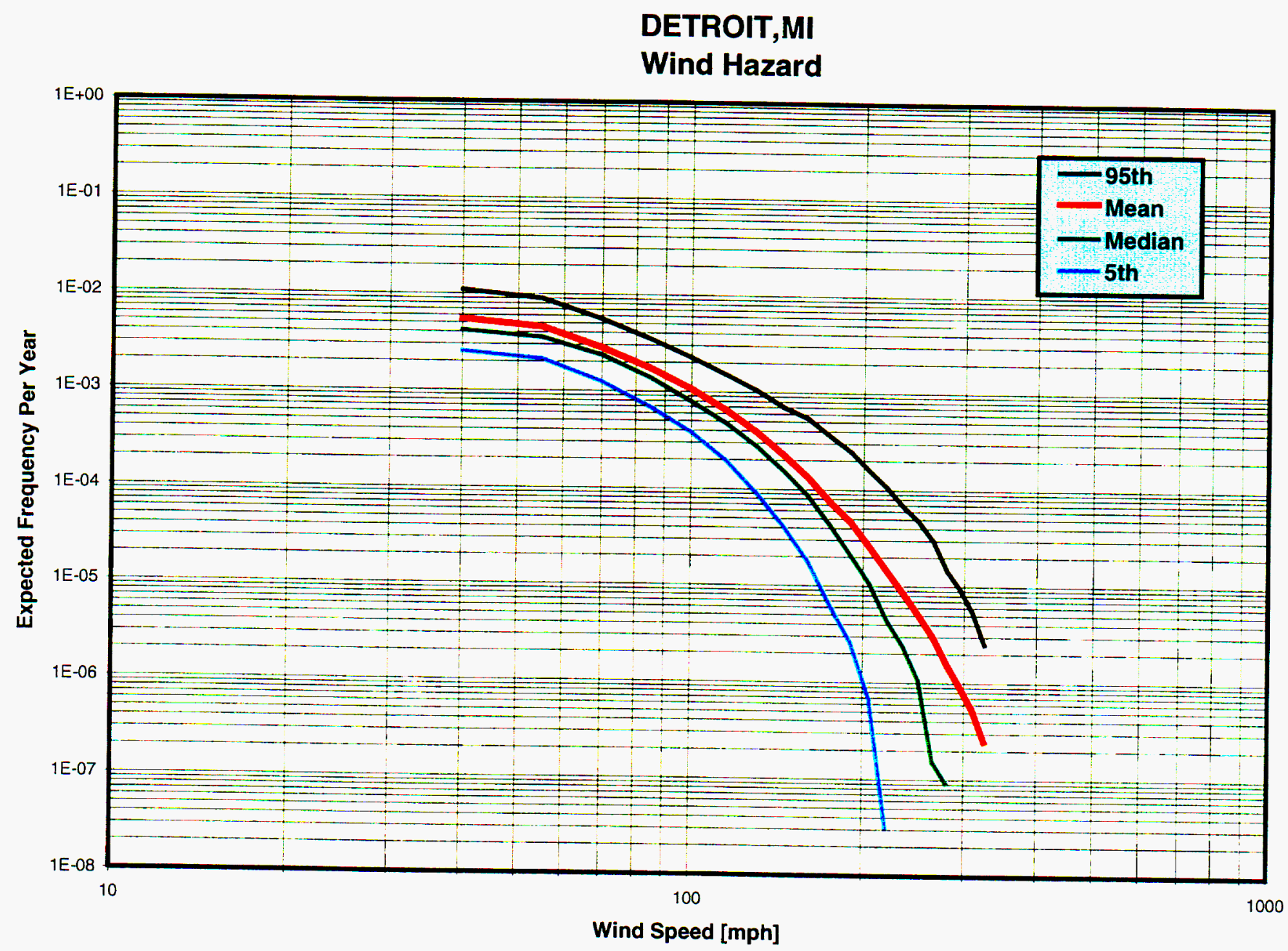


Figure 13-10

NEW ORLEANS Wind Hazard

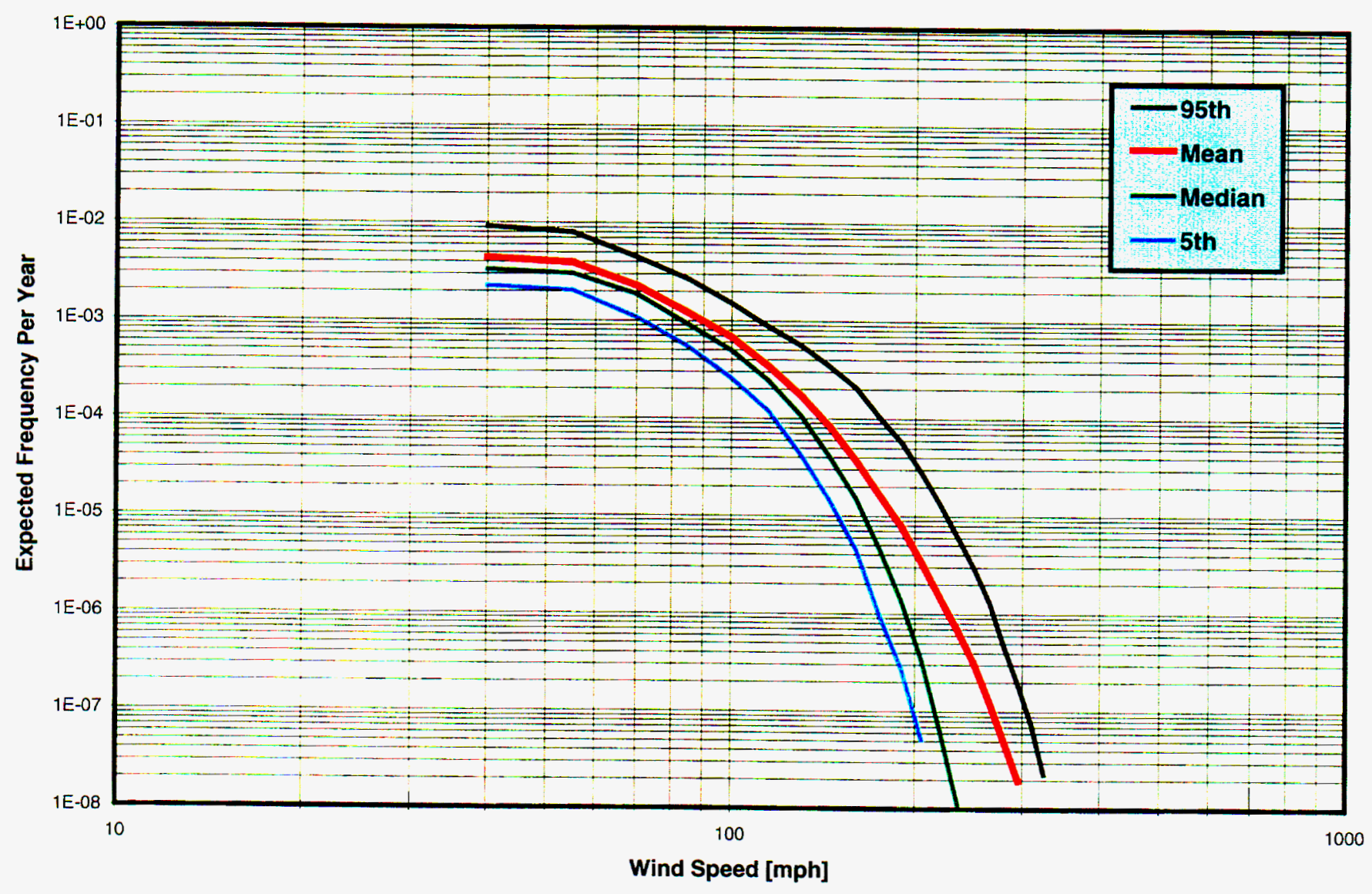


Figure 13-11

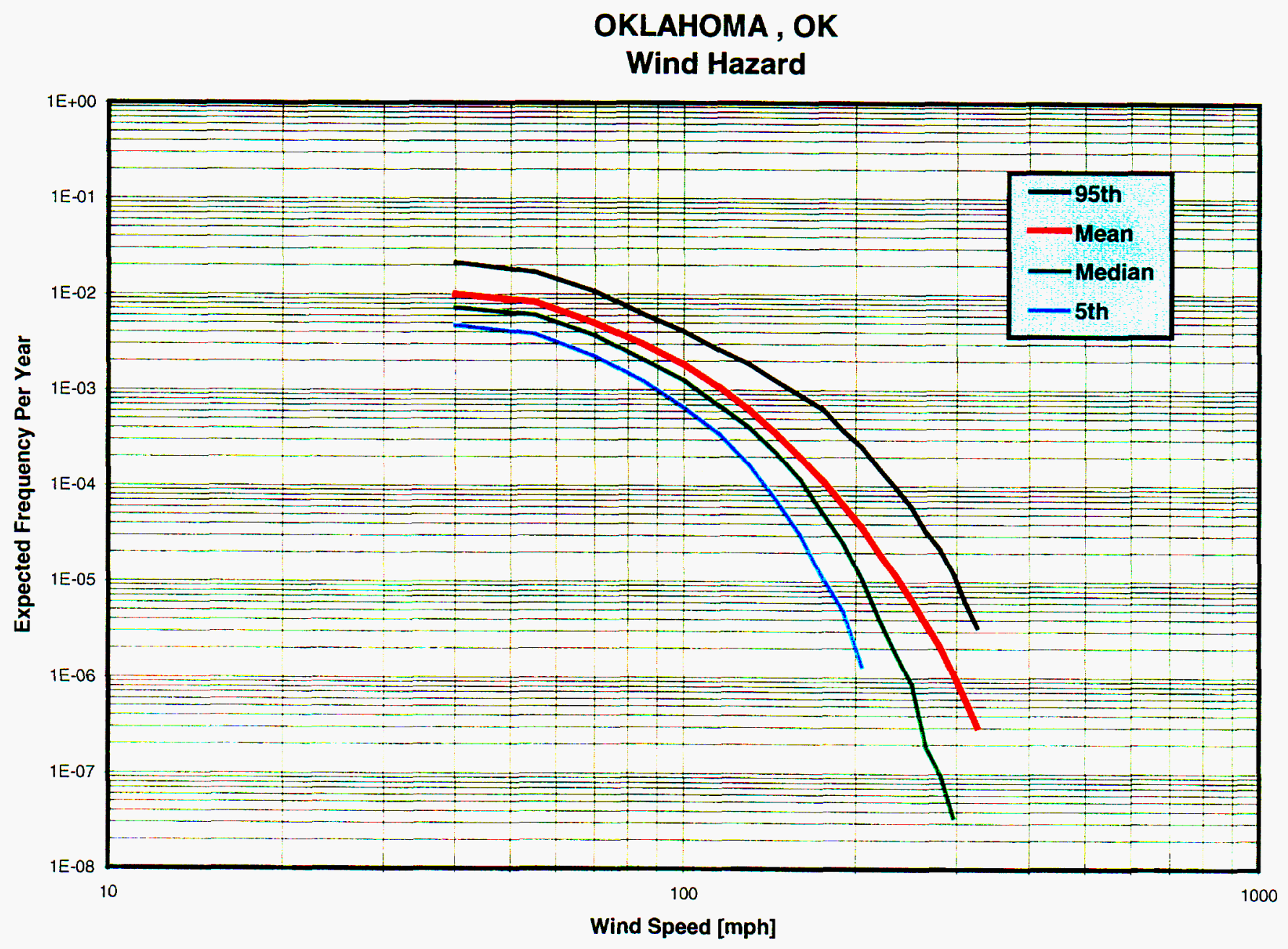


Figure 13-12

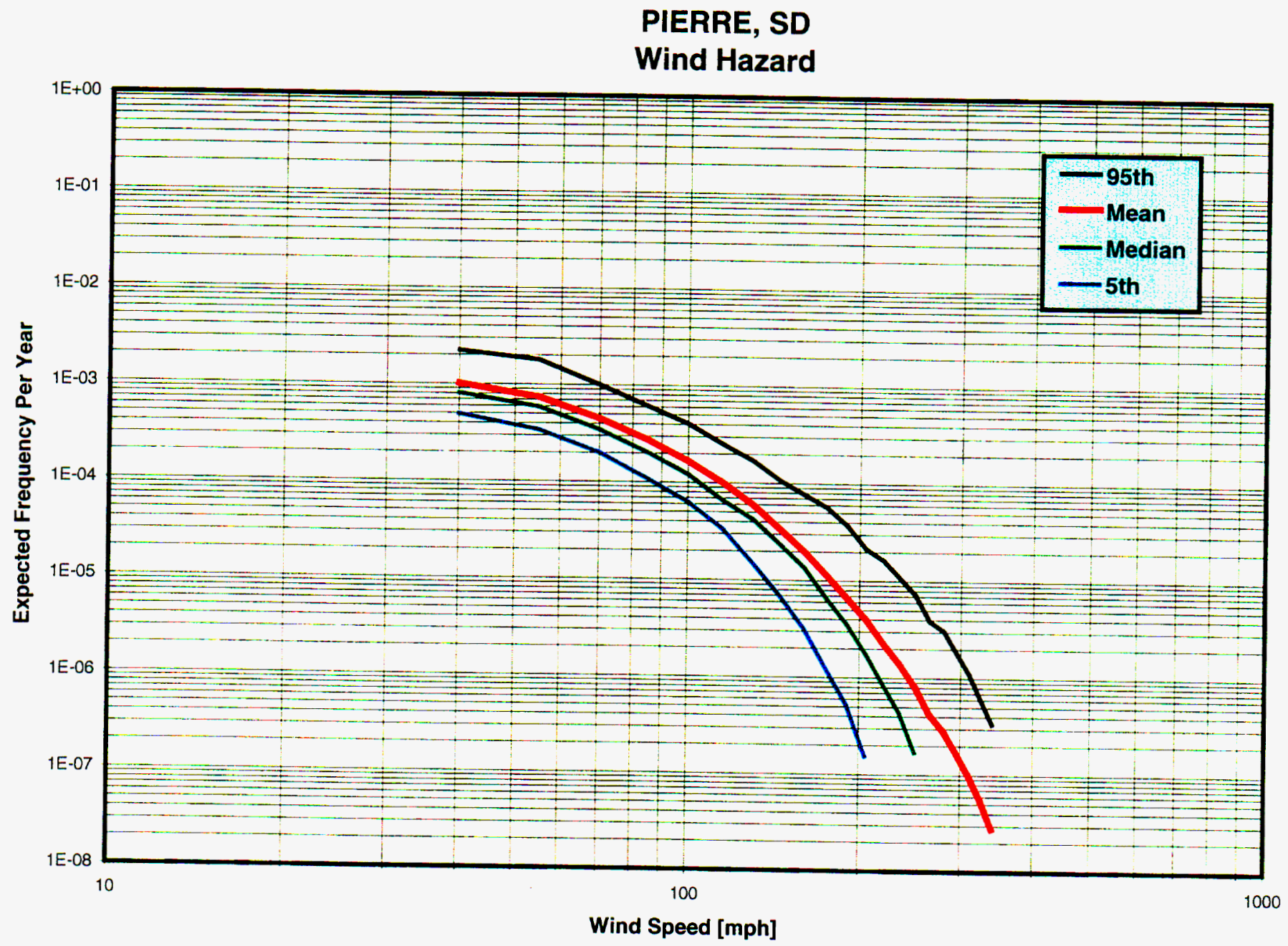


Figure 13-13

\section{SALT LAKE CITY, UT Wind Hazard}

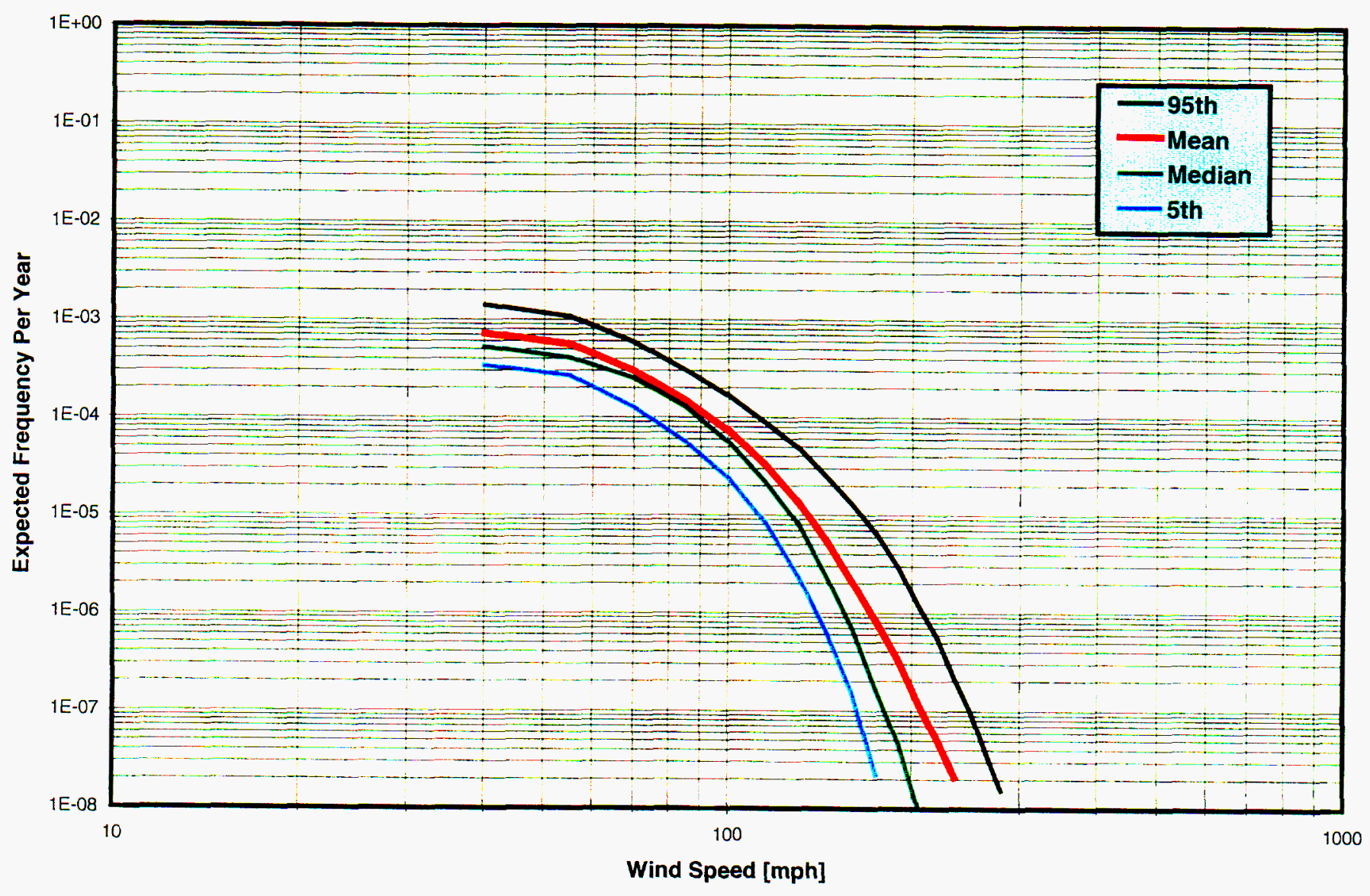


Figure 13-14

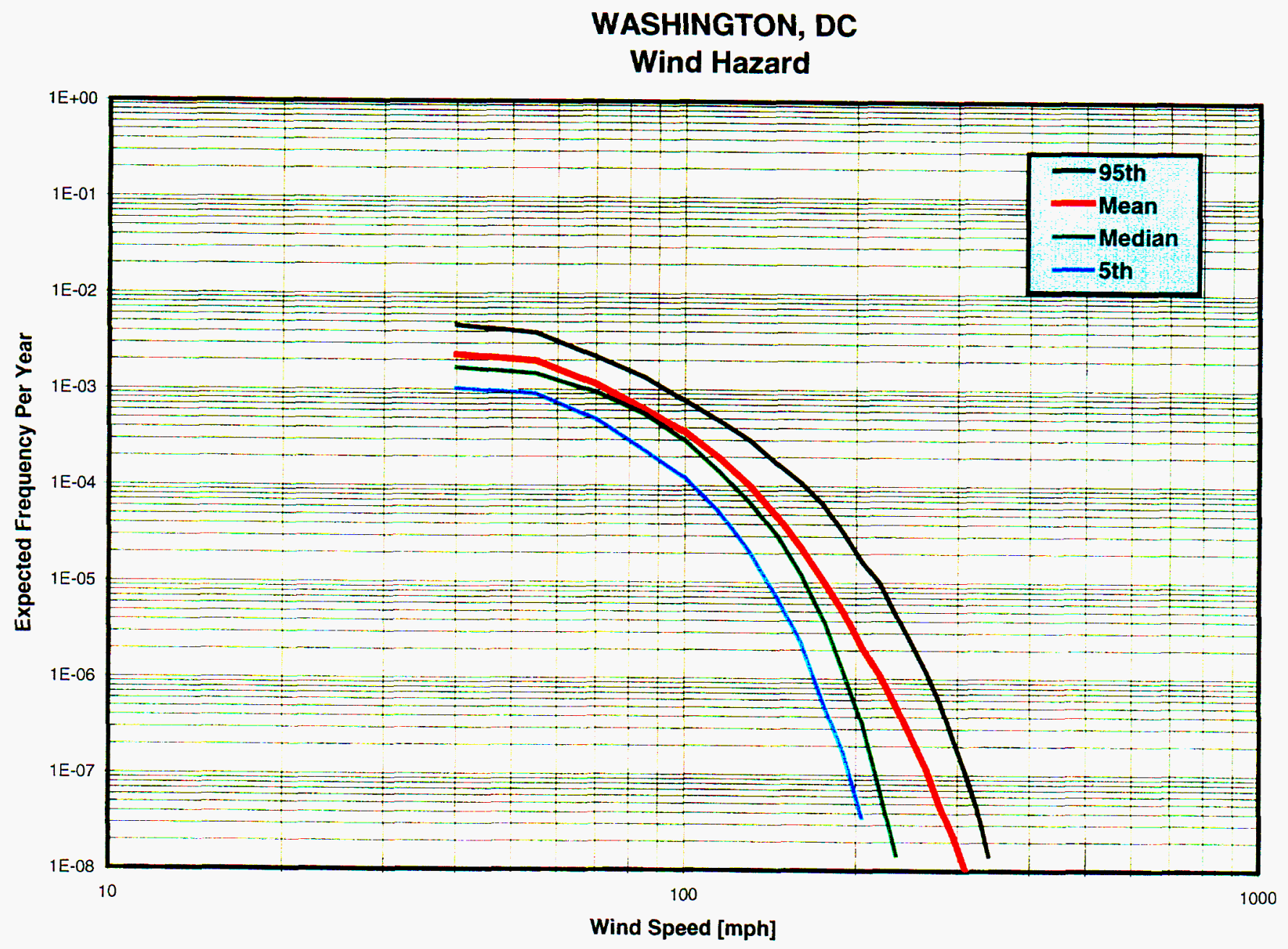




\subsection{Conclusions and Recommendations}

The product of this project, the TORNADO software program, is a powerful tool, based on risk analysis principles, for assessing the tornado wind hazard at any site in the contiguous U.S. The methodology underlying the program is based on the techniques of probabilistic risk assessment technology. It uses the existing database of the historical tornadoes. The database is used as the basis for the inputs into the program, to the extent that the data supports development of estimates of the model parameters and probability distributions. When the data is inadequate, the inputs are based on studies done within the tornado wind hazard scientific community, that are available in the publicly accessible literature.

The methodology presented here has several features, some of which may have been used individually in other studies. But, all of these features have been combined into one methodology in this project. Significant features included in the methodology programmed in TORNADO include:

1. Site-specific tornado occurrence rates and F-scale intensity distributions.

2. Site-specific touchdown location distributions based on the distribution of locations of the historical tornadoes.

3. Modeling the site of interest as an area rather then a point.

4. Recognition of the uncertainties associated with using probability models to model physical phenomena by including alternatives for many of the model parameters in the program.

5. Eliciting the judgements of tornado wind hazard experts in the development and weighting of the alternative inputs.

There are several other features, which if incorporated in the methodology and in the TORNADO code, would enhance the power of the TORNADO code and the quality of the results. These features are listed below, and should be considered for future development:

1. Estimator of the Touchdown Location Distribution: To develop a distribution of the tornado touchdown locations throughout the contiguous U.S., a 2-dimensional normal kernel was chosen for this project. Other kernel estimators could have been used instead of the normal kernel. The normal kernel was selected because the normal shaped distribution is considered a reasonable representation of the distribution of future tornado touchdown locations, given a location of a past tornado touchdown. Perhaps more significant, the choice of values of the two parameters, $h_{x}, h_{y}$ (the smoothing parameters), should be further analyzed and considered as uncertain parameters in the methodology. As discussed in Section 10, Sensitivity Analyses, a study was done to 'optimize' the value of these parameters, based on the ability of the estimator to estimate the occurrence rate of tornadoes in an area. More extensive studies, which expand on the sensitivity concepts 
considered in the initial studies, should be considered. In addition, in the current program single values of these parameters are used. Future consideration should be given to extending the current code to allow these parameters to be included in the set of uncertain inputs in the uncertainty analysis portion of the methodology. A question to be considered regarding this issue is the potential run time of the code when these parameters are considered uncertain versus the sensitivity of the hazard estimate as a function of the parameter values.

2. Damage Area Length and Width Distribution: At the Second Tornado Wind Workshop and in the responses to the elicitation questionnaire, some members of the Expert Panel indicated a preference for modeling the joint distribution of the length and width of the damage area using a continuous distribution. The current length and width distributions in TORNADO are based on modeling the joint distributions in terms of discrete empirical distributions. It is recommended that the selection of the distribution model be further researched. Continuous models should be considered in lieu of the discrete distributions currently used. Minimally, the continuous distribution should be considered as another alternative in the uncertainty analysis.

3. Damage Area Length and Width Distribution for a F6 Tornado: Because there are no recorded F6 tornadoes, it was not possible to estimate the joint distribution for the length and width of the damage area for F6 tornadoes based on historical data. However, the methodology requires such a distribution because the issue of classification errors allows for the possibility that some tornadoes have been under classified. Thus, it was necessary to develop an empirical estimate of a joint distribution of the length and width. The distribution currently in the file of default inputs in TORNADO is based on an empirical analysis of the change in the distributions between F4 and F5 tornadoes. Further study of this issue is recommended.

4. Dames \& Moore (D\&M) F-Scale to Wind Speed Relation: The D\&M Fscale intensity to wind speed relation associates overlapping intervals of wind speeds to the F-scale intensity values. This feature created difficulties in modeling the site-specific intensity distribution, which were not solvable in the current project. Since some of the Expert Panel members indicated that the $\mathrm{D} \& \mathrm{M}$ relation is credible, it is recommended that this issue be further analyzed and the relation be included in future versions of the TORNADO program.

5. Unreported Tornadoes: As pointed out by J. McDonald, the historical tornado records are not complete. This incompleteness has an affect on the estimates of the model parameters and distributions. Therefore, it is recommended that this issue be considered for additional research with a goal to developing methods for accounting for the incompleteness in the estimates 
of the model parameters as well as in the uncertainties associated with the parameters.

6. Models of "natural barriers": During the discussions and reviews of the historical tornado data, the hazard model and the results of some test runs, it was apparent that some "natural barriers" for tornado occurrence exist throughout the U.S., such as mountains, large bodies of water and general geographical and meteorological conditions. These barriers preclude the occurrence of any tornadoes and/or tornadoes of higher intensities. For example, tornadoes tend not to pass over mountains. Also, since a significant proportion of the tornado path headings are in a northeasterly direction and tornadoes tend not to be initiated over water, locations along the west and gulf coasts generally do not experience F5 intensity events. Thus, it is recommended that this issue be further researched and the model be adjusted, as appropriate, to recognize such "natural barriers".

7. Time dependent models: Analysis of trends in the occurrences and intensities of the historical tornadoes suggest that there may be some changes in the frequency and distribution of intensities over time. Thus, it is suggested that this question be further investigated and time dependent models be considered for inclusion in the model, as deemed appropriate.

8. Efficiency of TORNADO: As currently designed, the hazard calculations in TORNADO are inefficient. An inefficiency of note is the calculation of the site-specific frequency and intensity distribution. Rather than calculate these for each site (thus performing many duplicate calculations) separately, it would be more efficient to pre-process the calculation of the frequency and intensity distribution over a grid of points across the U.S., store the pair in a file and retrieve the appropriate frequency and intensity distribution from the file using a look-up operation. It is recommended that this improvement be further investigated. 


\subsection{References}

Abbey, R.F., Jr., "Research Efforts in Severe Storms Applied to Nuclear Reactors", Second U.S. National Conference on Wind Engineering Research, Ft. Collins, CO, 1975.

Abbey, R.F. and Fujita, T.T., “The DAPPLE Method for Computing Tornado Hazard Probabilities: Refinements and Theoretical Considerations," 11th Conference on Severe Local Storms, American Meteorological Society, Boston, 1979.

Beebe, R. C., et al., "A Meteorological and Engineering Approach to the Regionalization of Tornado Wind Criteria for Nuclear Power Plant Design," AEC Contract No. AT(111)-2396, Dames and Moore, Bethesda, MD, 1975.

Budnitz, et al., "Recommendations for Probabilistic Seismic Hazard Analysis: Guidance on Uncertainty and Use of Experts”, NUREG/CR-6372, August 1995.

Coats, D.W. and R.C. Murray, "Natural Phenomena Hazards Modeling Project: Extreme Wind/Tornado Hazard Models for Department of Energy Sites," Lawrence Livermore National Laboratory, UCRL-53526, August 1985.

DOE, “Standard 1020 - Natural Phenomena Hazards Design Criteria and Evaluation Criteria for Department of Energy Facilities”, U.S. Department of Energy, April 1994.

DOE, “Standard 1023 - Natural Phenomena Hazards Assessment Criteria”, U.S. Department of Energy, January 1996.

Fujita, T.T., "Proposed Characterization of Tornadoes and Hurricanes by Area and Intensity" SMRP Research Paper No. 91, University of Chicago, Chicago, IL, February 1971

Fujita, T.T., "Workbook of Tornadoes and High Winds for Engineering Applications," SMRP Research Paper 165, Department of the Geophysical Sciences, the University of Chicago, September 1978.

Fujita, T.T. and A.D. Pearson, "Results of FPP Classification of 1971 and 1972 Tornadoes," Paper presented at the Eighth Conference on Severe Local Storms, 1973.

Garson, R.C., J.M. Catalan, and C.A. Cornell, "Tornado Design Winds based on Risk, " Journal of the Structural Division, ASCE, Vol. 101, No.9, September 1975.

Grazulis, T.P., "Significant Tornadoes 1680-1991," The Tornado Project of Environmental Films, St. Johnsbury, VT, 1993. 
Grazulis, T.P., “Significant Tornadoes Update, 1992-1995”, The Tornado Project of Environmental Films, St. Johnsbury, VT, 1997.

Lehmann, E.L., "Theory of Point Estimation," John Wiley and Sons, Inc., New York, 1983

Lindley, D.V., "Making Decisions," $2^{\text {nd }}$ Ed., John Wiley and Sons, Inc., New York, 1985

Markee, E.H., Beckerly, J.G., and Sanders, K.E., "Technical Basis for Interim Regional Tornado Criteria", WASH-1300, U.S. Government Printing Office, Washington D.C., May 1974.

McDonald, J.R., “A Methodology for Tornado Risk Assessment,” report prepared for Lawrence Livermore National Laboratory, Livermore, CA, April 1979.

McDonald, J.R., “A Methodology for Tornado Hazard Probability Assessment,” Institute for Disaster Research, Texas Tech University, Lubbock, Texas, 1980.

McDonald, J.R., "The Modified IDR Model - Short Course Notes," Engineering for Extreme Winds: 1996, Texas Tech University, February 1996.

ONRR, Office of Nuclear Reactor Regulation, "Safety Evaluation by the Office of Nuclear Regulation of Recommended Modification to the R.G. 1.76 Tornado Design Basis for the ALWR," Washington, DC, March 1988.

Ramsdell, J.V. and G.L. Andrews, "Tornado Climatology of the Contiguous United States," Pacific Northwest Laboratory, prepared for the US Nuclear Regulatory Commission, NUREG/CR-4461, May 1986.

Reinhold, T. and B. Ellingwood, "Tornado Damage Risk Assessment," National Bureau of Standards, NUREG/CR-2944, 1982.

Scott, D.R., "Multivariate Density Estimation”, John Wiley and Sons, Inc., New York, 1992.

Thom, H.C.S., “Tornado Probabilities,” Monthly Weather Review, Vol. 91, 1963

Twisdale, L.A., "Tornado Characterization and Wind Speed Risk," ASCE Journal of the Structural Division, Vol. 104, No. ST10, October 1978

Twisdale, L.A. and W.L. Dunn, "Tornado Missile Simulation and Design Methodology," Research Triangle Institute, NP-2005, Vol. 1, 1981.

Twisdale, L.A., W.L. Dunn and J. Chu, “Tornado Missile Risk Analysis", EPRI Reports NP-768 and NP-769, Electric Power Research Institute, Palo Alto, 1978. 
Twisdale, L.A. et al., "Probabilistic Analysis of Tornado Wind Risk," ASCE Journal of Structural Engineering, Vol. 109, No. 2, February 1983.

Twisdale, L.A. and M.B. Hardy, "Tornado Windspeed Frequency Analysis of the Savannah River Plant," Prepared for U.S. Department of Energy, E.I. Dupont de Nemours \& Co., Savannah River Plant, Aiken, SC, April 1985.

USNRC, Regulatory Guide 1.76, “Design Basis Tornado for Nuclear Power Plants," U.S. AEC Directorate of Regulatory Standards, April 1974. 